\title{
Defective cyclophilin A induces TDP-43 proteinopathy: implications for amyotrophic lateral sclerosis and frontotemporal dementia
}

Laura Pasetto, ${ }^{1}$ Maurizio Grassano, ${ }^{2}$ Silvia Pozzi,${ }^{3}$ Silvia Luotti, ${ }^{1}$ Eliana Sammali, ${ }^{1}$ Alice Migazzi, ${ }^{4}$ Manuela Basso, ${ }^{1,4}$ Giovanni Spagnolli, ${ }^{4,5}$ Emiliano Biasini, ${ }^{4,5}$ Edoardo Micotti, ${ }^{1}$ Milica Cerovic, ${ }^{1}$ Mirjana Carli, ${ }^{1}$ Gianluigi Forloni, ${ }^{1}$ Giovanni De Marco, ${ }^{2}$ Umberto Manera, ${ }^{2}$ Cristina Moglia, ${ }^{2}$ Gabriele Mora, ${ }^{6}$ Bryan J. Traynor, ${ }^{7,8,9}$ Adriano Chiò, ${ }^{2}$ Andrea Calvo ${ }^{2}$ and Valentina Bonetto ${ }^{1}$

\begin{abstract}
Aggregation and cytoplasmic mislocalization of TDP-43 are pathological hallmarks of amyotrophic lateral sclerosis (ALS) and frontotemporal dementia (FTD) spectrum. However, the molecular mechanism by which TDP-43 aggregates form and cause neurodegeneration remains poorly understood. Cyclophilin A, also known as peptidyl-prolyl cis-trans isomerase A (PPIA), is a foldase and molecular chaperone. We previously found that PPIA interacts with TDP-43 and governs some of its functions, and its deficiency accelerates disease in a mouse model of ALS. Here we characterized PPIA knock-out mice throughout their lifespan and found that they develop a neurodegenerative disease with key behavioural features of FTD, marked TDP-43 pathology and lateonset motor dysfunction. In the mouse brain, deficient PPIA induces aggregation of the GTP-binding nuclear protein Ran, a PPIA substrate required for TDP-43 nucleocytoplasmic trafficking. Moreover, in absence of PPIA, TDP-43 autoregulation is perturbed and TDP-43 and proteins involved in synaptic function are downregulated, leading to impairment of synaptic plasticity. Finally, we found that PPIA was downregulated in several ALS and ALS-FTD patients and identified a PPIA loss-offunction mutation in a sporadic ALS patient. The mutant PPIA has low stability, altered structure and impaired interaction with TDP-43. These findings strongly implicate that defective PPIA function causes TDP-43 mislocalization and dysfunction and should be considered in future therapeutic approaches.
\end{abstract}

\section{Author affiliations:}

1 Istituto di Ricerche Farmacologiche Mario Negri IRCCS, 20156 Milano, Italy

2 "Rita Levi Montalcini” Department of Neuroscience, University of Torino, Torino, Italy

3 CERVO Brain Research Centre, Quebec City, Québec, Canada 
4 Department of Cellular, Computational and Integrative Biology (CIBIO), University of Trento, Trento, Italy

5 Dulbecco Telethon Institute, University of Trento, Trento, Italy

6 Department of Neurorehabilitation, ICS Maugeri IRCCS, Milano, Italy

7 Neuromuscular Diseases Research Section, Laboratory of Neurogenetics, National Institute on Aging, NIH, Bethesda, MD 20892, USA

8 Department of Neurology, Johns Hopkins University Medical Center, Baltimore, MD 21287, USA

9 Reta Lila Weston Institute, UCL Queen Square Institute of Neurology, University College London, London, UK

Correspondence to: Valentina Bonetto

Department of Biochemistry and Molecular Pharmacology, Istituto di Ricerche Farmacologiche Mario Negri IRCCS, Via Mario Negri 2, 20156 Milano, Italy

Email: valentina.bonetto@marionegri.it

Running title: Defective PPIA induces TDP-43 proteinopathy

Keywords: TDP-43 pathology; mouse model; nucleocytoplasmic transport; Ran; FTD; ALS

Abbreviations: TDP-43 = TAR DNA-binding protein-43; ALS $=$ amyotrophic lateral sclerosis; FTD $=$ frontotemporal dementia; PBMCs $=$ peripheral blood mononuclear cells; PPIA $=$ cyclophilin $\mathrm{A} /$ peptidyl-prolyl cis-trans isomerase A; hnRNPs = heterogeneous nuclear ribonucleoproteins; PPIA$/$ - mice = PPIA knock-out mice on 129S6/Sv genetic background; C57_PPIA-/- mice $=$ PPIA-/- mice on $\mathrm{C} 57 \mathrm{BL} / 6 \mathrm{~J}$ genetic background; Micro-CT = Micro-computed tomography; pTDP-43 = phosphorylated TDP-43; GFAP = glial fibrillary acidic protein; NFL = neurofilament light chain; TIF $=$ Triton-insoluble fraction; $\mathrm{WB}=$ Western blot; $\mathrm{TA}=$ Tibialis anterior; Ran $=$ GTP-binding nuclear protein Ran; $\mathrm{MD}=$ molecular dynamics; ePPIA = extracellular PPIA; iPPIA = intracellular PPIA; bvFTD = behavioural variant of FTD 


\section{Introduction}

TAR DNA-binding protein-43 (TDP-43), encoded by the TARDBP gene, is a predominantly nuclear RNA/DNA-binding protein that exerts vital functions in various steps of RNA metabolism, shuttling between the nucleus and the cytoplasm ${ }^{1}$. To do that TDP-43 physiological levels and correct localization have to be tightly controlled also through autoregulation ${ }^{2,3}$.

Cytoplasmic mislocalization of TDP-43 and aggregation of its hyperphosphorylated, ubiquitinated and C-terminal fragmented forms are common histopathological hallmarks of the amyotrophic lateral sclerosis (ALS) and frontotemporal dementia (FTD) disease spectrum ${ }^{4,5}$. TDP43 proteinopathy is observed in $\sim 97 \%$ of ALS and $\sim 50 \%$ of FTD patients, in brain and spinal cord, but also in peripheral blood mononuclear cells (PBMCs) ${ }^{6,7}$. TARDBP mutations in ALS and FTD cases have established a direct link between TDP-43 abnormalities and neurodegeneration. However, the molecular mechanism by which TDP-43 aggregates form and cause neurodegeneration remains poorly understood. Besides impairments in RNA and protein homeostasis, nucleocytoplasmic transport defects are emerging as converging disease mechanisms in ALS/FTD ${ }^{8,9}$. Therapeutic interventions aiming to target the triad of TDP-43 control, i.e. autoregulation, nucleocytoplasmic transport and aggregation, is viewed as a promising strategy to prevent neurodegeneration ${ }^{10}$.

Cyclophilin A/peptidyl-prolyl cis-trans isomerase A (PPIA) is highly expressed in the CNS, where it localizes mainly in neurons ${ }^{11}$. Despite its abundance, its primary function in the CNS remains largely undefined. PPIA is involved in several cellular processes with double-edged functions. Inside the cells it is mainly beneficial. Besides promoting de novo protein folding ${ }^{12}$, it acts as a molecular chaperone and protects against oxidative stress and protein misfolding ${ }^{13-15}$. PPIA interacts with heterogeneous nuclear ribonucleoproteins (hnRNPs), regulates their nucleocytoplasmic transport and plays a role in the stability of the RNP complexes ${ }^{13,16}$. PPIA interacts with TDP-43 and governs some of its functions ${ }^{13}$. In particular, it influences TDP-43 binding to its RNA targets affecting the expression of genes, such as $H D A C 6, A T G 7, V C P, F U S$ and $G R N$, involved in the clearance of protein aggregates, and/or mutated in ALS and $\mathrm{FTD}^{13}$. Since PPIA Lys-acetylation favours the interaction with TDP-43, a post-translational regulation is hypothesized. Extracellularly, PPIA behaves as a proinflammatory cytokine ${ }^{17}$. Aberrantly secreted in response to stress, PPIA activates an EMMPRIN/CD147-NF-кB-MMP-9 pathway, promoting neuroinflammation and selective motor neuron death ${ }^{18}$.

Although PPIA has been studied in connection with several human diseases, some neurodegenerative, its role in pathogenesis has not been established ${ }^{19}$. We firstly reported that PPIA is altered in $\mathrm{ALS}^{20-22}$. In particular, we observed that PPIA accumulates in Triton-insoluble protein aggregates from the spinal cord in ALS mouse models and sporadic patients ${ }^{20}$. Next, we reported that 
low levels of soluble PPIA in PBMCs of ALS patients are associated with early onset of the disease ${ }^{23}$ and short disease duration ${ }^{7}$. In agreement with this, PPIA deficiency exacerbated aggregation and accelerated disease progression in a mutant SOD1 mouse model of ALS ${ }^{13}$. However, selective inhibition of extracellular PPIA protected motor neurons, reduced neuroinflammation and increased survival ${ }^{18}$.

In previous work we noted that PPIA knock-out (PPIA-/-) mice presented features of TDP-43 pathology but with no overt clinical phenotype up to four months of age ${ }^{13}$. Here we have characterized PPIA-/- mice neuropathologically and behaviourally throughout their entire lifespan and found that they develop a neurodegenerative disease with marked TDP-43 pathology. PPIA is also defective in several sporadic ALS and ALS-FTD patients, and a rare loss-of-function PPIA mutation was identified in an ALS patient, supporting its involvement in the etiopathogenesis.

\section{Materials and methods}

\section{Animal model}

Procedures involving animals and their care were conducted in conformity with the following laws, regulations, and policies governing the care and use of laboratory animals: Italian Governing Law (D.lgs 26/2014; Authorization 19/2008-A issued March 6, 2008 by Ministry of Health); Mario Negri Institutional Regulations and Policies providing internal authorization for persons conducting animal experiments (Quality Management System Certificate, UNIENISO9001:2008, Reg.No.6121); the National Institutes of Health's Guide for the Care and Use of Laboratory Animals (2011 edition), and European Union directives and guidelines (EEC Council Directive, 2010/63/UE). The Mario Negri Institutional Animal Care and Use Committee and the Italian Ministry of Health (Direzione Generale della Sanità Animale e dei Farmaci Veterinari, Ufficio 6) prospectively reviewed and approved the animal research protocols of this study (prot. no. 14-02/C and 9F5F5.60) and ensured compliance with international and local animal welfare standards.

PPIA-/- mice were originally generated and characterized as described ${ }^{24,25}$. We obtained PPIA-/- mice (strain 129S6/SvEvTac Ppiatm1Lubn/Ppiatm1Lbn; stock no. 005320) from The Jackson Laboratory; they were maintained on a 129S6/SvEvTac background. The PPIA-/- mice on 129S6/Sv genetic background and corresponding PPIA+/+ littermates were used for micro-CT, MRI, immunohistochemistry, biochemistry, long-term potentiation, Rotarod, Grid test, Extension reflex, and will be indicated hereafter as PPIA-/- mice. PPIA-/- mice on C57BL/6J genetic background (C57_PPIA-/- mice), kindly provided by Dr. Bradford C. Berk (University of Rochester Medical Center, Rochester, New York, USA), and corresponding PPIA $+/+$ littermates, were used for 
cognitive tests (open field, elevated-plus maze, three-chamber sociability, Morris water maze, novel object recognition). Animals were bred and maintained at the Istituto di Ricerche Farmacologiche Mario Negri IRCCS, Milano, Italy, as described in the Supplementary material.

\section{Micro-computed tomography (micro-CT) and MRI}

Micro-CT and MRI analysis were done essentially as previously described ${ }^{26,27}$. Further details are reported in the Supplementary material.

\section{Immunohistochemistry}

Immunohistochemistry was done on coronal sections of brain for TDP-43, phosphorylated TDP-43 (pTDP-43), glial fibrillary acidic protein (GFAP), Ibal and Nissl staining was done on brain and lumbar spinal cord sections, as described in the Supplementary material.

\section{Neurofilament light chain (NFL) measurements}

Plasma samples were collected from PPIA+/+ and PPIA-/- mice in K2-EDTA BD Microtainer blood collection tube and centrifuged at $5000 \mathrm{xg}$ for 5 minutes to isolate plasma sample. The plasma NFL concentration was measured using the Simoa ${ }^{\circledR}$ NF-light ${ }^{\mathrm{TM}}$ Advantage (SR-X) Kit (\#103400) on the Quanterix SR-X $\mathrm{X}^{\mathrm{TM}}$ platform with reagents from a single lot, according to the protocol issued by the manufacturer (Quanterix Corp, Boston, MA, USA).

\section{Subcellular fractionation}

Nuclear and cytoplasmic fractions were isolated from mouse cortex and cerebellum essentially as described $^{13,18}$. Further details are reported in the Supplementary material.

\section{Extraction of detergent-insoluble proteins}

Mouse tissues were homogenized and the Triton-insoluble fraction (TIF) was obtained essentially as described in $^{13}$. Quantification of the insoluble and soluble protein fractions was done as described in the Supplementary material.

\section{Immunoblotting}

Western blot (WB) and dot blot were done as previously described ${ }^{7,20}$. The antibodies used for immunoblot are reported in the Supplementary material. 


\section{Real-time PCR}

The total RNA from mouse cortex and human PBMC was extracted using the RNeasy® Mini Kit (Qiagen) and real-time PCR was done as described in the Supplementary material.

\section{Long-term potentiation (LTP) analysis}

Coronal brain slices $(350 \mu \mathrm{m})$ were cut and processed for LTP recordings as described in the Supplementary material.

\section{Behavioural analysis}

In this study both male and female mice were tested, at 6 and 12 months of age. All behavioural tests were done at the same time of day, in the afternoon. Mice were allowed to habituate to the test room for at least $1 \mathrm{~h}$. Test environments were thoroughly cleaned between test sessions and males were tested before females. The open field, elevated-plus maze, three-chamber sociability, Morris water maze and novel object recognition test used Ethovision XT, 5.0 software (Noldus Information Technology, Wageningen, The Netherlands) to record the parameters. Further details are described in the Supplementary material.

\section{Muscle atrophy}

Tibialis anterior muscles were freshly dissected, as previously described ${ }^{28}$, immediately frozen and weighted on an analytical balance with $0.1 \mathrm{mg}$ readability and $\pm 0.2 \mathrm{mg}$ linearity (Crystal series, Gibertini). To evaluate muscle atrophy, the weight of the muscle was normalized to mouse body weight.

\section{Subjects in the study}

Informed written consent was obtained from all subjects involved and the study was approved by the ethics committee of Azienda Ospedaliero Universitaria Città della Salute e della Scienza, Turin and ICS Maugeri IRCCS, Milano. The diagnosis of ALS was based on a detailed medical history and physical examination, and confirmed by electrophysiological evaluation. Inclusion criteria for ALS patients were: i) 18-85 years old; ii) diagnosis of definite, probable or laboratory-supported probable ALS, according to revised El Escorial criteria ${ }^{29}$. Exclusion criteria were: i) diabetes or severe inflammatory conditions; ii) active malignancy; iii) pregnancy or breast-feeding. ALS patients underwent a battery of neuropsychological tests and were classified according to the consensus 
criteria for the diagnosis of frontotemporal cognitive and behavioural syndromes in $\operatorname{ALS}^{30-32}$. We analysed clinical samples from three independent cohorts of ALS patients and controls (Cohort \#13), totally 151 ALS patients and 128 healthy subjects. The characteristics of the patients and controls are described in the Supplementary Table 1.

\section{Isolation of PBMCs and plasma}

Blood was drawn by standard venipuncture into Vacutainer ${ }^{\circledR}$ Plus Plastic K2EDTA Tubes (Becton, Dickinson and Company) and kept at $4^{\circ} \mathrm{C}$ until shipment to the Istituto di Ricerche Farmacologiche Mario Negri IRCCS. PBMCs were isolated from ALS patients and healthy individuals, as previously described ${ }^{7}$. Further details are described in the Supplementary material.

\section{Mutation screening}

We examined a cohort of 959 ALS patients from Northern Italy and 677 healthy controls matched by age, sex and geographical origin. Informed written consent was obtained for all subjects and the study was approved by the ethics committees involved. Whole-genome sequencing was done at The American Genome Center (Uniformed Services University, Walter Reed National Military Medical Center campus, Bethesda, MD, USA) as described in the Supplementary material.

\section{Molecular dynamics (MD) simulations}

The structure of WT PPIA was retrieved from PDB 1CWA. The mutant form was generated by swapping the lysine 76 with glutamate using UCSF Chimera ${ }^{33}$. MD simulations were carried out as described in the Supplementary material.

\section{Comparative analysis with retrospective cohort}

To compare protein levels of the PPIA K76E patient with the retrospective cohort analysed in Luotti et al. $2020^{7}$, PBMCs were isolated and proteins extracted exactly as previously reported ${ }^{7}$. Slot blot analysis was done with the same internal standard (IS) as the previous work, which is a pool of all samples in the analysis. Immunoreactivity was normalized to Red Ponceau staining (Fluka) and to the immunosignal of the IS.

\section{AlphaLISA assay of MMP-9}


The level of MMP-9 in plasma was measured with an AlphaLISA kit for the human protein (\#AL3138, PerkinElmer). AlphaLISA signals were measured using an Ensight Multimode Plate Reader (PerkinElmer).

\section{Cell and molecular biology procedures}

Mutant PPIA cloning, cell culture, transfection and treatments were done as described in the Supplementary material.

\section{Immunoprecipitation}

Magnetic beads coupled with sheep polyclonal antibodies anti-rabbit IgG (Dynabeads, Invitrogen) were used for co-immunoprecipitation studies. Cells were lysed in $50 \mathrm{mM}$ Tris- $\mathrm{HCl}, \mathrm{pH}$ 7.2, 2\% CHAPS, protease inhibitor cocktail (Roche) and quantified with the BCA protein assay (Pierce). Proteins $(500 \mu \mathrm{g})$ were diluted to $0.5 \mu \mathrm{g} / \mu \mathrm{L}$ with lysis buffer. Magnetic beads with coupled sheep antibodies anti-rabbit IgG (Dynabeads ${ }^{\circledR}$ M280; Invitrogen) were washed with $0.5 \%$ bovine serum albumin immonuglobulin-free (BSA Ig-free) in PBS to remove preservatives. Three $\mu \mathrm{g}$ of rabbit polyclonal anti-human TDP-43 primary antibody (Proteintech; RRID: AB_2200505) or rabbit polyclonal anti-human Ran primary antibody (Abcam) was incubated with $20 \mu \mathrm{L}$ of anti-rabbit IgGconjugated Dynabeads for $2 \mathrm{~h}$ at $4^{\circ} \mathrm{C}$ in $0.1 \% \mathrm{BSA} / \mathrm{PBS}$. Immunoprecipitation and analysis of the proteins are described in the Supplementary material.

\section{Statistical analysis}

Prism 7.0 (GraphPad Software Inc., San Diego, CA) was used. For each variable, the differences between experimental groups were analysed by Student's $t$ test, or one-way ANOVA followed by post-hoc tests. Pearson's correlation coefficient (r) was calculated to measure the linear strength of the association between PPIA and TDP-43 total protein levels. Two-way ANOVA followed by the Bonferroni post-hoc test was used to analyse Rotarod performance and compare the body weight of PPIA -/- mice with controls. Survival curves were analysed using a log-rank Mantel Cox test. $P$ values below 0.05 were considered significant.

\section{Data availability}

The whole genome sequence data is publicly available on dbGaP at phs001963. The other data that support the findings of this study are available within the manuscript and supplementary material. Source data are available from the corresponding author upon reasonable request. 


\section{Results}

\section{PPIA is defective in sporadic ALS patients}

In PBMCs of ALS patients we detected a low level of Lys-acetylated PPIA ${ }^{13}$. We also observed, an impaired soluble/insoluble partitioning of PPIA and TDP-43 in PBMCs of a relatively large cohort of sporadic ALS and ALS-FTD patients in comparison with healthy controls, with significant accumulation of PPIA and TDP-43 in the insoluble fraction and substantially less PPIA in the soluble fraction $^{7}$. Here we measured the total PPIA and TDP-43 protein levels in the retrospective cohort (Cohort \#1, Supplementary Table 1). PPIA was significantly lower than controls, while TDP-43 did not differ (Fig. 1A-B). We checked whether this reflected downregulation of the PPIA gene. There was in fact significant downregulation of PPIA at the mRNA level too, in an independent cohort of sporadic ALS patients compared to healthy controls (Cohort \#2, Supplementary Table 1), and only a tendency to lower TDP-43 mRNA (Fig.1C-D). Finally, we detected a significant, although weak, positive correlation $(\mathrm{r}=0.3, \mathrm{p}=0.01)$ between PPIA and TDP-43 total protein levels.

In conclusion, defective PPIA is a common feature of ALS and ALS-FTD patients and could trigger TDP-43 pathology.

\section{PPIA-/- mice display neuropathological alterations, worsening with age}

To explore PPIA's impact on TDP-43 biology we did deep characterization of PPIA-/- mice throughout their lifespan. In our previous studies PPIA-/- mice had a higher burden of Tritoninsoluble phosphorylated TDP-43 (insoluble pTDP-43) in the spinal cord and brain cortex already at four months of age ${ }^{13}$. We detected no motor neuron $\operatorname{loss}^{18}$ and no motor phenotype (Supplementary Fig. 1A-B), but there was a tendency to kyphosis (Supplementary Fig. 1C).

To see whether these were prodromal signs of neurodegeneration, we did a neuropathological analysis of older PPIA-/- mice. Quantitative MRI was done longitudinally on PPIA-/- and PPIA+/+ mice at 6 and 12 months. PPIA-/- mice had a smaller total brain volume than controls, with the most marked difference at 12 months (-13\%) (Supplementary Fig. 1D).

Next, we verified the effect of PPIA depletion on hippocampus, cortex and cerebellum, adjusting for total brain volume (Fig. 2 and Supplementary Fig. 1). PPIA-/- mice had a significantly smaller hippocampus than PPIA+/+ mice at 6 and 12 months (Fig. 2A). There was also a reduction of the relative volume with age, independently from the genotype, slightly more marked in PPIA-/mice (-23\% versus $-21 \%)$. The cortex volume of PPIA-/- mice was also smaller than in PPIA+/+ mice, but less so: $3 \%$ and $10 \%$ smaller respectively at 6 and 12 months of age, but the difference was significant only at 12 months (Fig. 2B). However, PPIA-/- mice had significant cortex atrophy at 12 
compared to 6 months (-16\%); this was less marked in control mice $(-10 \%)$. In contrast, cerebellum relative volume did not significantly differ in PPIA-/- mice and controls and did not change with age (Supplementary Fig. 1E).

To investigate whether brain atrophy reflected neuronal loss we did a histological analysis on the hippocampus and cortex (Fig. 2C-D). There were substantially fewer Nissl-positive neurons in the hippocampus CA1 region of PPIA-/- mice than in controls at 6 and 12 months, and this tended to be more pronounced at 12 months (Fig. 2C). In the cortex PPIA-/- mice had fewer Nissl-positive neurons than controls at 6 and 12 months, but this was significant only at 12 months (Fig. 2D). They also had significantly greater neuron loss at 12 months than at 6 months, similarly to the MRI picture. The progressive neurodegenerative process in PPIA-/- mice was also confirmed by the plasma NFL level, a marker of neuro-axonal damage, that increased substantially with age compared to controls from 6 months (Fig. 2E).

We next examined the glial response in the hippocampus and cortex of PPIA-/- mice (Fig. 2F, Supplementary Fig. 1F-G). In the hippocampus, PPIA deficiency tended to increase astroglial activation at 12 months (Fig. 2F), but had no effect on microglia (Supplementary Fig. 1F). In the cortex, PPIA deficiency did not affect either astroglia or microglia (Supplementary Fig. 1G), confirming PPIA role in microglial activation and the neuroinflammatory response ${ }^{18}$.

To explore whether the neuropathological alterations were associated with TDP-43 pathology, we did biochemical and immunohistochemistry analyses for TDP-43 and pTDP-43 in brains of PPIA/- mice and controls at 6 and 12 months of age (Fig. 3, Supplementary Fig. 2). In the cortex of PPIA/- mice there was a significant increase in pTDP-43 in the cytoplasm and a concomitant decrease of TDP-43 in the nucleus compared to controls already at 6 months (Fig. 3A), while we saw no change in cerebellum (Supplementary Fig. 2A). We analysed the Triton-insoluble protein fraction from brain cortex of PPIA-/- and PPIA+/+ mice and found that in PPIA-/- mice there was significantly larger amount of insoluble proteins, TDP-43 and pTDP-43 (Supplementary Fig. 2B-D). We also analysed other proteins associated with ALS/FTD that interact with TDP-43 in RNP complexes and/or stress granules (Supplementary Fig. 2E-F). In the absence of PPIA, there was a higher level of insoluble hnRNPA2/B1 and TIA1, confirming the negative effect of deficient PPIA folding/refolding activity in the brain ${ }^{13}$.

Finally, we examined TDP-43 fragmentation in soluble and insoluble brain cortex fractions (Fig. 3B). Characteristic C-terminal 35- and 25-kDa TDP-43 fragments were abundant, mainly in the insoluble fraction. While TDP-43 bands at 43 and $35 \mathrm{kDa}$ respectively slightly decrease (-6\%) and increase (+12\%) in PPIA-/- mice, but not significantly (data not shown), the 25-kDa TDP-43 fragment accumulated substantially (+61\%). As often happens in ALS/FTD patients ${ }^{34,35}$, the burden of TDP- 
$43 \mathrm{C}$-terminal fragments is greater than that of TDP-43 full-length and the $25 \mathrm{kDa}$ accumulates more than the $35 \mathrm{kDa}$ fragment, probably because is less readily degraded ${ }^{36}$.

To better explore TDP-43 pathology and C-terminal TDP-43 fragments we did an histopathological analysis with an antibody that targets the C-terminus of the protein ${ }^{37}$. At 12 months of age, there was a widespread TDP-43 signal in different brain regions of PPIA-/- mice, with higher intensity in hippocampus and cortex, that accumulates in aggregated structures (Fig. 3C-E). We confirmed the presence of TDP-43 inclusions in PPIA-/- brain regions using a pTDP-43 antibody that targets the Cterminus, does not react with physiological nuclear TDP-43 but identifies only pathological brain lesions (Fig. 3F-G and Supplementary Fig. 2G-H).

We concluded that PPIA deficiency induces a clear-cut neuropathological phenotype in the mouse brain, with marked TDP-43 pathology and other alterations related to protein and RNA homeostasis, getting worsen with age.

\section{PPIA deficiency affects proteins involved in nucleocytoplasmic transport, TDP-43 autoregulation and synaptic function}

PPIA is a foldase and a molecular chaperone potentially for a wide range of substrates and interacts with GTP-binding nuclear protein Ran (Ran) ${ }^{13}$. TDP-43 requires functional Ran for import into the nucleus and regulates its expression ${ }^{38}$. In the cortex of PPIA-/- mice, Ran total protein level did not differ from controls (data not shown). However, Ran accumulated substantially $(+69 \%)$ in the detergent-insoluble fraction and decreased in the soluble fraction (-38\%) (Fig. 4A), already at 6 months of age. These findings may indicate that depletion of the folding/refolding activity of PPIA is at the basis of the reduced solubility of Ran and contribute to defective nucleocytoplasmic transport.

PPIA deficiency affects the expression of a number of TDP-43 RNA targets, including $G R N^{13}$. $G R N$ mutations in patients result in haplo-insufficiency and GRN knock-out mice present an FTDlike phenotype associated with synaptic dysfunction ${ }^{39}$. We verified whether knocking out PPIA influenced $G R N$ expression in the brain cortex of the mice. GRN mRNA levels were slightly but significantly lower in PPIA-/- mice than controls (Fig. 4B). Surprisingly, TDP-43 at mRNA and protein levels was also lower in PPIA-/- mice than controls (Fig. 4C-D). TDP-43 adjusts its own expression by binding sequences within the $3^{\prime}$ UTR of its own transcript, promoting processing of alternative introns (e.g. intron 7) and mRNA destabilization ${ }^{2,3}$. We found a $45 \%$ increase in the exclusion of TARDBP intron 7 in PPIA-/- compared to PPIA+/+ mice (Fig. 4E). This suggests that PPIA deficiency may also interfere with the mechanism of TDP-43 autoregulation leading to TDP43 downregulation. 
TDP-43 depletion in brain downregulates genes involved in synaptic function ${ }^{3}$. To assess whether GRN and TARDBP downregulation was associated with synaptic dysfunction, we first measured the levels of synaptophysin and PSD95, markers of pre- and post-synaptic structures, in the cortex of PPIA-/- mice and controls at 6 and 16 months of age (Fig. 4F-G). Both synaptophysin and PSD95 were lower in PPIA-/- than PPIA+/+ mice. Next, we made extracellular field recordings of excitatory postsynaptic potentials in the CA1 hippocampal region of PPIA-/- mice at 16 months of age compared to controls. Long-term potentiation induced with theta burst stimulation had a smaller amplitude in PPIA-/- mice (Fig. 4H), suggesting impairment of synaptic plasticity in the hippocampus.

\section{PPIA-/- mice develop cognitive, behavioural impairments and late- onset motor neuron disease}

We checked whether PPIA deficiency, besides compromising neuronal functions, promotes cognitive, behavioural and motor impairments. Since mice on a 129S6/Sv genetic background do not perform well in cognitive tasks ${ }^{40}$, C57_PPIA-/- mice were used for these experiments. We first confirmed that also C57_PPIA-/- mice display TDP-43 pathology (Supplementary Fig. 3). Next, we found that C57_PPIA-/- mice showed no exploratory abnormalities, as they spent the same time as C57_PPIA $+/+$ mice in the inner zone in the open field test, at both 6 and 12 months of age (Fig. 5A). In the elevated-plus maze paradigm C57_PPIA-/- mice showed less anxiety and more disinhibition as they spent twice the time in the open arms compared with controls (Fig. 5B). This behaviour is lost with time.

We used the three-chamber test to examine sociability and social memory in C57_PPIA-/mice. C57_PPIA-/- mice at 6 months spent twice the time of controls sniffing the stranger than the empty cage (Fig. 5C), suggesting a more social attitude. However, at 12 months C57_PPIA-/- mice behaved differently, spending the same time with the stranger and the empty cage and significantly less time sniffing the stranger compared with mice at 6 months.

Combining the results of the elevated-plus maze and the three-chamber tests suggests that the greater social attitude of C57_PPIA-/- mice may be the consequence of greater disinhibition. During the social recognition memory task, which requires normal hippocampal function, C57_PPIA-/- mice at 6 months distinguished the stranger mouse (Stranger 2) from the familiar one (Stranger 1) (Fig. 5D), suggesting a normal social memory. However, at 12 months they no longer did it, suggesting social impairment and hippocampal dysfunction. 
To investigate the role of impaired hippocampus in C57_PPIA-/- mice further, we used the Morris water maze and novel object recognition tests. C57_PPIA-/- and control mice showed no differences (Fig. 5E-F), suggesting no memory impairment. However, these tests were developed to study Alzheimer's disease-related memory defects in mice and specific tests for FTD are not available $^{41}$. Furthermore, also FTD patients show mild memory impairments despite the hippocampal degeneration $^{42}$.

At 12 months C57_PPIA-/- mice had lower locomotor speed (Fig. 5G). In PPIA-/- mice, there was no evident motor impairment, as detected by rotarod and grid test throughout the lifespan (Supplementary Fig. 4A-B). However, at 12 months PPIA-/- mice had mild muscle atrophy (Fig. 5H), from 16 months impaired extension reflex (Fig. 5I), and from 21 months loss of body weight (Fig. $5 J)$. These results correlated with gradual loss of motor neurons in the lumbar spinal tract of PPIA-/mice, that became significant in the final stage of the disease (Fig. 5K). Finally, there was more than four months shorter survival of PPIA-/- mice than PPIA+/+ mice $(702 \pm 90$ days versus $837 \pm 107$ days) (Fig. 5L).

In summary, mice knock-out for PPIA present cognitive, behavioural and motor impairments reminiscent of ALS-FTD in patients.

\section{Identification of a PPIA loss-of-function mutation in a sporadic ALS patient}

We identified an ALS patient with an heterozygous PPIA missense mutation (NM_021130: c.226A $>$ G.; p.K76E) in an evolutionarily conserved region of the protein (Fig. 6A). To our knowledge, the PPIA:p.K76E is a novel variant absent in the large population dataset gnomAD v2.1.1, in our internal control cohort of 677 healthy subjects, matched by age and ancestry, and in the large ALS/FTD dataset ProjectMine (http://databrowser.projectmine.com/). The patient had difficulty walking at age 56 and slowly progressed to weakness and spasticity of the lower limbs. Neurological examination revealed increased deep tendon reflex in all extremities and pathological reflexes, including bilateral Hoffman sign and Babinski sign. No additional neurologic or systemic abnormalities were detected. The electromyography showed signs of lower motor neuron involvement in the upper and lower limbs. Genetic screening for mutations in the most common ALS genes and in a large panel of hereditary spastic paraplegia genes was negative. Appropriate investigations excluded other diseases, and motor impairment progressed over time. He was diagnosed with ALS at age 59. Cognitive testing was normal. No weakness in the upper limbs or 
bulbar and respiratory symptoms was reported after five years. The patient reported no family history of neurodegenerative disease, psychiatric disease or walking impairment.

We analysed TDP-43 partitioning in PBMCs as a surrogate marker of TDP-43 pathology and found that in the mutant PPIA patient TDP-43 accumulated in the insoluble fraction like the sporadic ALS and ALS-FTD patients of the retrospective cohort (Fig. 6B), confirming the diagnostic value of this parameter in PBMCs ${ }^{7}$. TDP-43 mRNA levels in the PPIA mutant patient were higher than in healthy controls and other ALS patients, while the protein level tended to be lower than the retrospective cohort (Supplementary Fig. 5C-D).

Known PPIA variants have low protein stability and are rapidly degraded ${ }^{43}$. We hypothesized that PPIA K76E could be a loss-of-function variant. We transfected HEK293 cells with myc-tagged PPIA wild-type (WT) and K76E and detected a lower level of the exogenous mutant protein than in WT after 48 hours in culture (Fig. 6C), despite equivalent transfection as detected in parallel wells by WB with anti-myc antibody after 24 hours in culture (Fig. 6D, timepoint 0 ). The lower stability of the mutant protein was confirmed by the accelerated degradation over time in cells treated with an inhibitor of new protein synthesis (Fig. 6D). Moreover, PPIA total protein levels in PBMCs were lower in the PPIA mutant patient than in the retrospective cohort ${ }^{7}$ of healthy subjects (-34\%) and ALS patients (-21\%) (Supplementary Fig. 5A). PPIA mRNA levels, however, were higher in the mutant PPIA patient than in other ALS patients, although lower than in healthy controls (Supplementary Fig. $5 B)$.

We also examined possible structural differences between PPIA WT and K76E by molecular dynamics (MD) simulations (Fig. 7 and Supplementary Fig. 6). The analysis identified two regions (residues 26-30 and 43-45) outlining $\alpha$-helix 1 in which the conformation of PPIA K76E significantly differed from the WT form (Fig. 7A-B). The mutant protein the 43-45 loop is significantly closer to the nearby $\beta$-strand (residues 156-165) (Fig. 7C). Since the K76E mutation lies within a coil in direct contact with helix-1, this suggested that the effect of the mutation is not only limited to a local change of electrostatic properties, but could instead result in a structural alteration of nearby regions essential for catalytic activity and protein interaction ${ }^{44}$. PPIA has a wide interaction network ${ }^{13}$. We tested whether the mutation impaired PPIA interaction with TDP-43 and Ran by co-immunoprecipitation (Fig. 7D-E). We found that both TDP-43 and Ran have an aberrant interaction with PPIA K76E, with a substantial increase in the affinity of both proteins for the mutant PPIA compared to PPIA WT.

The extracellular form of PPIA is toxic for motor neurons by activating the EMMPRIN/CD147 receptor and inducing MMP-9 expression ${ }^{18}$. We measured MMP-9 plasma levels in the mutant PPIA patient and in a cohort of ALS patients and healthy subjects (Fig. 7F). While ALS 
patients had a higher level of MMP-9 than healthy controls, the PPIA mutant patient had one of the lowest levels of MMP-9, suggesting also a reduced toxic extracellular function of PPIA.

We conclude that $\mathrm{K} 76 \mathrm{E}$ is a loss-of-function mutation that may affect both intracellular protective and extracellular toxic PPIA functions, leading to ALS with a slowly progressive phenotype in the patient. Further studies directly testing the function of mutant PPIA are necessary to dissect all possible implications.

\section{Discussion}

TDP-43 proteinopathy is a prominent neuropathological feature in the ALS/FTD disease spectrum that is also seen in a wide range of neurodegenerative diseases, inherited and sporadic ${ }^{4}$. Neither the factors driving TDP-43 pathology nor its involvement in neurodegeneration have been defined yet. We propose that defective PPIA is a key factor in the cytoplasmic mislocalization and aggregation of TDP-43, induces neurodegeneration, and is a common feature in ALS/FTD patients.

PPIA is an evolutionarily conserved foldase and molecular chaperone, abundant in the cytoplasm but also present in the nucleus ${ }^{7,12}$. Its PPIase activity has been regarded as fundamental in protein folding and refolding especially under stress conditions ${ }^{13-15}$. PPIA was found entrapped in aggregates isolated from spinal cord and brain of ALS/FTD patients and mouse models while exerting its protective function against misfolding ${ }^{20,45}$. However, the absence of an overt phenotype in the PPIA-/- mouse in the work of Colgan et al. and its dispensable function in mammalian cells have kept its physiological role enigmatic ${ }^{24,25}$, especially in the CNS where it is highly expressed.

In a previous work characterizing the protein interacting network of PPIA under basal conditions we found that it includes several proteins involved in RNA homeostasis, hnRNPs and TDP- $43^{13}$. We also reported that PPIA regulates key TDP-43 functions, such as gene expression regulation ${ }^{13}$. In fact, knocking down PPIA affected the expression of TDP-43 RNA targets implicated in FTD/ALS, such as GRN, VCP and FUS, or in protein clearance, such as HDAC6 and ATG7. As a consequence, the mutant SOD1 mouse cross-bred with the PPIA-/- mouse had a more severe disease phenotype, with more protein aggregation and less survival. Besides SOD1, TDP-43, and hnRNPs ${ }^{13}$, PPIA interacts with other proteins linked to genetic forms of ALS/FTD, such as ubiquilin $2^{46}$ and Arg-containing dipeptide repeat proteins ${ }^{47}$. We therefore concluded that PPIA could be a modifier of ALS/FTD pathology.

In this work we demonstrate that the loss of PPIA in mice is sufficient to induce neurodegeneration leading to a clinical phenotype of the ALS/FTD spectrum. We also show that PPIA is defective in several ALS and ALS-FTD patients and that a subject carrying a loss-of-function PPIA mutation develops ALS. Therefore, besides the general intracellular protective effect under 
stress, we provide evidence that PPIA has specific, non-redundant functions that are particularly relevant for TDP-43 biology.

Deficient PPIA alters the biochemical properties of Ran and this may underlie the impaired TDP-43 nuclear import. Ran is a master regulator of the nuclear protein import and is required for the majority of the proteins that shuttle between the nucleus and cytoplasm. Non-functional Ran reduced TDP-43 nuclear localization in cortical neurons ${ }^{38}$. Ran is also a PPIA interactor ${ }^{13}$ and has a GP-motif (residues 57-58), the recognition site for the foldase activity of PPIA, present also in TDP-43 and other PPIA substrates ${ }^{13,44,48,49}$. In the absence of PPIA, Ran is increasingly recovered in the detergentinsoluble aggregates of the mouse brain. Ran and other regulators of nucleocytoplasmic trafficking accumulate in the cytoplasm of ALS/FTD cellular models ${ }^{50-52}$, either as de-mixed droplets or in stress granules, suggesting that defective PPIA may have a role in the pathogenic mechanisms that couple cellular stress with impaired nucleocytoplasmic transport. Biochemical analysis of the detergentinsoluble fraction of the cortex of PPIA-/- mice did in fact indicate a general increase in insoluble proteins and TIA1 stress granule marker.

Defective PPIA alters TDP-43 mRNA expression. In PPIA-/- mice TDP-43 mRNA is downregulated, and in the mutant PPIA patient it is upregulated. TDP-43 physiological levels are tightly controlled at a transcriptional level by an autoregulatory loop, which keeps intracellular TDP43 within a narrow range ${ }^{2,3}$. This is necessary, for example, for TDP-43's role in RNP complexes that may become dysfunctional if the stoichiometry between TDP-43 and the other protein/RNA components is disrupted ${ }^{13}$. In a previous work, we demonstrated that PPIA through its foldase activity influences the binding of TDP-43 to RNA ${ }^{13}$. Therefore, we can assume that in absence of PPIA-/increased TARDBP intron 7 splicing and TDP-43 mRNA destabilization in mice may be caused by an impaired binding of TDP-43 to its $3^{\prime}$ UTR. In the mutant patient, we can hypothesize that PPIA K76E, that has an aberrant interaction with TDP-43, sequesters TDP-43 and affects autoregulation in the opposite direction, promoting the production of stable mRNA species ${ }^{53}$. Further studies are needed to decipher the exact mechanism at the basis of these divergent effects at a mRNA level, while at a protein level in both cases TDP-43 decreases. However, TDP-43 homeostasis and function are controlled not only by autoregulation, but also by nucleocytoplasmic transport and aggregation, in a coordinated fashion ${ }^{10}$. Interestingly, PPIA seems to be involved in all of them.

In brain of PPIA-/- mice TDP-43 is downregulated also at the protein level. If complete ablation of TDP-43 is embryonically lethal, conditional knock-out and limited knock-down of TDP43 results in neurodegeneration ${ }^{54,55}$. Moreover, TDP-43 depletion in brain downregulates genes with very long introns that encode proteins involved in synaptic function ${ }^{3,56}$. In agreement with this, we detected downregulation of synaptic proteins and impairment of synaptic plasticity in the 
hippocampus of PPIA-/- mice, indicating that PPIA deficiency also has an effect on synaptic structure and function.

In several pathological conditions oxidative stress and inflammation increase PPIA secretion into biofluids ${ }^{57}$. The levels of PPIA were high in the CSF of ALS patients and mutant SOD1 rodent models ${ }^{18}$. Once secreted, PPIA activates a proinflammatory pathway by the EMMPRIN/CD147 receptor, leading to NF- $\mathrm{BB}$ activation and induction of MMP-9 expression in neurons and glia ${ }^{18}$. Large, fast-twitch, fatigable $\alpha$ motor neurons, which are the most susceptible to degeneration in ALS, express the highest level of MMP-9, which enhances endoplasmic reticulum stress and promotes neurodegeneration ${ }^{58}$. High levels of MMP-9 in tissues and biofluids of ALS patients have been detected in this work and by other groups ${ }^{59,60}$ and has been associated with blood-brain barrier breakdown ${ }^{61}$. We previously reported that selective pharmacological inhibition of extracellular PPIA (ePPIA) reduced MMP-9, promoted a pro-healing phenotype in glia, rescued motor neurons and increased survival in the SOD1 G93A mouse model of ALS ${ }^{18}$. We also showed that ePPIA was toxic toward motor neurons, which express high levels of EMMPRIN/CD147, but had no effect on cortical and cerebellar granule neurons ${ }^{18}$.

The late-onset and slowly progressing motor dysfunction in PPIA-/- mice can be explained with the substantially reduced activation of the EMMPRIN/CD147-dependent proinflammatory pathway to which motor neurons are particularly susceptible (Fig. 8). In the patient heterozygous for mutant PPIA, half the ePPIA may be unable to activate EMMPRIN/CD147, reducing neuroinflammation and slowing progression of the disease. Defective intracellular PPIA (iPPIA) increases cellular stress, ultimately leading to PPIA secretion. We hypothesize a tug-of-war between iPPIA and ePPIA, in which the prevalence of ePPIA over iPPIA accelerates disease progression. Increasing iPPIA function may reduce ePPIA and be an effective therapeutic approach.

Several mouse models of ALS/FTD have been generated targeting genes with known pathogenic roles but each one recapitulates only certain aspects of the human disease. For instance, TDP-43 pathology in mice is often absent or mild and is not always linked to neurodegeneration or behavioural phenotypes ${ }^{62}$. In TDP-43 mouse models overexpressing wild-type TDP-43 or diseaseassociated mutations, C-terminal TDP-43 fragments are detected at low levels or are absent ${ }^{63}$. PPIA/- mice are characterized by diffuse, marked TDP-43 pathology in cortex, hippocampus and spinal $\operatorname{cord}^{13}$, with all the key neuropathological features of ALS/FTD including cytoplasmic mislocalization and accumulation of C-terminal fragments of TDP-43 associated with neurodegeneration and cognitive and behavioural impairments. In PPIA-/- mice the behavioural symptoms follow a peculiar course. Initially, they present disinhibition with no social impairment, and later they show loss of disinhibition and develop apathy and social disinterest. Interestingly, while 
most patients with the behavioural variant of FTD (bvFTD) display both disinhibition and apathy during the course of the disease, some may initially present as primarily disinhibited or primarily apathetic and later develop either signs of inertia or disinhibition ${ }^{64}$. Moreover, despite clear evidence that cognitive/behavioural impairment may appear early in the course of ALS not always deterioration seems to occur with disease progression ${ }^{65}$.

There is a significant genetic and neuropathological overlap between ALS and FTD with up to $50 \%$ of ALS patients having cognitive and behavioural manifestations and up to $40 \%$ of FTD patients developing motor dysfunction ${ }^{66}$. However, it is not clear which pathway is at the basis of either phenotype. Interestingly, PPIA-/- mice display early key symptoms of bvFTD and only later develop motor dysfunction. The resulting picture resembles a behaviourally predominant ALS-FTD in which behavioural symptoms typically evolve before motor symptoms ${ }^{67}$. GRN deficiency, the cause of a tau-negative familial form of $\mathrm{FTD}^{68}$, probably contributes to the development of a predominant FTD phenotype in PPIA-/- mice.

PPIA genetic variants are very rare, so individuals homozygous for any of them even more unlikely ${ }^{43}$. The identification of a PPIA variant in a single patient cannot definitely demonstrate its causality. However, the structural and functional properties of the mutant protein are suggestive of its possible involvement in disease pathogenesis. More relevant for the disease is the regulation of PPIA at a post-translational level. PPIA is commonly and variably post-translationally modified and these modifications regulate its functions ${ }^{13,21,69,70}$. The interaction with TDP-43 is favoured by PPIA Lys-acetylation, which is low in ALS patients ${ }^{13}$. Here we also report downregulated PPIA in two independent cohorts of patients; therefore, we predict that an overall defective PPIA is likely in several patients and needs to be further investigated in large clinical studies.

In conclusion, our findings indicate that PPIA is involved in multiple pathways that protect CNS from TDP-43-mediated toxicity. In fact, if deficient and/or dysfunctional PPIA can trigger TDP43 proteinopathy leading to neurodegeneration. PPIA-/- mice recapitulate key features of ALS-FTD and are useful experimental model to investigate the mechanisms of TDP-43 proteinopathy, with the aim of developing novel therapeutic approaches.

\section{Acknowledgments}

We thank Bradford C. Berk and Patrizia Nigro for providing the PPIA-/- mice on C57BL/6J genetic background and the Laboratory of Neurogenetics (NIH) staff for their collegial support and technical assistance. We thank Judith Baggott for editorial assistance and Fabrizio Aspesi for graphics assistance by BioRender.com. 


\section{Funding}

This work was supported by grants from the "Fondazione Regionale per la Ricerca Biomedica di Regione Lombardia”, project TRANS-ALS (to V.B.), ERA-Net for Research Programmes on Rare Diseases, project MAXOMOD (to V.B.), the Italian Ministry of Health, project RF-2018-12365614 (to A.C. and V.B.) and RF-2013-02356221 (to V.B.), and in part by the Intramural Research Program of the National Institutes of Health (1ZIAAG000935). SP is the recipient of the 2019 Marlene Reimer Brainstar of the year award from CIHR-CAN (ICT-171454).

\section{Competing interests}

B.J.T. is an editorial board member for Journal of Neurology, Neurosurgery and Psychiatry and Neurobiology of Aging and is an associate editor for Brain. All other authors report no competing interests.

\section{References}

1. Ratti A, Buratti E. Physiological functions and pathobiology of TDP-43 and FUS/TLS proteins. J Neurochem. 2016;138 Suppl 1:95-111. doi:10.1111/jnc.13625

2. Ayala YM, De Conti L, Avendaño-Vázquez SE, et al. TDP-43 regulates its mRNA levels through a negative feedback loop. EMBO J. 2011;30(2):277-288. doi:10.1038/emboj.2010.310

3. Polymenidou M, Lagier-Tourenne C, Hutt KR, et al. Long pre-mRNA depletion and RNA missplicing contribute to neuronal vulnerability from loss of TDP-43. Nat Neurosci. 2011;14(4):459-468. doi:10.1038/nn.2779

4. de Boer EMJ, Orie VK, Williams T, et al. TDP-43 proteinopathies: a new wave of neurodegenerative diseases. J Neurol Neurosurg Psychiatry. Published online November 11, 2020. doi:10.1136/jnnp-2020-322983

5. Neumann M, Sampathu DM, Kwong LK, et al. Ubiquitinated TDP-43 in frontotemporal lobar degeneration and amyotrophic lateral sclerosis. Science. 2006;314(5796):130-133. doi:10.1126/science. 1134108

6. De Marco G, Lupino E, Calvo A, et al. Cytoplasmic accumulation of TDP-43 in circulating lymphomonocytes of ALS patients with and without TARDBP mutations. Acta Neuropathol. 2011;121:611-622. doi:10.1007/s00401-010-0786-7

7. Luotti S, Pasetto L, Porcu L, et al. Diagnostic and prognostic values of PBMC proteins in amyotrophic lateral sclerosis. Neurobiol Dis. Published online February 2020:104815. doi:10.1016/j.nbd.2020.104815

8. Guo L, Kim HJ, Wang H, et al. Nuclear-Import Receptors Reverse Aberrant Phase Transitions of RNA-Binding Proteins with Prion-like Domains. Cell. 2018;173(3):677-692.e20. doi:10.1016/j.cell.2018.03.002 
9. Kim HJ, Taylor JP. Lost in Transportation: Nucleocytoplasmic Transport Defects in ALS and Other Neurodegenerative Diseases. Neuron. 2017;96(2):285-297. doi:10.1016/j.neuron.2017.07.029

10. Tziortzouda P, Van Den Bosch L, Hirth F. Triad of TDP43 control in neurodegeneration: autoregulation, localization and aggregation. Nat Rev Neurosci. Published online March 2, 2021. doi:10.1038/s41583-021-00431-1

11. Ryffel B, Woerly G, Greiner B, Haendler B, Mihatsch MJ, Foxwell BM. Distribution of the cyclosporine binding protein cyclophilin in human tissues. Immunology. 1991;72(3):399-404.

12. Fischer G, Wittmann-Liebold B, Lang K, Kiefhaber T, Schmid FX. Cyclophilin and peptidylprolyl cis-trans isomerase are probably identical proteins. Nature. 1989;337(6206):476-478. doi:10.1038/337476a0

13. Lauranzano E, Pozzi S, Pasetto L, et al. Peptidylprolyl isomerase A governs TARDBP function and assembly in heterogeneous nuclear ribonucleoprotein complexes. Brain. 2015;138(4):974991. doi:10.1093/brain/awv005

14. Lee JP, Palfrey HC, Bindokas VP, et al. The role of immunophilins in mutant superoxide dismutase-1linked familial amyotrophic lateral sclerosis. Proc Natl Acad Sci $U$ A. 1999;96(6):3251-3256.

15. Boulos S, Meloni BP, Arthur PG, Majda B, Bojarski C, Knuckey NW. Evidence that intracellular cyclophilin A and cyclophilin A/CD147 receptor-mediated ERK1/2 signalling can protect neurons against in vitro oxidative and ischemic injury. Neurobiol Dis. 2007;25(1):5464. doi:10.1016/j.nbd.2006.08.012

16. Pan H, Luo C, Li R, et al. Cyclophilin A is required for CXCR4-mediated nuclear export of heterogeneous nuclear ribonucleoprotein A2, activation and nuclear translocation of ERK1/2, and chemotactic cell migration. $J$ Biol Chem. 2008;283(1):623-637. doi:10.1074/jbc.M704934200

17. Sherry B, Yarlett N, Strupp A, Cerami A. Identification of cyclophilin as a proinflammatory secretory product of lipopolysaccharide-activated macrophages. Proc Natl Acad Sci U A. 1992;89(8):3511-3515.

18. Pasetto L, Pozzi S, Castelnovo M, et al. Targeting Extracellular Cyclophilin A Reduces Neuroinflammation and Extends Survival in a Mouse Model of Amyotrophic Lateral Sclerosis. J Neurosci. 2017;37(6):1413-1427. doi:10.1523/JNEUROSCI.2462-16.2016

19. Nigro P, Pompilio G, Capogrossi MC. Cyclophilin A: a key player for human disease. Cell Death Dis. 2013;4:e888. doi:10.1038/cddis.2013.410

20. Basso M, Samengo G, Nardo G, et al. Characterization of Detergent-Insoluble Proteins in ALS Indicates a Causal Link between Nitrative Stress and Aggregation in Pathogenesis. Petrucelli L, ed. PLoS ONE. 2009;4(12):e8130. doi:10.1371/journal.pone.0008130

21. Massignan T, Casoni F, Basso M, et al. Proteomic analysis of spinal cord of presymptomatic amyotrophic lateral sclerosis G93A SOD1 mouse. Biochem Biophys Res Commun. 2007;353(3):719-725. doi:10.1016/j.bbrc.2006.12.075 
22. Nardo G, Pozzi S, Pignataro M, et al. Amyotrophic lateral sclerosis multiprotein biomarkers in peripheral blood mononuclear cells. PLoS One. 2011;6(10):e25545. doi:10.1371/journal.pone.0025545

23. Filareti M, Luotti S, Pasetto L, et al. Decreased Levels of Foldase and Chaperone Proteins Are Associated with an Early-Onset Amyotrophic Lateral Sclerosis. Front Mol Neurosci. 2017;10. doi:10.3389/fnmol.2017.00099

24. Colgan J, Asmal M, Luban J. Isolation, characterization and targeted disruption of mouse ppia: cyclophilin A is not essential for mammalian cell viability. Genomics. 2000;68(2):167-178. doi:10.1006/geno.2000.6295

25. Colgan J, Asmal M, Neagu M, et al. Cyclophilin A regulates TCR signal strength in CD4+ T cells via a proline-directed conformational switch in Itk. Immunity. 2004;21(2):189-201. doi:10.1016/j.immuni.2004.07.005

26. Mancini S, Balducci C, Micotti E, et al. Multifunctional liposomes delay phenotype progression and prevent memory impairment in a presymptomatic stage mouse model of Alzheimer disease. J Controlled Release. 2017;258:121-129. doi:10.1016/j.jconrel.2017.05.013

27. Pasetto L, Olivari D, Nardo G, et al. Micro-computed tomography for non-invasive evaluation of muscle atrophy in mouse models of disease. PloS One. 2018;13(5):e0198089. doi:10.1371/journal.pone.0198089

28. Nardo G, Trolese MC, de Vito G, et al. Immune response in peripheral axons delays disease progression in SOD1(G93A) mice. J Neuroinflammation. 2016;13(1):261. doi:10.1186/s12974016-0732-2

29. Brooks BR, Miller RG, Swash M, Munsat TL. El Escorial revisited: revised criteria for the diagnosis of amyotrophic lateral sclerosis. Amyotroph Lateral Scler Mot Neuron Disord. 2000;1(5):293-299.

30. Iazzolino B, Peotta L, Zucchetti JP, et al. Differential Neuropsychological Profile of Patients With Amyotrophic Lateral Sclerosis With and Without C9orf72 Mutation. Neurology. 2021;96(1):e141-e152. doi:10.1212/WNL.0000000000011093

31. Rascovsky K, Hodges JR, Knopman D, et al. Sensitivity of revised diagnostic criteria for the behavioural variant of frontotemporal dementia. Brain J Neurol. 2011;134(Pt 9):2456-2477. doi:10.1093/brain/awr179

32. Strong MJ, Abrahams S, Goldstein LH, et al. Amyotrophic lateral sclerosis - frontotemporal spectrum disorder (ALS-FTSD): Revised diagnostic criteria. Amyotroph Lateral Scler Front Degener. 2017;18(3-4):153-174. doi:10.1080/21678421.2016.1267768

33. Pettersen EF, Goddard TD, Huang CC, et al. UCSF Chimera--a visualization system for exploratory research and analysis. $J$ Comput Chem. 2004;25(13):1605-1612. doi:10.1002/jec.20084

34. Lee EB, Lee VM-Y, Trojanowski JQ. Gains or losses: molecular mechanisms of TDP43mediated neurodegeneration. Nat Rev Neurosci. 2011;13(1):38-50. doi:10.1038/nrn3121 
35. Josephs KA, Zhang Y-J, Baker M, Rademakers R, Petrucelli L, Dickson DW. C-terminal and full length TDP-43 specie differ according to FTLD-TDP lesion type but not genetic mutation. Acta Neuropathol Commun. 2019;7(1):100. doi:10.1186/s40478-019-0755-x

36. Cicardi ME, Cristofani R, Rusmini P, et al. Tdp-25 Routing to Autophagy and Proteasome Ameliorates its Aggregation in Amyotrophic Lateral Sclerosis Target Cells. Sci Rep. 2018;8(1):12390. doi:10.1038/s41598-018-29658-2

37. Jeon GS, Shim Y-M, Lee D-Y, et al. Pathological Modification of TDP-43 in Amyotrophic Lateral Sclerosis with SOD1 Mutations. Mol Neurobiol. 2019;56(3):2007-2021. doi:10.1007/s12035-018-1218-2

38. Ward ME, Taubes A, Chen R, et al. Early retinal neurodegeneration and impaired Ran-mediated nuclear import of TDP-43 in progranulin-deficient FTLD. J Exp Med. 2014;211(10):1937-1945. doi:10.1084/jem.20140214

39. Petkau TL, Neal SJ, Milnerwood A, et al. Synaptic dysfunction in progranulin-deficient mice. Neurobiol Dis. 2012;45(2):711-722. doi:10.1016/j.nbd.2011.10.016

40. Brooks SP, Pask T, Jones L, Dunnett SB. Behavioural profiles of inbred mouse strains used as transgenic backgrounds. II: cognitive tests. Genes Brain Behav. 2005;4(5):307-317. doi:10.1111/j.1601-183X.2004.00109.x

41. Vernay A, Sellal F, René F. Evaluating Behavior in Mouse Models of the Behavioral Variant of Frontotemporal Dementia: Which Test for Which Symptom? Neurodegener Dis. 2016;16(34):127-139. doi:10.1159/000439253

42. de Souza LC, Chupin M, Bertoux M, et al. Is hippocampal volume a good marker to differentiate Alzheimer's disease from frontotemporal dementia? J Alzheimers Dis JAD. 2013;36(1):57-66. doi:10.3233/JAD-122293

43. von Hahn T, Ciesek S. Cyclophilin polymorphism and virus infection. Curr Opin Virol. 2015;14:47-49. doi:10.1016/j.coviro.2015.07.012

44. Howard BR, Vajdos FF, Li S, Sundquist WI, Hill CP. Structural insights into the catalytic mechanism of cyclophilin A. Nat Struct Biol. 2003;10(6):475-481. doi:10.1038/nsb927

45. Seyfried NT, Gozal YM, Donovan LE, et al. Quantitative analysis of the detergent-insoluble brain proteome in frontotemporal lobar degeneration using SILAC internal standards. $J$ Proteome Res. 2012;11(5):2721-2738. doi:10.1021/pr2010814

46. Blokhuis AM, Koppers M, Groen EJN, et al. Comparative interactomics analysis of different ALS-associated proteins identifies converging molecular pathways. Acta Neuropathol (Berl). 2016;132(2):175-196. doi:10.1007/s00401-016-1575-8

47. Lee K-H, Zhang P, Kim HJ, et al. C9orf72 Dipeptide Repeats Impair the Assembly, Dynamics, and Function of Membrane-Less Organelles. Cell. 2016;167(3):774-788.e17. doi:10.1016/j.cell.2016.10.002

48. Yurchenko V, Zybarth G, O'Connor M, et al. Active site residues of cyclophilin A are crucial for its signaling activity via CD147. J Biol Chem. 2002;277(25):22959-22965. doi:10.1074/jbc.M201593200 
49. Piotukh K, Gu W, Kofler M, Labudde D, Helms V, Freund C. Cyclophilin A binds to linear peptide motifs containing a consensus that is present in many human proteins. $J$ Biol Chem. 2005;280(25):23668-23674. doi:10.1074/jbc.M503405200

50. Chou C-C, Zhang Y, Umoh ME, et al. TDP-43 pathology disrupts nuclear pore complexes and nucleocytoplasmic transport in ALS/FTD. Nat Neurosci. 2018;21(2):228-239. doi:10.1038/s41593-017-0047-3

51. Gasset-Rosa F, Lu S, Yu H, et al. Cytoplasmic TDP-43 De-mixing Independent of Stress Granules Drives Inhibition of Nuclear Import, Loss of Nuclear TDP-43, and Cell Death. Neuron. 2019;102(2):339-357.e7. doi:10.1016/j.neuron.2019.02.038

52. Zhang K, Daigle JG, Cunningham KM, et al. Stress Granule Assembly Disrupts Nucleocytoplasmic Transport. Cell. 2018;173(4):958-971.e17. doi:10.1016/j.cell.2018.03.025

53. White MA, Kim E, Duffy A, et al. TDP-43 gains function due to perturbed autoregulation in a Tardbp knock-in mouse model of ALS-FTD. Nat Neurosci. 2018;21(4):552-563. doi:10.1038/s41593-018-0113-5

54. Iguchi $\mathrm{Y}$, Katsuno M, Niwa J, et al. Loss of TDP-43 causes age-dependent progressive motor neuron degeneration. Brain. 2013;136(5):1371-1382. doi:10.1093/brain/awt029

55. Wu L-S, Cheng W-C, Shen C-KJ. Targeted depletion of TDP-43 expression in the spinal cord motor neurons leads to the development of amyotrophic lateral sclerosis-like phenotypes in mice. J Biol Chem. 2012;287(33):27335-27344. doi:10.1074/jbc.M112.359000

56. Sephton CF, Cenik C, Kucukural A, et al. Identification of neuronal RNA targets of TDP-43containing ribonucleoprotein complexes. $J$ Biol Chem. 2011;286(2):1204-1215. doi:10.1074/jbc.M110.190884

57. Hoffmann H, Schiene-Fischer C. Functional aspects of extracellular cyclophilins. Biol Chem. 2014;395(7-8):721-735. doi:10.1515/hsz-2014-0125

58. Kaplan A, Spiller KJ, Towne C, et al. Neuronal matrix metalloproteinase-9 is a determinant of selective neurodegeneration. Neuron. 2014;81(2):333-348. doi:10.1016/j.neuron.2013.12.009

59. Beuche W, Yushchenko M, Mader M, Maliszewska M, Felgenhauer K, Weber F. Matrix metalloproteinase-9 is elevated in serum of patients with amyotrophic lateral sclerosis. Neuroreport. 2000;11(16):3419-3422.

60. Fang L, Huber-Abel F, Teuchert M, et al. Linking neuron and skin: matrix metalloproteinases in amyotrophic lateral sclerosis (ALS). $J$ Neurol Sci. 2009;285(1-2):62-66. doi:10.1016/j.jns.2009.05.025

61. Bell RD, Winkler EA, Singh I, et al. Apolipoprotein E controls cerebrovascular integrity via cyclophilin A. Nature. 2012;485(7399):512-516. doi:10.1038/nature11087

62. Solomon DA, Mitchell JC, Salcher-Konrad M-T, Vance CA, Mizielinska S. Review: Modelling the pathology and behaviour of frontotemporal dementia. Neuropathol Appl Neurobiol. 2019;45(1):58-80. doi:10.1111/nan.12536

63. Berning BA, Walker AK. The Pathobiology of TDP-43 C-Terminal Fragments in ALS and FTLD. Front Neurosci. 2019;13:335. doi:10.3389/fnins.2019.00335 
64. Le Ber I, Guedj E, Gabelle A, et al. Demographic, neurological and behavioural characteristics and brain perfusion SPECT in frontal variant of frontotemporal dementia. Brain $J$ Neurol. 2006;129(Pt 11):3051-3065. doi:10.1093/brain/awl288

65. Bersano E, Sarnelli MF, Solara V, et al. Decline of cognitive and behavioral functions in amyotrophic lateral sclerosis: a longitudinal study. Amyotroph Lateral Scler Front Degener. 2020;21(5-6):373-379. doi:10.1080/21678421.2020.1771732

66. Burrell JR, Kiernan MC, Vucic S, Hodges JR. Motor neuron dysfunction in frontotemporal dementia. Brain J Neurol. 2011;134(Pt 9):2582-2594. doi:10.1093/brain/awr195

67. Lulé DE, Aho-Özhan HEA, Vázquez C, et al. Story of the ALS-FTD continuum retold: rather two distinct entities. J Neurol Neurosurg Psychiatry. 2019;90(5):586-589. doi:10.1136/jnnp2018-318800

68. Baker M, Mackenzie IR, Pickering-Brown SM, et al. Mutations in progranulin cause taunegative frontotemporal dementia linked to chromosome 17. Nature. 2006;442(7105):916-919. doi:10.1038/nature 05016

69. Ghezzi P, Casagrande S, Massignan T, et al. Redox regulation of cyclophilin A by glutathionylation. Proteomics. 2006;6(3):817-825. doi:10.1002/pmic. 200500177

70. Lammers M, Neumann H, Chin JW, James LC. Acetylation regulates cyclophilin A catalysis, immunosuppression and HIV isomerization. Nat Chem Biol. 2010;6(5):331-337. doi:10.1038/nchembio.342

71. Tan CF, Eguchi H, Tagawa A, et al. TDP-43 immunoreactivity in neuronal inclusions in familial amyotrophic lateral sclerosis with or without SOD1 gene mutation. Acta Neuropathol. 2007;113(5):535-542. doi:10.1007/s00401-007-0206-9

72. Tschenett A, Singewald N, Carli M, et al. Reduced anxiety and improved stress coping ability in mice lacking NPY-Y2 receptors. Eur J Neurosci. 2003;18(1):143-148. doi:10.1046/j.14609568.2003.02725.X

73. Van Der Spoel D, Lindahl E, Hess B, Groenhof G, Mark AE, Berendsen HJC. GROMACS: fast, flexible, and free. $J$ Comput Chem. 2005;26(16):1701-1718. doi:10.1002/jcc.20291

74. Huang J, Rauscher S, Nawrocki G, et al. CHARMM36m: an improved force field for folded and intrinsically disordered proteins. Nat Methods. 2017;14(1):71-73. doi:10.1038/nmeth.4067

75. Bussi G, Donadio D, Parrinello M. Canonical sampling through velocity rescaling. J Chem Phys. 2007;126(1):14101. doi:10.1063/1.2408420

76. Parrinello M, Rahman A. Polymorphic transitions in single crystals: A new molecular dynamics method. J Appl Phys. 1981;52:7182. doi:10.1063/1.328693

77. Hunter JD. Matplotlib: A 2D Graphics Environment. Comput Sci Eng. 2007;9:90-95. doi:10.1109/MCSE.2007.55 


\section{Figure legends}

Figure 1. PPIA is downregulated in sporadic ALS patients. (A,B) Total PPIA (A) and TDP-43 (B) protein levels were analysed in PBMCs from ALS patients and healthy subjects of a retrospective cohort $^{7}$ (Cohort \#1, Supplementary Table1). Scatter dot plots (mean \pm SD; PPIA: $n=89$ healthy controls, $n=74$ ALS patients; TDP-43: $n=69$ healthy controls, $n=65$ ALS patients) are percentages of healthy controls and the dotted lines indicate the median of healthy controls. ${ }^{*} \mathrm{p}<0.05$ versus healthy controls, Student's t-test. (C,D) Real-time PCR for PPIA (C) and TARDBP (D) mRNA transcripts in PBMCs of ALS patients and healthy subjects (Cohort \#2, Supplementary Table1). Data (mean \pm SD; $\mathrm{n}=19$ healthy subjects; $\mathrm{n}=21$ ALS patients) are normalized to $\beta$-actin and expressed as percentages of the healthy control relative mRNA. Dotted lines indicate the median of healthy controls. ${ }^{*} p<0.05$ versus healthy controls, Student's t-test

Figure 2. PPIA-/- mice show progressive neuropathological alterations. (A,B) The volume of hippocampus (A) and cortex (B) was measured using quantitative MRI in PPIA+/+ and -/- mice, at 6 and 12 months (mo) of age. Representative MRI images of PPIA+/+ and -/- brain regions at 12 months are shown. The white dashed lines indicate the ROI considered for MRI quantification. Scale bar $1 \mathrm{~mm}$. The volume of hippocampus and cortex were adjusted for total brain volume and data are expressed as relative volume: mean $\pm \mathrm{SD}$ ( $\mathrm{n}=5$ or 6 in each experimental group). (C,D) Depletion of PPIA induces progressive neuron loss. Neurons in CA1 region $(\mathbf{C})$ and cortex $(\mathbf{D})$ were counted in $P P I A+/+$ and -/- mice at 6 and 12 months. Representative Nissl-stained brain section are shown. Scale bar $50 \mu \mathrm{m}$. Mean \pm SD ( $\mathrm{n}=5$, CA1 region; $\mathrm{n}=4$, cortex). (E) NFL plasma levels were analysed in PPIA+/+ and PPIA-/- mice at 3, 6 and 12 months. Data are mean $\pm \mathrm{SD}(\mathrm{n}=4$ or 5 in each experimental group). ${ }^{*} \mathrm{p}>0.05$ versus $P P I A+/+$ mice and $\# \mathrm{p}<0.05$ versus the 3 months, by Student's t-test. (F) GFAP-immunostaining in hippocampus was quantified in PPIA+/+ and -/- mice at 6 and 12 months. Representative GFAP-stained brain sections are shown. Scale bar $50 \mu \mathrm{m}$. Data (mean \pm $\mathrm{SD} ; \mathrm{n}=4$ or 5 in each experimental group) are percentages of the $P P I A+/+$. (A-D, F) $* \mathrm{p}<0.05$ versus the PPIA+/+ mice and ${ }^{\#} \mathrm{p}<0.05$ versus the 6 months, by one-way ANOVA, Tukey’s post hoc test.

Figure 3. TDP-43 pathology in hippocampus and cortex of PPIA-/- mice. TDP-43 pathology was analysed by biochemical (A,B) and histological (C-G) approaches, at 6 and 12 months. (A) Equal amounts of nuclear and cytoplasmic fractions from cortex of PPIA+/+ and -/- mice were analysed by WB for TDP-43 (left) and pTDP-43 (right). Representative WB are shown. Data (mean \pm SD; $n=5$ in each experimental group) indicates the immunoreactivity normalized to total protein loading, in arbitrary units (A.U.). ${ }^{*} \mathrm{p}<0.05$ versus $P P I A+/+$ mice Student's t-test. (B) Representative WB of 
TDP-43 in soluble and insoluble fractions from cortex of $P P I A+/+$ and $-/-$ mice and quantification of the $25 \mathrm{kDa}$ TDP-43 fragment are shown. Data (mean $\pm \mathrm{SD}, \mathrm{n}=4-6$ in each experimental group) are percentages of immunoreactivity in PPIA+/+ insoluble fraction. ${ }^{*} \mathrm{p}<0.05$ versus the $P P I A+/+$ mice by one-way ANOVA, Tukey's post hoc test. (C) Diffuse TDP-43 immunostaining was observed in brains of PPIA-/- mice at 12 months compared to PPIA+/+. Scale bar $1 \mathrm{~mm}$. (D) In hippocampus of PPIA-/- mice, there were TDP-43 inclusions in the pyramidal layer of CA3 and CA1 (1-2), in the granule cell layer of dentate gyrus (3-4), in stratum radiatum of CA1 (5-6) and in stratum oriens of CA3 and CA1 (7-8). Panels 2,4,6,8 are magnified images of the dashed area in panels 1,3,5,7. Scale bar $50 \mu \mathrm{m}$ in panels 7,8 ; scale bar $25 \mu \mathrm{m}$ in panels $1,3,5$; scale bar $20 \mu \mathrm{m}$ in panels 2 ; scale bar 10 $\mu \mathrm{m}$ in panels 4,6. (E) PPIA-/- mice had TDP-43 inclusions in the somatosensory (1-6) and temporal cortex (7-8). Panels 2,3,5,6,8 are magnified images of the dashed area in panels 1,4,7. Scale bar 50 $\mu \mathrm{m}$ in panels $1,4,7$; scale bar $20 \mu \mathrm{m}$ in panels 3,8; scale bar $10 \mu \mathrm{m}$ in panels 2,5,6. (F,G) pTDP-43 immunostaining was analysed in hippocampus $(\mathbf{F})$ and cortex $(\mathbf{G})$ of PPIA-/- mice and control PPIA+/+ mice (Supplementary Fig. 2G-H) at 12 months. (F) pTDP-43 inclusions are widespread in the CA1 pyramidal layer (1-2), stratum oriens (or) of CA1 (3), stratum radiatum (rad) of CA3 (4-6) and subiculum (sub) (7-9). Panels 2,3,5,6,8,9 are magnified images of the dashed area in panels 1,4,7. Scale bar $50 \mu \mathrm{m}$ in panels $1,4,7$; scale bar $25 \mu \mathrm{m}$ in panels 5,8,9; scale bar $20 \mu \mathrm{m}$ in panels 2,3,6. (G) pTDP-43 staining was observed in the somatosensory (1) and auditory-temporal (2-3) cortex. Scale bar $20 \mu \mathrm{m}$.

Figure 4. PPIA deficiency affects proteins involved in nucleocytoplasmic transport and synaptic function. (A) Dot blot analysis for Ran-soluble and -insoluble protein in cortex of PPIA+/+ and PPIA-/- mice at 6 months of age. Data (mean $\pm \mathrm{SD} ; \mathrm{n}=4$ or 5 in each experimental group) are normalized to protein loading and expressed as percentages of total protein, of Ran in soluble and insoluble fractions. Representative dot blots are shown. (B-D) Real-time PCR for GRN (B) and TARDBP (C) mRNA transcripts and dot blot analysis for TDP-43 total protein (D), in cortex of $P P I A+/+$ and PPIA-/- mice at 6 months. $(\mathbf{B}, \mathbf{C})$ Data $($ mean $\pm \mathrm{SD} ; \mathrm{n}=5)$ are normalized to $\beta$-actin and expressed as percentages of $P P I A+/+$ relative mRNA. (D) Data (mean $\pm \mathrm{SD}, \mathrm{n}=6$ ) are normalized to protein loading and are percentages of immunoreactivity in $P P I A+/+$ mice. Representative dot blots are shown. (E) Real-time PCR for TARDBP intron 7 exclusion in cortex of PPIA+/+ and PPIA-/mice at 6 months. Data (mean $\pm \mathrm{SD} ; \mathrm{n}=4$ or 5 in each experimental group) are normalized to $\beta$-actin and expressed as percentages of $P P I A+/+$ relative mRNA. (A-E) $* \mathrm{p}<0.05$ versus $P P I A+/+$ mice, Student's t-test. $(\mathbf{F}, \mathbf{G})$ Dot blot analysis of synaptophysin $(\mathbf{F})$ and PSD95 $(\mathbf{G})$ in cortex of PPIA+/+ and -/- mice at 6 and 16 months. Immunoreactivity was normalized to protein loading. Representative 
dot blots are shown. Data (mean $\pm \mathrm{SD}, \mathrm{n}=3$ or 5 in each experimental group) are percentages of immunoreactivity in $P P I A+/+$ mice. ${ }^{*} \mathrm{p}<0.05$ versus $P P I A+/+$ mice and $\# \mathrm{p}<0.05$ versus 6 months, by one-way ANOVA, uncorrected Fisher's LSD post hoc test $(\mathbf{F})$ and Tukey's post hoc test $(\mathbf{G})$. (H) CA1 long-term potentiation (LTP) induced with theta burst stimulation (TBS) was lower in PPIA-/mice (white rectangle) than $P P I A+/+$ mice (black circles) at 16 months. Data were analysed with two-way ANOVA for repeated measures, $\mathrm{p}<0.05(\mathrm{n}=6)$. Representative traces recorded in slices from PPIA+/+ and PPIA-/- mice, before and after TBS, are shown.

Figure 5. PPIA-/- mice present cognitive, behavioural and motor function deficits. (A) Open Field: C57_PPIA+/+ and -/- mice spent similar time in the inner zone both at $6(\mathrm{n}=10)$ and 12 months of age (n=10 C57_PPIA+/+, n=8 C57_PPIA-/-). (B) Elevated plus maze: C57_PPIA-/- mice spent more time than controls in open arms (n=10 C57_PPIA+/+ and -/- at 6 months, $\mathrm{n}=7 \mathrm{C} 57 \_P P I A+/+$ and n=5 C57_PPIA-/- at 12 months) at 6, but not at 12 months of age. (C-D) Three-chamber sociability test. In the sociability trial (C), C57_PPIA-/- mice spent more time than controls sniffing Stranger 1 than Empty cage at 6, but not 12 months of age ( $\mathrm{n}=10 \mathrm{C} 57 \_P P I A+/+, \mathrm{n}=8$ C57_PPIA-/-). In the social memory trial (D), C57_PPIA-/- mice spent more time sniffing Stranger 2 than Stranger 1, compared to controls, at $6(\mathrm{n}=10)$, but not at 12 months ( $\mathrm{n}=10$ C57_PPIA+/+, $\mathrm{n}=7$ C57_PPIA-/-). (E) Morris water maze: C57_PPIA-/- and +/+ mice spent similar time in the target quadrant (Q1) both at $6(\mathrm{n}=10)$ and $12(\mathrm{n}=10$ C57_PPIA+/+, $\mathrm{n}=8$ C57_PPIA-/-) months. (F) Novel object recognition test: C57_PPIA+/+ and -/- mice had similar discrimination indexes (DI) at $6(\mathrm{n}=8)$ and $12\left(\mathrm{n}=8\right.$ C57_PPIA+/+, $\mathrm{n}=5$ C57_PPIA-/-) months of age. (A-F) Mean $\pm \mathrm{SD}$. ${ }^{*} \mathrm{p}<0.05$ versus the $P P I A+/+$ mice and ${ }^{\#} \mathrm{p}<0.05$ versus the 6-month-old control by one-way ANOVA, Tukey's post hoc test (A-C, E, F) and uncorrected Fisher's LSD post hoc test (D). (G) Velocity measurement: C57_PPIA+/+ and -/- mice had the same velocity in the open field test at 6 months $(\mathrm{n}=10)$ but at 12 months (n=10 C57_PPIA+/+, n=8 C57_PPIA-/-) C57_PPIA-/- had slower velocity than controls. Data are mean $\pm \mathrm{SD}$ and are expressed in $\mathrm{cm} / \mathrm{s} .{ }^{*} \mathrm{p}<0.05$ versus C57_PPIA $+/+$ mice, Student's t-test. (H) PPIA-/- mice show mild atrophy of tibialis anterior (TA) muscle at 12 months $(\mathrm{n}=20$ PPIA+/+, $\mathrm{n}=14$ PPIA-/- at 6 months, $\mathrm{n}=12$ PPIA-/- at 12 months). Data (mean $\pm \mathrm{SD}$ ) are muscle weights as percentage of 6-month-old control. \#p $<0.05$ versus 6-month-old control by Student's t-test. (I) Extension reflex: PPIA-/- mice had less extension of hindlimbs than controls $(n=13$ PPIA+/+, $n=14$ PPIA-/-). Mean \pm SEM. *p $<0.05$ by two-way ANOVA, Bonferroni's post hoc test. (J) PPIA-/- mice had greater weight loss than controls from 21 months ( $\mathrm{n}=13$ PPIA+/+, $\mathrm{n}=14$ PPIA-/-). Mean $\pm \mathrm{SEM}$. $* \mathrm{p}<0.05$ by two-way ANOVA, Bonferroni's post hoc test. (K) Quantification of Nissl-stained motor neurons $\left(\mathrm{MNs}>250 \mu \mathrm{m}^{2}\right)$ in lumbar spinal cord hemisections from PPIA+/+ and $-/-$ mice at 6,12 
and 24 months. Data are mean $\pm \mathrm{SD}(\mathrm{n}=3$ or 4 in each experimental group) and are percentages of $P P I A+/+$ mice. ${ }^{*} \mathrm{p}<0.05$ versus $P P I A+/+$ mice, Student's t-test. (l) Kaplan-Meier curve for survival of PPIA+/+ $(\mathrm{n}=13)$ and PPIA-/- mice $(\mathrm{n}=14)$. Log-rank Mantel-Cox test for comparing $P P I A+/+$ and -- mice.

Figure 6. PPIA K76E mutant identified in a sporadic ALS patient. (A) PPIA is evolutionarily highly conserved, $89 \%$ of the amino acid residues are identical in all the species listed. Multiple sequence alignment of PPIA, focused on the mutated lysine in position 76 and surrounding residues, is shown. (*), indicates conserved sites; (:) indicates conservative replacements (amino acids with similar biochemical properties); acidic residues $(\mathrm{D}, \mathrm{E})$ are in orange, basic residues $(\mathrm{K}, \mathrm{R})$ in blue, small aliphatic residues (I, L) in green, all other residues in grey. (B) Slot blot analysis of TDP-43 insoluble protein levels was done in PBMCs from the PPIA K76E ALS patient and compared to TDP43 insoluble levels from ALS patients and healthy subjects of a retrospective cohort (Cohort \#1, Supplementary Table 1). Immunoreactivity of the PPIA K76E patient was normalized to total protein loading and to the internal standard of the retrospective cohort ${ }^{7}$, in order to compare the two analyses. Scatter dot plot (mean $\pm S D ; n=76$ healthy controls, $n=79$ ALS patients and $n=3$ technical replicates of the PPIA K76E ALS patient) are percentages of healthy controls and dotted line indicates the median value of healthy controls. ${ }^{*} \mathrm{p}<0.05$ versus healthy controls, Student's t-test. (C) PPIA protein level was lower in HEK293 cells transfected with PPIA K76E mutant than PPIA WT plasmid, after 48 hours in culture. Immunoreactivity was normalized to protein loading. Representative WB are shown. Data (mean $\pm \mathrm{SEM} ; \mathrm{n}=6$ ) are percentages of PPIA WT. * $<<0.05$ versus PPIA WT Student's t-test. (D) PPIA protein level was lower in HEK293 cells transfected with PPIA K76E mutant than PPIA WT plasmid after treatment with $100 \mu \mathrm{g} / \mathrm{mL}$ cycloheximide (CHX) for $0,15,30,45$ and 60 minutes. Immunoreactivity was normalized to protein loading. Representative WB are shown. Data (mean $\pm \mathrm{SD} ; \mathrm{n}=4)$ are percentages of PPIA WT. ${ }^{*} \mathrm{p}<0.05$ versus PPIA WT Student's t-test.

Figure 7. PPIA K76E shows structural differences from WT and is a loss-of-function mutant.

(A,B) Structural analysis of protein loops composed residues 26-30 (A) and residues 43-45 (B) by molecular dynamics simulation. The protein RMSD of each frame, computed in comparison to the initial conformation, is plotted as a function of the simulation time (WT blue, K76E orange). Lines and filled curves represent the mean and standard error of the RMSD, respectively, computed for the three replicates of the WT and mutant protein. A significant difference between the two variants in loop 26-30 is evident after $400 \mathrm{~ns}$ of simulations (A); in the loop 43-45 the difference is clear after $700 \mathrm{~ns}$ (B). Three MD snapshots sampled at the end of the simulations for the WT protein (blue) 
superimposed on three MD snapshots sampled at the end of the simulations for the K76E variant (orange) are presented below the relative graph. (C) A detail of the structural variation of loop 43-45, with the probability distribution, computed considering the last $500 \mathrm{~ns}$ of dynamics, of the C $\alpha$ distance between the residue at the center of the 43-45 loop (lysine 44) and the residue in the center of the $\beta$ strand 156-165 (aspartate 160). In the simulations of the K76E variant, the loop spent significantly more time closer to the $\beta$-strand 156-165 than the WT. The side-chains of the loop-residues face opposite directions in the two protein variants, as shown with representative conformations sampled after $1 \mu$ s of MD and superimposed below the graph. Here side-chains of residues E43, K44, G45 and K/E76 are explicitly represented (WT blue, K76 orange), while the positions of residues I156, D160 and E165 are indicated in grey. (D-E) Cells were transfected with PPIA WT or PPIA K76E construct, or not transfected (NT). TDP-43 (D) or Ran (E) was co-immunoprecipitated from cells using respectively an anti-TDP-43 polyclonal antibody or anti-Ran polyclonal antibody followed by antiMyc WB. Controls for IP experiments: Lysate, lysate with magnetic beads linked to the secondary antibody (beads-IgGII); no AbI, lysis buffer with beads-IgGII; AbI, lysis buffer with beads-IgGII and primary antibody. WB anti-TDP-43 and anti-Ran show an equal amount of immunoprecipitated TDP43 or Ran in PPIA WT, PPIA K76, NT cells. Representative WB are shown. (F) AlphaLISA analysis of MMP-9 was done in plasma samples from the PPIA K76E ALS patient, ALS patients and healthy subjects (Cohort \#3, Supplementary Table 1). Scatter dot plots are mean $\pm \operatorname{SD}(n=20$ healthy controls, $\mathrm{n}=51$ ALS patients and $\mathrm{n}=3$ technical replicates of the PPIA K76E ALS patient). The dotted line indicates the median of healthy controls; $\mathrm{p}=0.057$ versus healthy controls, Student's t-test.

\section{Figure 8. Schematic representation of PPIA function in physiological and pathological} conditions. (A) PPIA (iPPIA) is highly expressed in neurons and motor neurons where it is protective thanks to its activity as a foldase and molecular chaperone that affects key proteins involved in RNA metabolism, nucleocytoplasmic transport and synaptic function. PPIA is secreted (ePPIA) in response to oxidative stress and inflammatory stimuli ${ }^{57}$. (B) In ALS/FTD, defective iPPIA induces TDP-43 pathology, nucleocytoplasmic transport defects, synaptic dysfunction and neurodegeneration. Persistent cellular stress in neurons and glia leads to aberrant secretion of PPIA that, through the interaction with its EMMPRIN/CD147 receptor, induces MMP-9 expression and an inflammatory response which is particularly toxic for motor neurons ${ }^{18,58}$. (C,D) In the PPIA-/- mouse (C) and PPIA WT/K76E patient (D), the detrimental effect of deficient iPPIA function is partially compensated by the lack (mouse) or lower (patient) ePPIA-induced inflammatory response, leading to marked TDP43 pathology associated with late onset/slowly progressive (mouse) or slowly progressive (patient) motor neuron disease. 
bioRxiv preprint doi: https://doi.org/10.1101/2020.06.08.129528; this version posted May 7, 2021. The copyright holder for this preprint (which

was not certified by peer review) is the author/funder, who has granted bioRxiv a license to display the preprint in perpetuity. It is made available under aCC-BY-NC 4.0 International license.

A

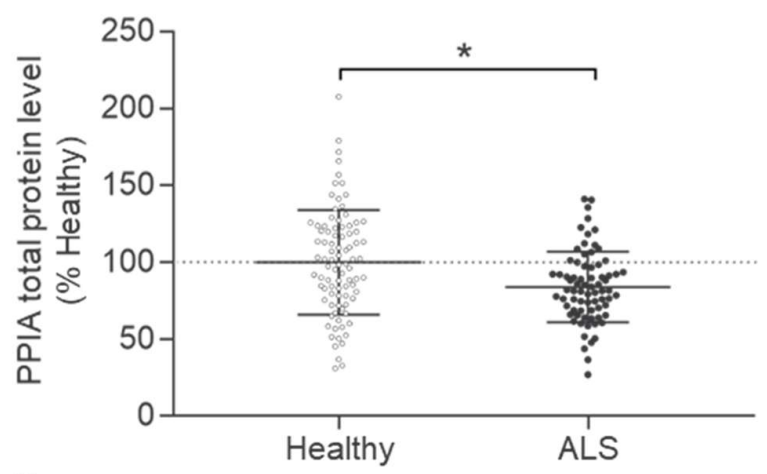

C

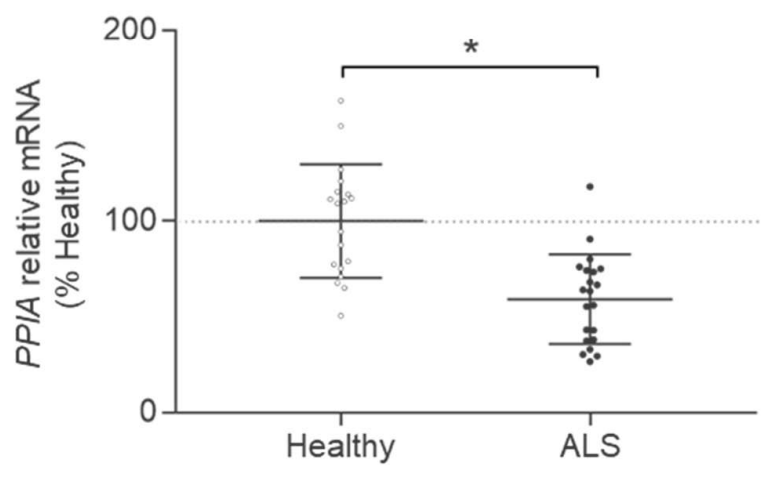

B

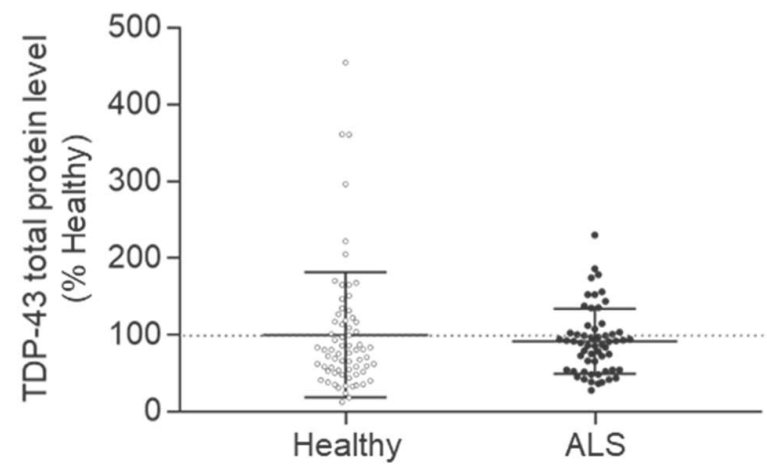

D

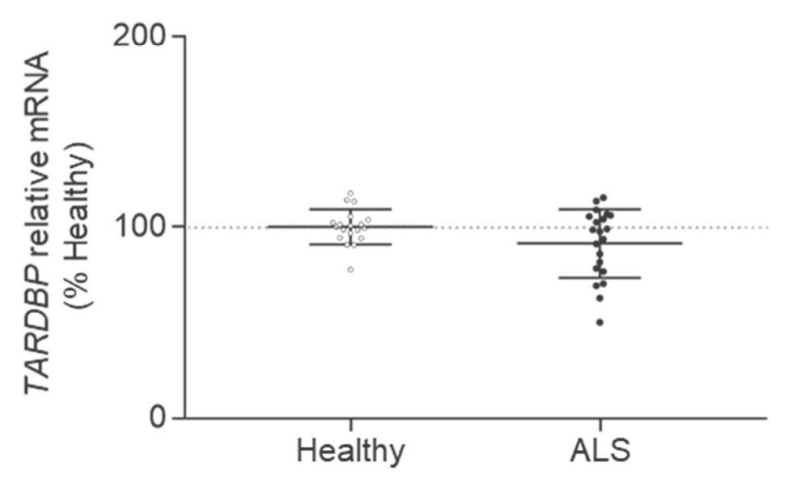

\section{Figure 1}


A
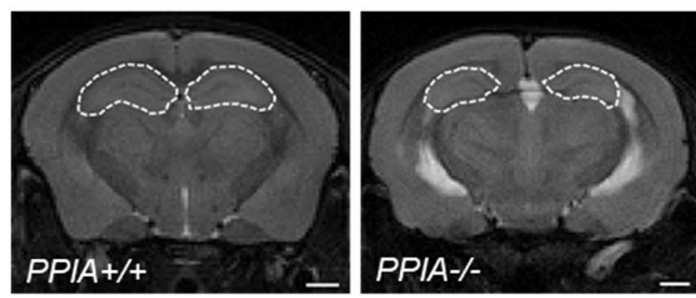

Hippocampus

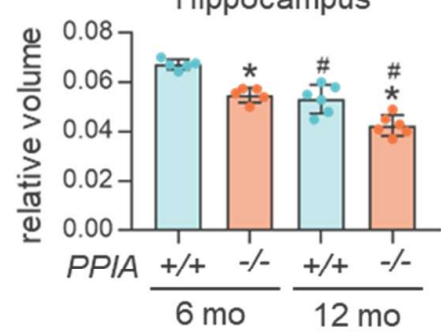

C

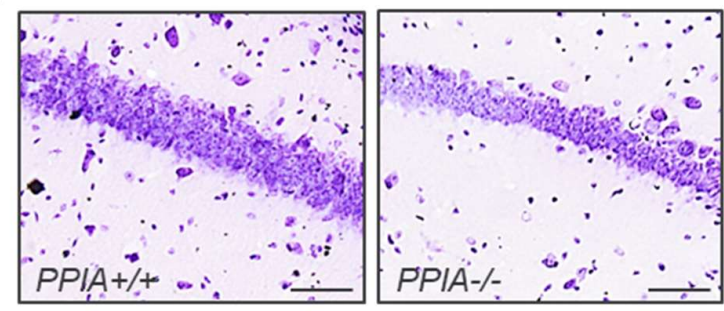

Hippocampus

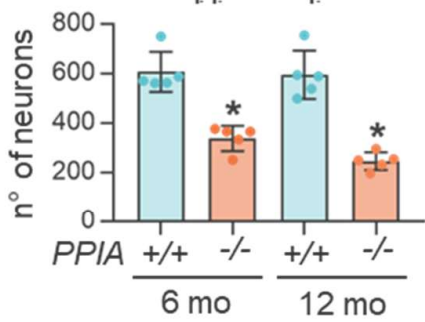

E

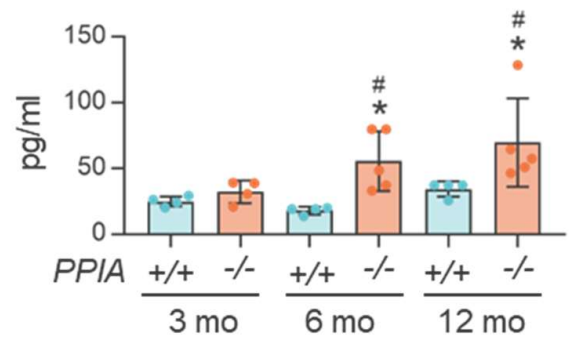

B
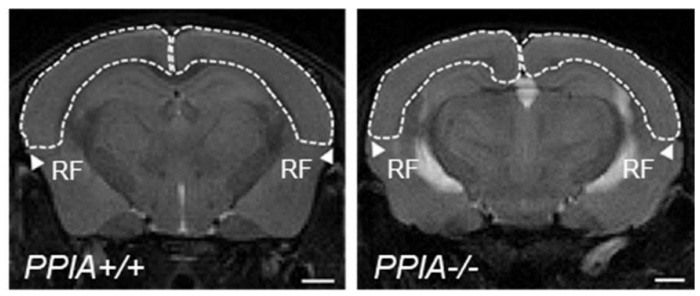

D
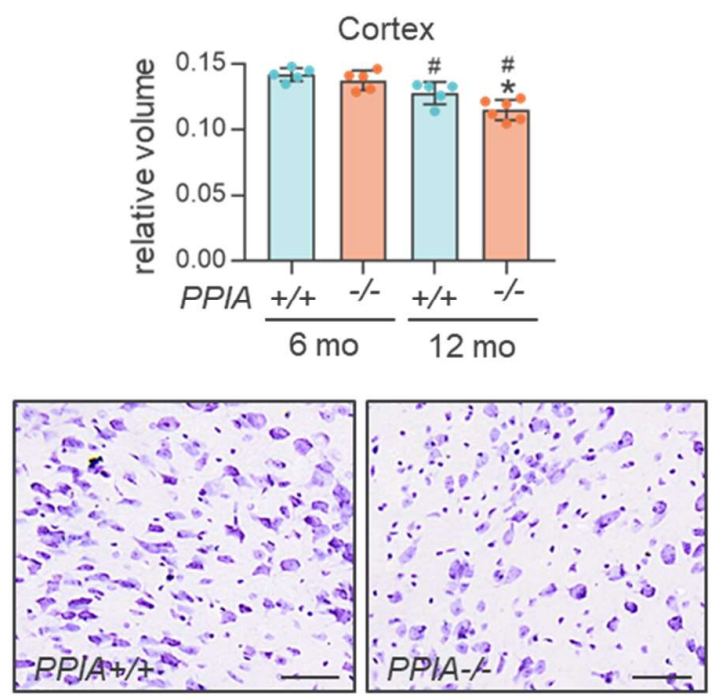

Cortex

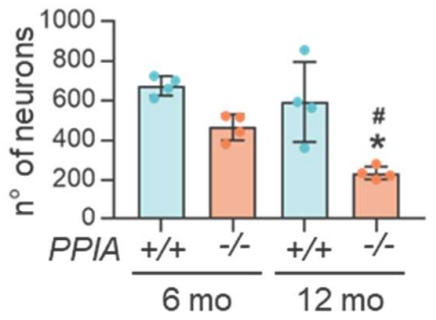

F

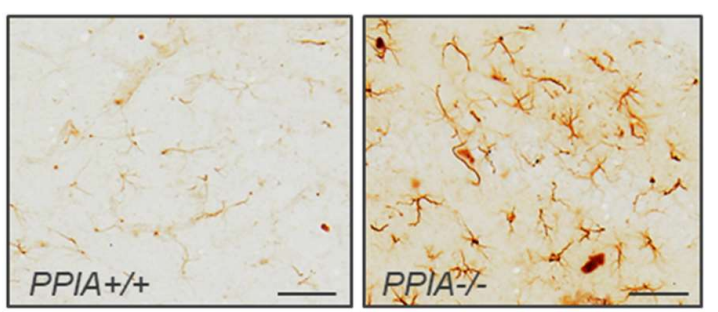

Hippocampus

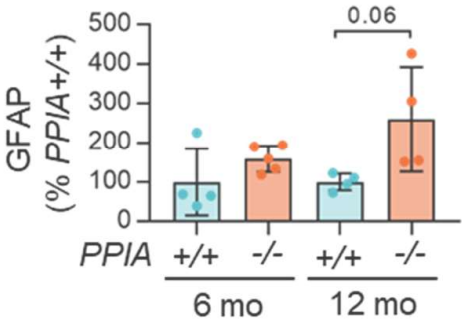

Figure 2 
A

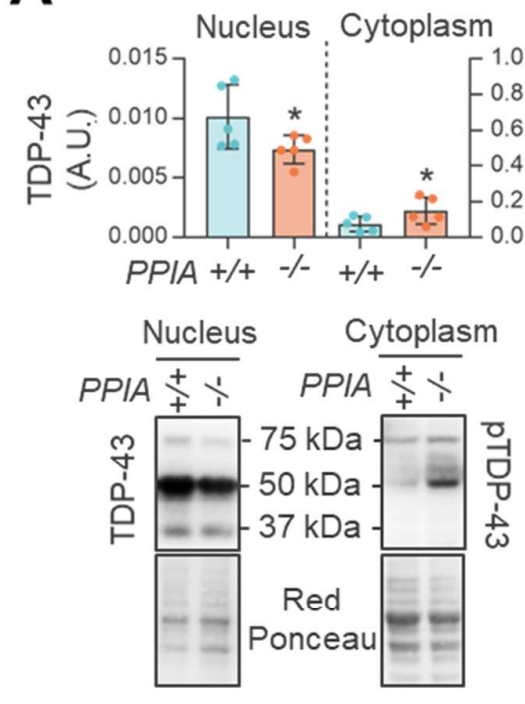

B
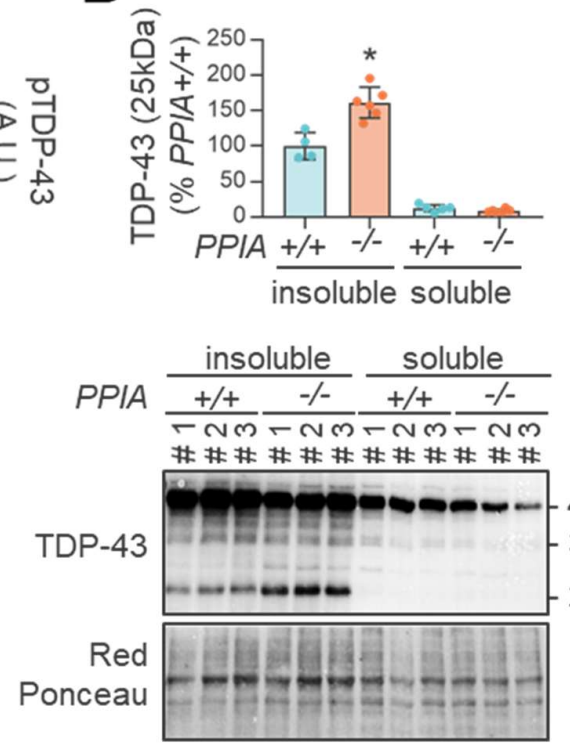

C

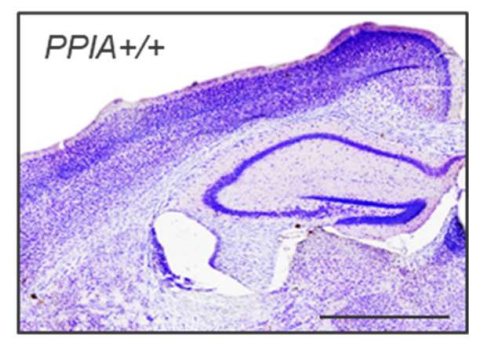

$43 \mathrm{kDa}$

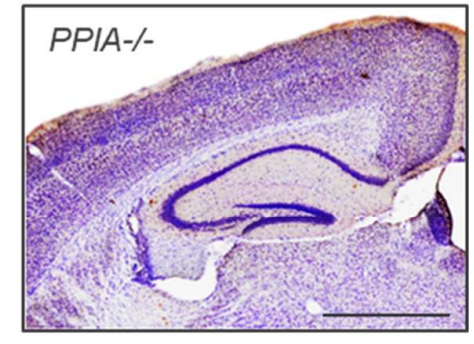

D

m
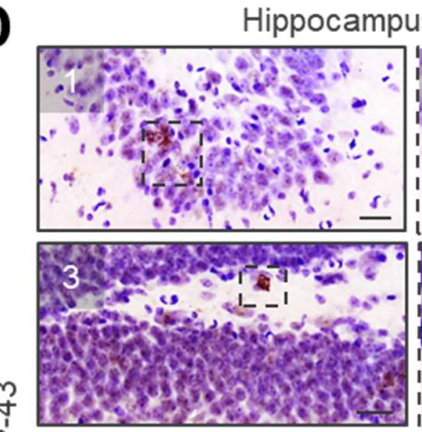

号

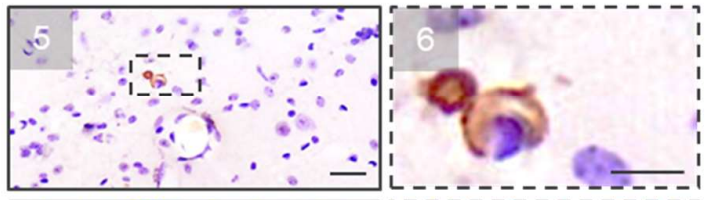

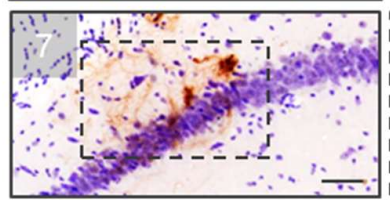

$\mathbf{F}$
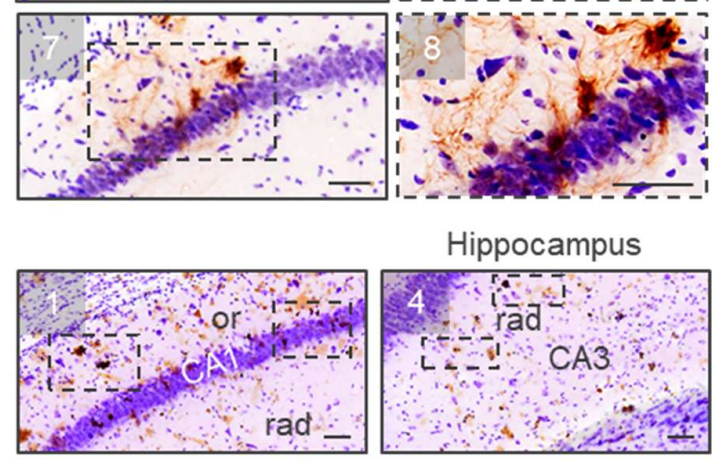

Hippocampus
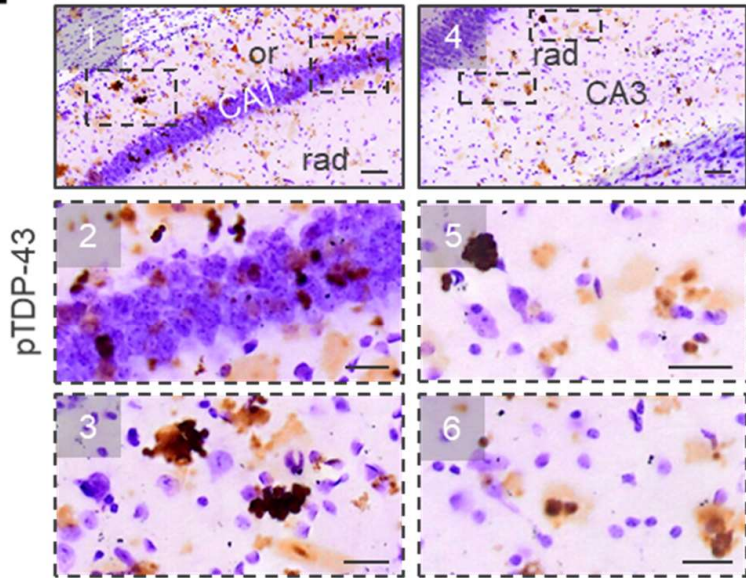

E
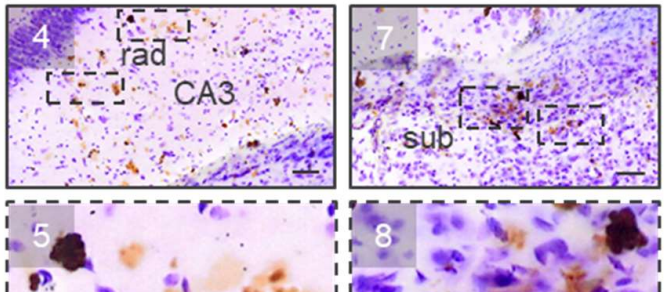

$11 \%$

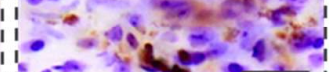

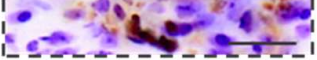

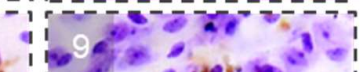

,

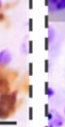

Cortex

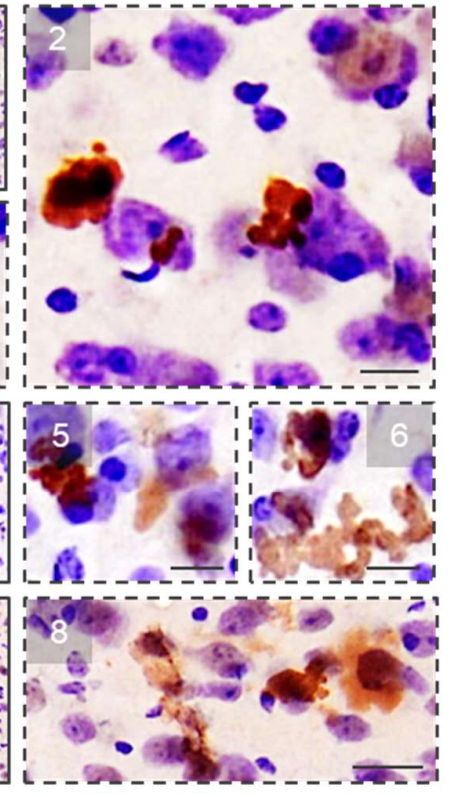

G

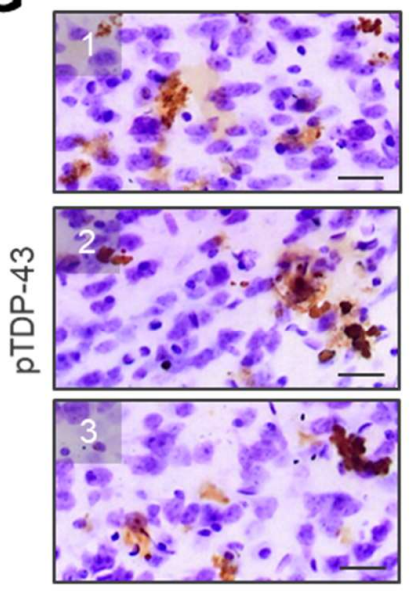


A

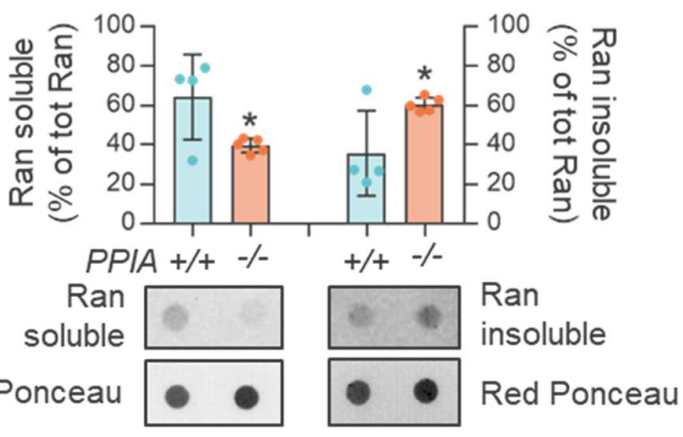

B
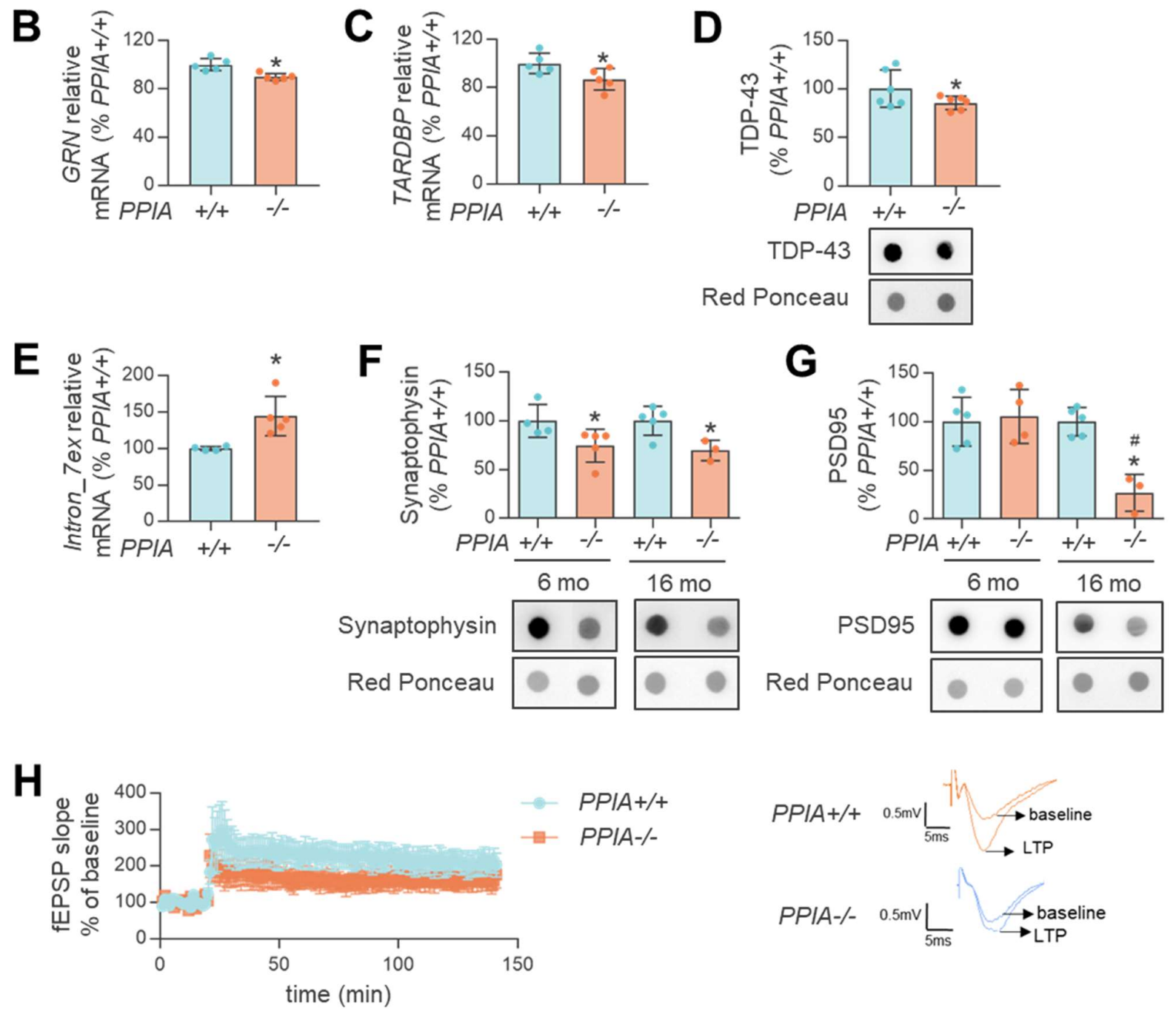

\section{Figure 4}


A

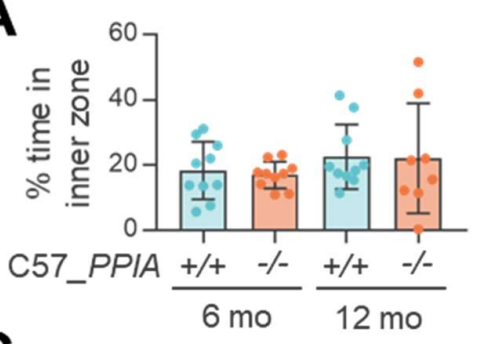

C

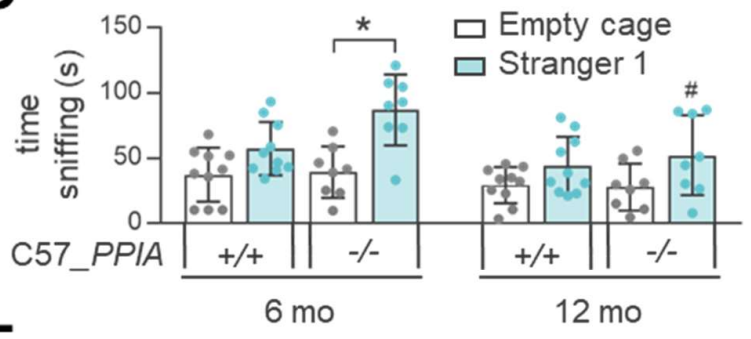

E

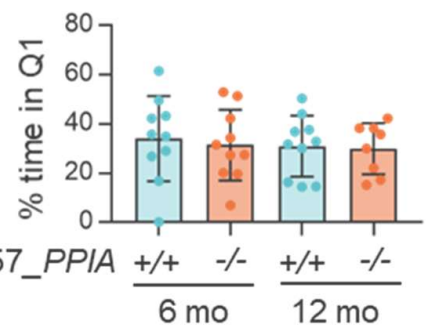

G
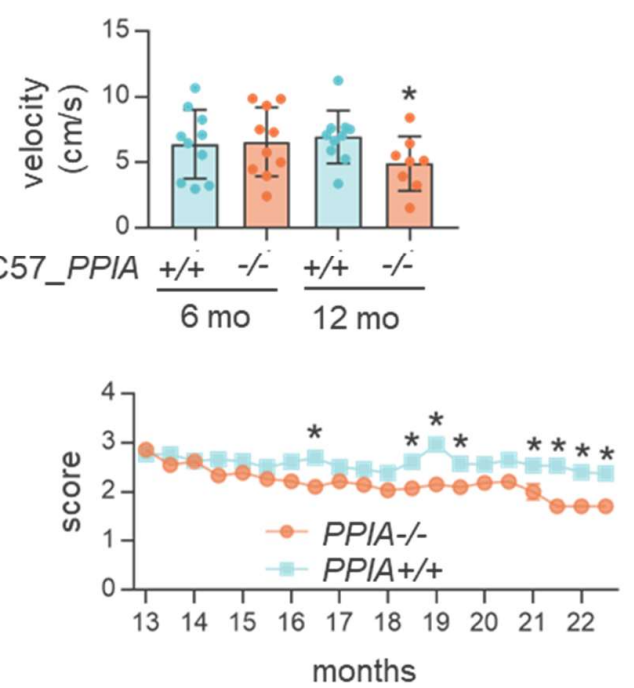

\section{K}

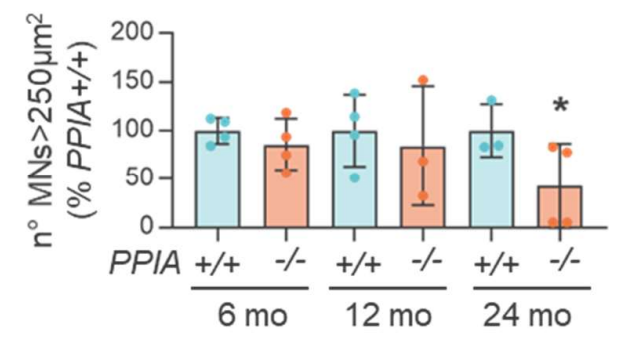

B

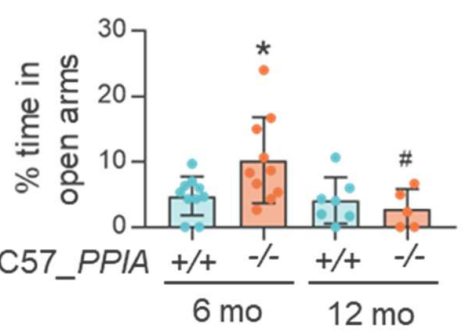

D

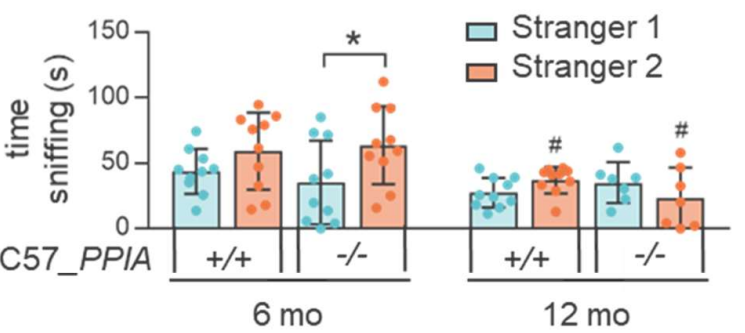

F

H
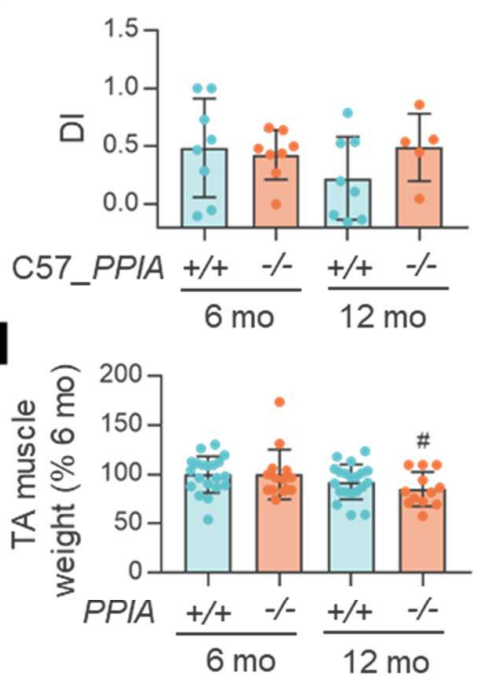

J

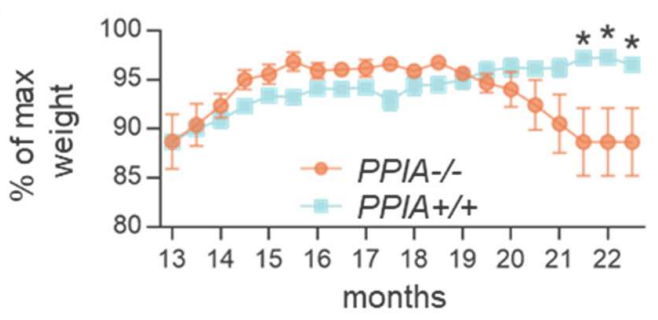

L

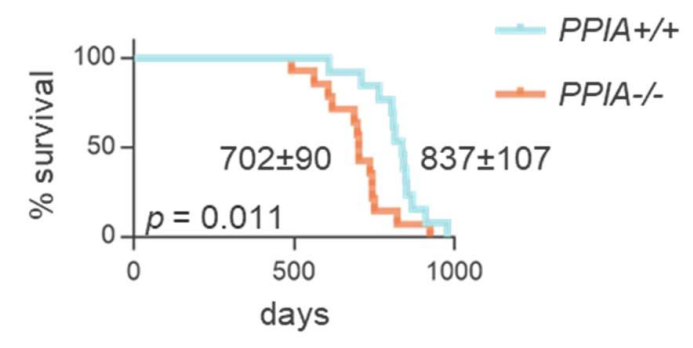


bioRxiv preprint doi: https://doi.org/10.1101/2020.06.08.129528; this version posted May 7, 2021. The copyright holder for this preprint (which

was not certified by peer review) is the author/funder, who has granted bioRxiv a license to display the preprint in perpetuity. It is made available under aCC-BY-NC 4.0 International license.

P62937|Homo sapiens
P17742|Mus musculus
P10111|Rattus norvegicus
P62936|Sus scrofa
P62935|Bos Taurus
Q02QL0|Cricetulus griseus
Q02QL1| Pan troglodytes
Q8HXS3|Felis catus
Q9TTC6|Oryctolagus cuniculus

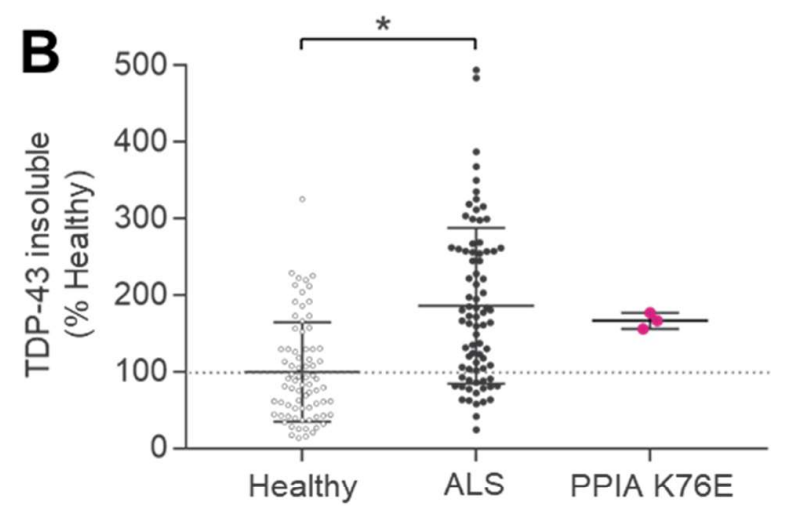

D

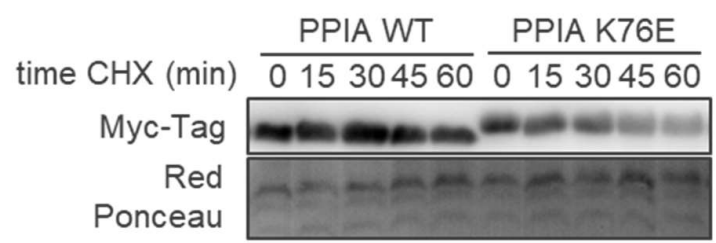

K76E

$\downarrow$

FHRI IPGFMCOGGDFTRHNGTGGKS IYGEKFEDENFILKHTGPGILS FHRI IPGFMCQGGDFTRHNGTGGRS IYGEKFEDENFILKHTGPGILS FHRI IPGFMCQGGDFTRHNGTGGKS IYGEKFEDENFILKHTGPGILS FHRI I GGMCQGGDFTRHNGT GGKS IYGEKFDDENFILKHTGPGILS FHRI IPGFMCQGGDFTRHNGTGGKSIYGEKFDDENFILKHTGPGILS FHRI IPGFMCQGGDFTRHNGTGGKS IYGEKFEDENFILKHTGPGILS FHRI I GFMCQGGDFTRHNGTGGKS IYGEKFEDENFILKHTGPGILS FHRIIPGFMCQGGDFTRHNGTGGKSIYGEKFDDENFILKHTGPGILS FHRIIPGEMCQGGDETRHNGTGGKSIYGEKEEDENELLKHTGPGILS
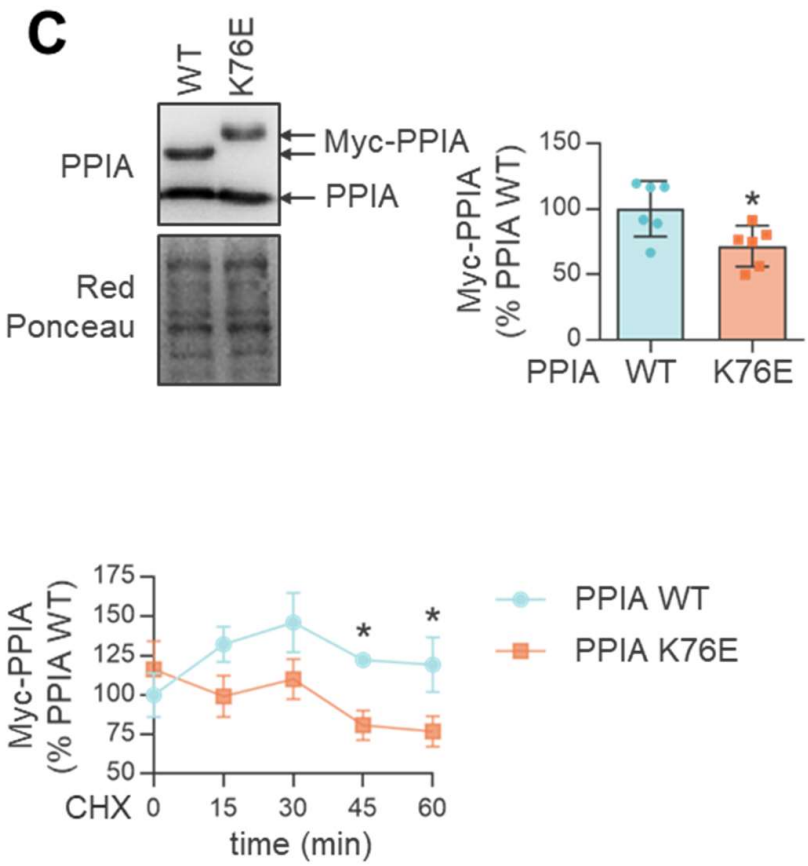

\section{Figure 6}


bioRxiv preprint doi: https://doi.org/10.1101/2020.06.08.129528; this version posted May 7, 2021. The copyright holder for this preprint (which

was not certified by peer review) is the author/funder, who has granted bioRxiv a license to display the preprint in perpetuity. It is made available under aCC-BY-NC 4.0 International license.

A
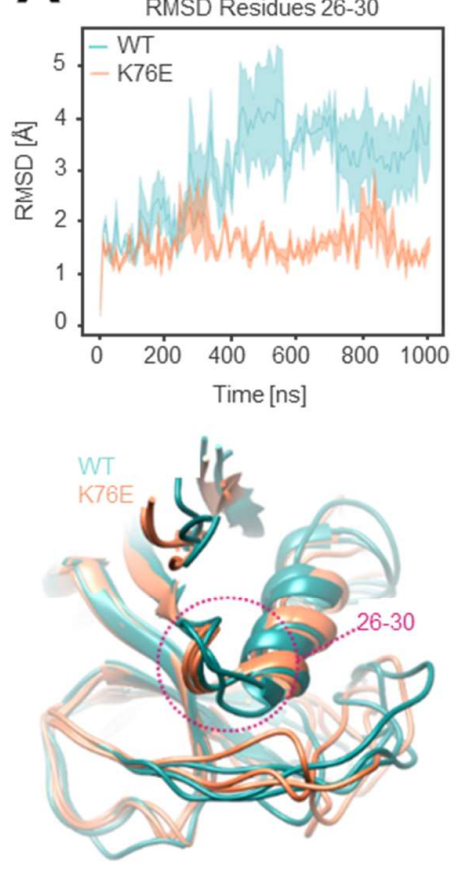

D

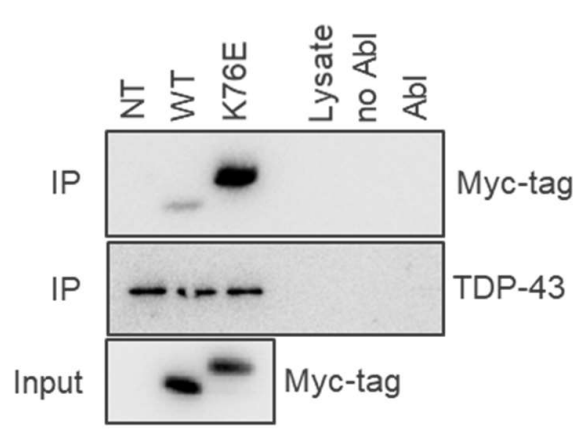

IP: TDP-43
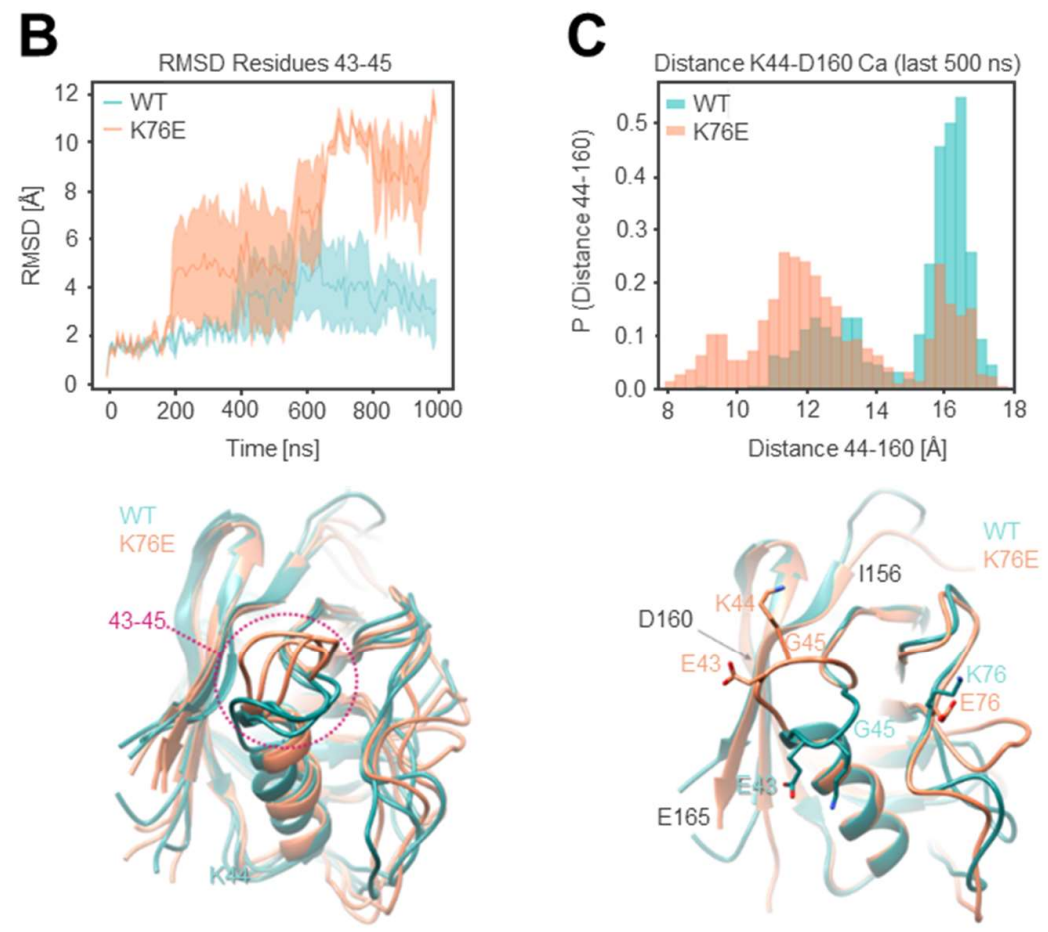

E
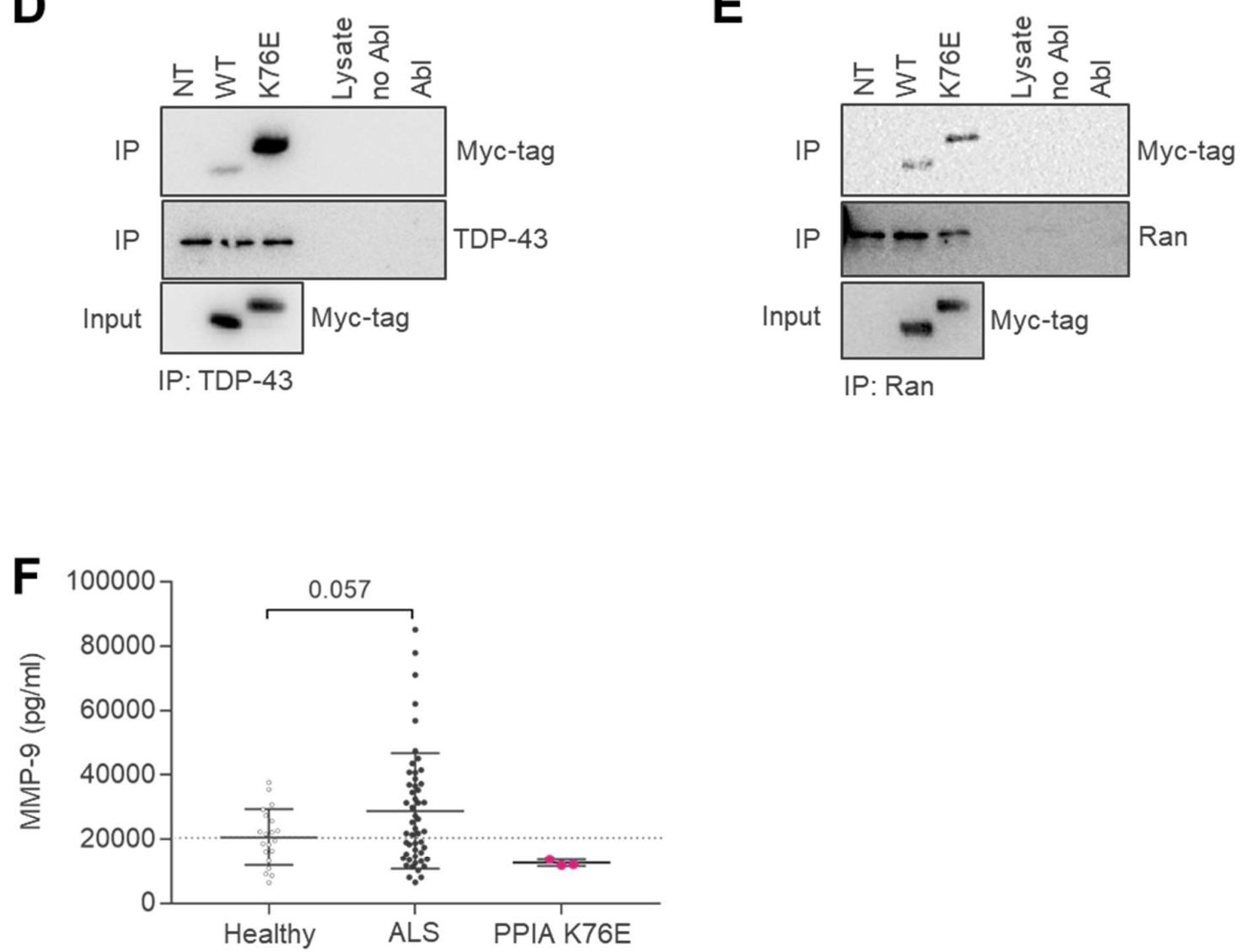

Figure 7 
A

Healthy $\rightarrow$ PPIA functional

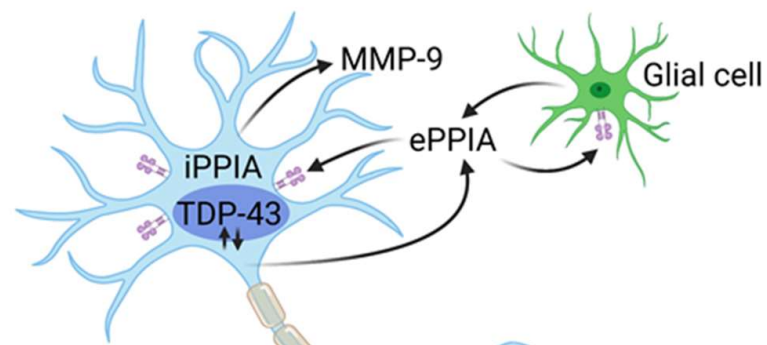

Motor neuron

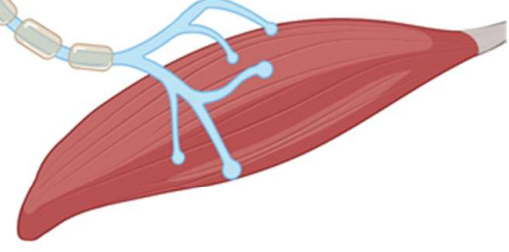

C

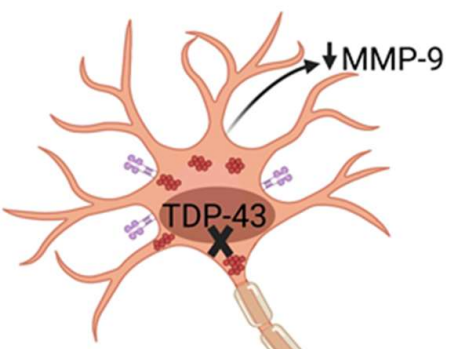

PPIA-/- mouse $\rightarrow$ PPIA absent

Motor neuron

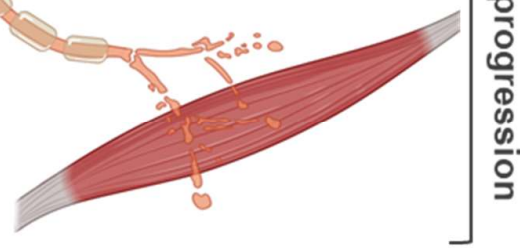

B

ALS/FTD patients $\rightarrow$ PPIA defective

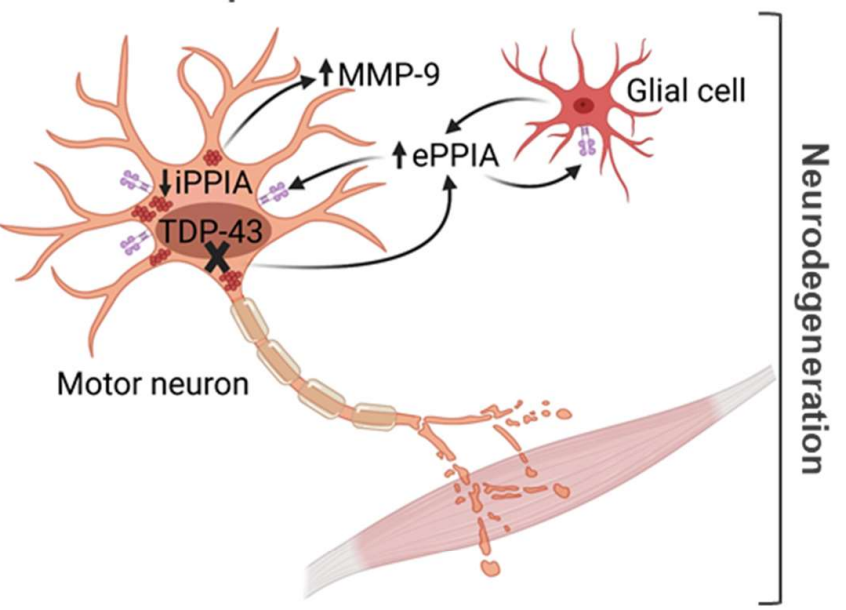

D

PPIA WT/K76E patient $\rightarrow$ PPIA defective

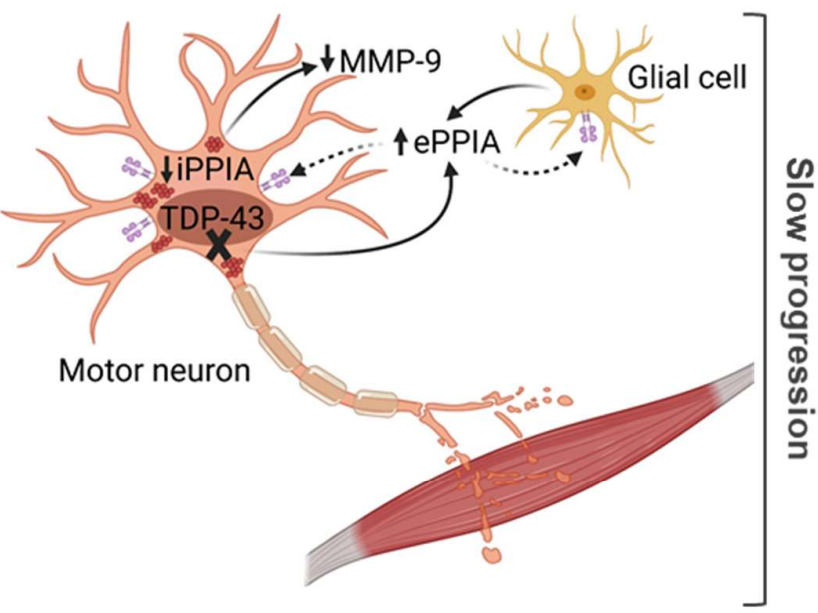

\section{Figure 8}




\section{Supplementary Material}

-Materials and methods

-Supplementary Table 1

-Supplementary figure legends

-Supplementary Fig. 1

-Supplementary Fig. 2

-Supplementary Fig. 3

-Supplementary Fig. 4

-Supplementary Fig. 5

-Supplementary Fig. 6

\section{Materials and methods}

\section{Animal model}

Animals were bred and maintained at the Istituto di Ricerche Farmacologiche Mario Negri IRCCS, Milan, Italy, under standard conditions: temperature $21 \pm 1^{\circ} \mathrm{C}$, relative humidity $55 \pm 10 \%$, $12 \mathrm{~h}$ light schedule, and food and water ad libitum. Before every analysis, animals were deeply anesthetized with ketamine hydrochloride (IMALGENE, $100 \mathrm{mg} / \mathrm{kg}$; Alcyon Italia) and medetomidine hydrochloride (DOMITOR, $1 \mathrm{mg} / \mathrm{kg}$; Alcyon Italia) by intraperitoneal injection and killed by decapitation. PPIA-/- mice were originally generated and characterized as described ${ }^{24,25}$. We obtained PPIA-/- mice (strain 129S6/SvEvTac Ppiatm1Lubn/Ppiatm1Lbn; stock no. 005320) from The Jackson Laboratory; they were maintained on a 129S6/SvEvTac background. The PPIA-/mice on 129S6/Sv genetic background and corresponding PPIA+/+ littermates were used for microCT, MRI, immunohistochemistry, biochemistry, long-term potentiation, Rotarod, grid test, extension reflex and are indicated as PPIA-/- mice. PPIA-/- mice on C57BL/6J genetic background (C57_PPIA/- mice), kindly provided by Dr. Bradford C. Berk (University of Rochester Medical Center, Rochester, New York, USA), and corresponding PPIA+/+ littermates, were used for open field, elevated-plus maze, three-chamber sociability, Morris water maze, novel object recognition. We verified that C57_PPIA-/- mice also display TDP-43 pathology (Supplementary Fig. 3). Genotyping for PPIA was done by standard PCR on DNA tail biopsies, using primer sets designed by The Jackson Laboratory. The number of animals was calculated on the basis of experiments designed to reach a power of 0.8 , with a minimum difference of $20 \%(\alpha=0.05)$. 


\section{Micro-CT}

Micro-CT was done with an Explore Locus micro-CT scanner (GE Healthcare) without contrast agents. Before the analysis, mice were anesthetized with a continuous flow of $3 \%$ isofluorane/oxygen mixture and placed prone on the micro-CT bed. A micro-CT lower resolution (Bin-4) protocol was employed using $80 \mathrm{kV}, 450 \mu \mathrm{A}$ with $100 \mathrm{msec}$ per projection and 400 projections over $360^{\circ}$ for a total scan time of 10 minutes, as previously described ${ }^{27}$. The isotropic resolution of this protocol is $93 \mu \mathrm{m}$. The scanned images were reconstructed in 3D and analysed using Micro View analysis software (version 2.1.1; GE Healthcare). We measured the distance from the last cervical vertebra to the last lumbar vertebra (segment AB; Supplementary Fig. 1C) and the perpendicular distance to the dorsal edge of the vertebra at the greatest curvature (segment CD; Supplementary Fig. 1C). The index of kyphosis was defined as the ratio of $\mathrm{AB}$ to $\mathrm{CD}$.

\section{MRI analysis}

MRI analysis was done in six- and twelve-month-old mice, as previously described ${ }^{26}$. Briefly animals were anesthetized with isoflurane in a mixture of $\mathrm{O}_{2}(30 \%)$ and $\mathrm{N}_{2} \mathrm{O}(70 \%)$. Body temperature was maintained at $\sim 37^{\circ} \mathrm{C}$ by a warm-water-circulated heating cradle. Imaging was done on a $7 \mathrm{~T}$ small bore animal Scanner (Bruker Biospec, Ettlingen, Germany). A 3D RARE T2 weighted sequence was used to assess anatomical changes. The volume measurements of structural MRI images were obtained using Java-based custom-made software. ROIs were selected manually and drawn on the images for volumetric assessment. Whole brain, hippocampus, cortex and cerebellum were measured. Cortex was quantified from the rhinal fissure (RF) up. Data from each animal were obtained by integrating the averaged ROI area for slice thickness, and normalized to whole brain volume.

\section{Immunohistochemistry}

Mice were anesthetized and perfused transcardially with $50 \mathrm{~mL}$ of phosphate-buffered saline (PBS) followed by $100 \mathrm{~mL}$ of 4\% paraformaldehyde (Sigma-Aldrich) in PBS. Brain and spinal cord were rapidly removed, postfixed for $3 \mathrm{~h}$, transferred to $20 \%$ sucrose in PBS overnight and then to $30 \%$ sucrose solution until they sank, frozen in $\mathrm{N}$-pentane at $45^{\circ} \mathrm{C}$ and stored at $\pm 80^{\circ} \mathrm{C}$. Before freezing, spinal cord was divided into cervical, thoracic, and lumbar segments and included in Tissue-tec OCT compound (Sakura). Coronal sections ( $30 \mu \mathrm{m}$; four slices per mouse) of brain were then sliced and immunohistochemistry was done for TDP-43, phosphorylated TDP-43 (pTDP-43), glial fibrillary acidic protein (GFAP) and Iba-1. Briefly, slices were incubated for $1 \mathrm{~h}$ at room temperature with blocking solutions (TDP-43 and pTDP-43: 0.2\% Triton X100 plus 2\% normal goat serum (NGS); 
GFAP: $0.4 \%$ Triton X100 plus 3\% NGS; Iba-1: 0.3\% Triton X100 plus 10\% NGS), then overnight at $4^{\circ} \mathrm{C}$ with the primary antibodies (TDP-43, 1:200; pTDP-43, 1:1000; GFAP, 1:2500; Iba-1, 1:1000). Brand and Research Resource Identifiers (RRID) of the antibodies are reported in the Immunoblotting section. After incubation with biotinylated secondary antibody $(1: 200 ; 1 \mathrm{~h}$ at room temperature; Vector Laboratories) immunostaining was developed using the avidin-biotin kit (Vector Laboratories) and diaminobenzidine (Sigma). Coronal brain sections (30 $\mu \mathrm{m}$; four slices per mouse) and lumbar spinal cord (30 $\mu \mathrm{m}$; twelve slices per mouse) were stained with $0.5 \%$ cresyl violet to detect the Nissl substance of neuronal cells. Stained sections were collected at $20 \mathrm{X}$ with an Olympus BX-61 Virtual Stage microscope so as to have complete stitching of the whole section, with a pixel size of $0.346 \mu \mathrm{m}$. Acquisition was done over 6 - $\mu \mathrm{m}$-thick stacks with a step size of $2 \mu \mathrm{m}$. The different focal planes were merged into a single stack by mean intensity projection to ensure consistent focus throughout the sample. Finally, signals were analysed for each slice with ImageJ software.

\section{Subcellular fractionation}

Nuclear and cytoplasmic fractions were separated from mouse cortex and cerebellum as described 13,18. Briefly, tissues were homogenized in six volumes (w/v) of buffer A (10 mM Tris-HCl pH 7.4, 5 $\mathrm{mM} \mathrm{MgCl} 2,25 \mathrm{mM} \mathrm{KCl}, 0.25 \mathrm{M}$ sucrose, $0.5 \mathrm{mM} \mathrm{DTT}$ ) containing a protease inhibitors cocktail (Roche), and centrifuged at $800 \mathrm{xg}$ for $10 \mathrm{~min}$ at $4{ }^{\circ} \mathrm{C}$. The supernatant was centrifuged twice at 800 $\mathrm{xg}$ for $10 \mathrm{~min}$ at $4^{\circ} \mathrm{C}$ (cytoplasmic fraction). The pellet was resuspended in three volumes of buffer A and centrifuged three times at $800 \mathrm{xg}$ for $10 \mathrm{~min}$ at $4^{\circ} \mathrm{C}$. The pellet was resuspended in one volume of buffer A and one volume of buffer B (10 mM Tris-HCl pH 7.4, $5 \mathrm{mM} \mathrm{MgCl} 2,25 \mathrm{mM} \mathrm{KCl}, 2 \mathrm{M}$ sucrose) containing a protease inhibitors cocktail, and loaded on a layer of one volume of buffer B. Samples were ultracentrifuged at $100,000 \mathrm{xg}$ for $45 \mathrm{~min}$ at $4^{\circ} \mathrm{C}$. The pellet (nuclear fraction) was resuspended in $100 \mu \mathrm{L}$ of buffer $\mathrm{A}$, centrifuged at $800 \mathrm{xg}$ for $10 \mathrm{~min}$ at $4^{\circ} \mathrm{C}$ and resuspended in 40 $\mu \mathrm{L}$ buffer $\mathrm{A}$.

\section{Extraction of detergent-insoluble}

Mouse tissues were homogenized in 10 volumes (w/v) of buffer, $15 \mathrm{mM}$ Tris- $\mathrm{HCl} \mathrm{pH} \mathrm{7.6,} 1 \mathrm{mM}$ DTT, $0.25 \mathrm{M}$ sucrose, $1 \mathrm{mM} \mathrm{MgCl}$, 2.5 mM EDTA, 1 mM EGTA, 0.25 M sodium orthovanadate, 2 $\mathrm{mM}$ sodium pyrophosphate, $25 \mathrm{mM} \mathrm{NaF}, 5 \mu \mathrm{M}$ MG132, and a protease inhibitors cocktail (Roche), essentially as described ${ }^{13}$. Samples were centrifuged at $10,000 \mathrm{xg}$ at $4^{\circ} \mathrm{C}$ for $15 \mathrm{~min}$ and supernatant 1 was collected in a new tube. The pellet was suspended in ice-cold homogenization buffer with $2 \%$ Triton X100 and $150 \mathrm{mM} \mathrm{KCl}$, sonicated and shaken for $1 \mathrm{~h}$ at $4^{\circ} \mathrm{C}$. The samples were then centrifuged 
twice at $10,000 \mathrm{xg}$ at $4^{\circ} \mathrm{C}$ for $10 \mathrm{~min}$ to obtain the Triton-insoluble fraction (TIF) pellet and supernatant 2. Supernatants 1 and 2 were pooled, as the Triton-soluble fraction. Immunoreactivity was normalized to protein loading (Ponceau red staining). The amount of Triton-resistant proteins isolated from the tissue was normalized to the soluble protein extracted. Proteins were quantified by the BCA protein assay (Pierce).

\section{Immunoblotting}

Protein levels were determined using the BCA protein assay (Pierce). For western blot (WB), samples $(15 \mu \mathrm{g})$ were separated in 12\% SDS-polyacrylamide gels and transferred to polyvinylidene difluoride membranes (Millipore), as described previously ${ }^{20}$. For dot blot, proteins ( $\left.3 \mu \mathrm{g}\right)$ were loaded directly onto nitrocellulose Trans-blot transfer membranes $(0.45 \mu \mathrm{m}$; Bio-Rad $)$, depositing each sample on the membrane by vacuum filtration, as described previously ${ }^{7}$. WB and dot blot membranes were blocked with 3\% (w/v) BSA (Sigma-Aldrich) and 0.1\% (v/v) Tween 20 in Tris-buffered saline, pH 7.5 , and incubated with primary antibodies and then with peroxidase-conjugated secondary antibodies (GE Healthcare). Antibodies used for immunoblot are the following: rabbit polyclonal anti-PPIA antibody (1:2500, Proteintech; RRID: AB_2237516); rabbit polyclonal anti-human C-terminal TDP43 antibody (1:2500, Proteintech; RRID: AB_2200505); mouse monoclonal anti-human pTDP-43 antibody (1:2000, Cosmo Bio Co., LTD; RRID: AB_1961900) ${ }^{71}$; rabbit polyclonal anti-Ran antibody (1:1000, Cell Signaling; RRID: AB_2284873); mouse monoclonal anti-PSD95 antibody (1:10000, Neuromab; RRID: AB_2292909); rabbit polyclonal anti-synaptophysin antibody (1:5000, Synaptic System; RRID: AB_887905); mouse monoclonal anti-Myc Tag antibody (1:1000, Millipore; RRID: AB_11211891); mouse monoclonal anti-GFAP antibody (1:1000; Millipore; RRID:AB_94844); rabbit polyclonal anti-Iba-1 antibody (1:500; Wako; RRID:AB_839504); mouse monoclonal antihnRNPA2/B1 antibody (1:2000, Abnova; RRID: AB_425488); rabbit polyclonal anti-TIA1 antibody (1:1000, Proteintech; RRID: AB_2201427); goat anti-mouse or anti-rabbit peroxidase-conjugated secondary antibodies (respectively 1:20000 and 1:10000, GE Healthcare). Blots were developed with the Luminata Forte Western Chemiluminescent HRP Substrate (Millipore) on the ChemiDoc ${ }^{\mathrm{TM}}$ Imaging System (Bio-Rad). Densitometry was done with Progenesis PG240 version 2006 software (Nonlinear Dynamics) and Image Lab 6.0 software (Bio-Rad). The immune reactivity of the different proteins was normalized to Ponceau Red staining (Fluka).

\section{Real-time PCR}


The total RNA from mouse cortex and human PBMC was extracted using the RNeasy® Mini Kit (Qiagen). RNA samples were treated with DNase I and reverse transcription was done with a HighCapacity cDNA Reverse Transcription Kit (Life Technologies). For human and mouse PPIA, TARDBP and mouse GRN real-time PCR we used the Taq Man Gene expression assay (Applied Biosystems), on cDNA specimens in triplicate, using 1X Universal PCR master mix (Life Technologies) and $1 \mathrm{X}$ mix containing specific receptor probes for mouse GRN (Mm00433848_m1; Life Technologies), mouse TARDBP (Mm01257504_g1; Life Technologies), human PPIA (Hs03045993_gH; Life Technologies) and human TARDBP (Hs00606522_m1; Life Technologies). Relative quantification was calculated from the ratio of the cycle number $(\mathrm{Ct})$ at which the signal crossed a threshold set within the logarithmic phase of the given gene to that of the reference mouse $\beta$-actin gene (Mm02619580_g1; Life Technologies) or human $\beta$-actin gene (Hs01060665_g1; Life Technologies). For TARDBP intron 7 exclusion real time PCR we used SYBR Green assay (Applied Biosystem), on cDNA specimens in triplicate, using 1X SYBR Green (Applied Biosystem) and specific primers for mouse TARDBP Intron 7 (F: TTCATCTCATTTCAAATGTTTATGGAAG; R: ATTAACTGCTATGAATTCTTTGCATTCAG) ${ }^{53}$. Relative quantification was calculated from the ratio of the cycle number $(\mathrm{Ct})$ at which the signal crossed a threshold set within the logarithmic phase of the given gene to that of the reference mouse $\beta$-actin gene (F: GCCCTGAGGCTCTTTTCCAG R: TGCCACAGGATTCCATACCC). For both experiments means of the triplicate results for each sample were used as individual data for $2^{-\Delta \Delta \mathrm{Ct}}$ statistical analysis.

\section{Long-term potentiation analysis}

For extracellular recordings coronal brain slices $(350 \mu \mathrm{m})$ were cut in ice-cold modified artificial cerebrospinal fluid (aCSF) containing the following: $87 \mathrm{mM} \mathrm{NaCl}, 2.5 \mathrm{mM} \mathrm{KCl}, 1 \mathrm{mM} \mathrm{NaH} \mathrm{PO}_{4}$, $75 \mathrm{mM}$ sucrose, $7 \mathrm{mM} \mathrm{MgCl}_{2}, 24 \mathrm{mM} \mathrm{NaHCO}_{3}, 11 \mathrm{mM}$ D-glucose, and $0.5 \mathrm{mM} \mathrm{CaCl}_{2}$. Slices where then transferred to an incubating chamber, submerged in aCSF containing $130 \mathrm{mM} \mathrm{NaCl}, 3.5 \mathrm{mM}$ $\mathrm{KCl}, 1.2 \mathrm{mM} \mathrm{NaH} \mathrm{PO}_{4}, 1.3 \mathrm{mM} \mathrm{MgCl}$, $25 \mathrm{mM} \mathrm{NaHCO}_{3}, 11 \mathrm{mM}$ D-glucose, $2 \mathrm{mM} \mathrm{CaCl}$, constantly bubbled with $95 \% \mathrm{O}_{2}$ and $5 \% \mathrm{CO}_{2}$ at room temperature. Slices were incubated in this condition for at least $1 \mathrm{~h}$ before recording, then transferred into a submerged recording chamber and perfused with oxygenated aCSF at $2 \mathrm{~mL} / \mathrm{min}$ at a constant temperature of $28-30^{\circ} \mathrm{C}$. Field EPSPs (fEPSPs) were recorded with glass micropipettes filled with $3 \mathrm{M} \mathrm{NaCl}$ electrode in CA1 stratum radiatum. The Schaffer collaterals were stimulated with a bipolar twisted $\mathrm{Ni} / \mathrm{Cr}$ stimulating electrode. Stimuli were delivered by a Constant Voltage Isolated Stimulator (Digitimer Ltd., Welwyn Garden City, UK). Data were amplified and filtered $(10 \mathrm{~Hz}$ to $3 \mathrm{kHz})$ with a DAM 80 AC Differential Amplifier (World Precision Instruments, Sarasota, FL), and digitized at $10 \mathrm{kHz}$ by a Digidata 1322 
(Molecular Devices, Foster City, CA). Long-term potentiation (LTP) was induced by a 4-theta burst tetanus stimulation protocol (each burst consists of four pulses at $100 \mathrm{~Hz}$ with $200 \mathrm{~ms}$ inter-burst intervals). LTP recordings in which the amplitude of the presynaptic fiber volley changed by more than $20 \%$ were discarded.

\section{Behavioural analysis}

In this study both male and female mice were tested, at 6 and 12 months of age. All behavioural tests were done at the same time of day, in the afternoon. Mice were allowed to habituate to the test room

for at least $1 \mathrm{~h}$. Test environments were thoroughly cleaned between test sessions and males were tested before females. Mice were weighed once every 15 days, at the same time of day, in the afternoon, on a balance with $0.1 \mathrm{~g}$ readability and $\pm 0.3 \mathrm{~g}$ linearity (EU-C 7500PT, Gibertini). The open field, elevated-plus maze, three-chamber sociability, Morris water maze and novel object recognition test used Ethovision XT, 5.0 software (Noldus Information Technology, Wageningen, The Netherlands) to record the parameters. Mice were randomized and the operators were blinded for the behavioural analysis.

\section{Open field}

The open field consists of a square Perspex box arena with walls $(40$ x 40 x $40 \mathrm{~cm})$. The "center zone" was defined as a square covering $16 \%$ of the total arena area $(16 \times 16 \mathrm{~cm}$ central square) and the "periphery zone" as the surrounding border. Each mouse was placed in the center of the arena and velocity, total distance moved and the time spent in the central and periphery zones of the open field were recorded for $5 \mathrm{~min}$. Velocity was analysed as a measure of the locomotor activity.

\section{Elevated-plus maze}

The device consisted of a central part $(5 \times 5 \mathrm{~cm})$, two opposing open arms $(30 \times 5 \mathrm{~cm})$ and two opposing closed arms (same size) with $14 \mathrm{~cm}$ high, non-transparent walls. The maze was elevated 73 $\mathrm{cm}$ off the floor. At the beginning of each trial, mice were placed on the central platform, facing an open arm. Their behaviour was recorded for $5 \mathrm{~min}$ then analysed by an operator blind to the genotype. Entry into an arm was recorded when the mouse placed its four paws in that $\operatorname{arm}^{72}$.

\section{Three-chamber sociability}

The apparatus for the social behaviour test consists of three chambers connected with retractable open doorways on two dividing walls. The two external chambers contained an inverted empty wire cup. 
The test comprised three main steps. After 5 min habituation, during which the test mouse was allowed to explore the arena freely, an unfamiliar mouse (stranger 1) was introduced into one of the empty wire cups to measure social preference. The time the test mouse spent sniffing each wire cup was recorded for $10 \mathrm{~min}$, then a new mouse (stranger 2) was introduced into the other empty wire cup to measure social recognition. Time spent sniffing each wire cup was measured. Unfamiliar mice of the same sex and age were used as strangers 1 and 2 .

\section{Morris water maze}

The Morris water maze test (MWM) consists of a round pool $(100 \mathrm{~cm}$ diameter) filled with water $\left(22^{\circ} \mathrm{C}\right)$ made opaque by the addition of nontoxic, odorless white tempera. The escape platform, made of transparent plastic, was placed $1 \mathrm{~cm}$ below the water surface. The test involved five days of training and a one-day probe trial. During each day of training mice were placed successively in north, east, south, and west positions, with the escape platform hidden in the middle of the southwest quadrant. Whenever the mice failed to reach the escape platform, they were placed on it for $10 \mathrm{~s}$. Latencies before reaching the platform were recorded in four-trial sessions. After the training, on the sixth day a probe trial was conducted, removing the platform from the pool. Time spent in the previously correct target quadrant $(\mathrm{Q} 1)$ was measured in a single 1-min trial.

\section{Novel object recognition}

The novel object recognition test was done in a square gray arena with walls $(40 \mathrm{x} 40 \mathrm{x} 40 \mathrm{~cm})$. The following objects were used: a black plastic cylinder $(4 \times 5 \mathrm{~cm})$ and a metal cube $(3 \times 5 \mathrm{~cm})$. After 5 min habituation during which the animal explored the empty arena freely, on the second day mouse was placed in the same arena containing two identical objects. On the last day mouse was again placed in the arena containing the object presented the second day (familiar), together with a new, different one, and the time spent exploring the two objects was recorded for $5 \mathrm{~min}$. The parameter analysed was the discrimination index $(\mathrm{DI})$, defined as: $\mathrm{DI}=\left(\mathrm{T}_{\mathrm{New}}-\mathrm{T}_{\text {Familiar }}\right) /\left(\mathrm{T}_{\mathrm{New}}+\mathrm{T}_{\text {Familiar }}\right)$ where $\mathrm{T}_{\mathrm{New}}$ is the time spent with the new object and $\mathrm{T}_{\text {Familiar }}$ the time spent with the familiar object.

\section{Rotarod}

Motor performance of the mice was determined using a Rotarod (Ugo Basile) in acceleration mode (7-44 rpm) over $5 \mathrm{~min}$. The mice were allowed up to three attempts and the longest latency to fall was considered in statistical analysis. Mice were tested at the same time of day, in the afternoon, once every 15 days, from 13 to 22 months of age. 


\section{Grid test}

Grip strength was measured using the following score:

$$
\text { Score }=T_{\text {tot }}-\sum_{i}^{n} \frac{T_{\text {double } i}}{2}-\sum_{j}^{n} \frac{T_{\text {single } j}}{4}
$$

where $T_{\text {tot }}$ is the time spent hanging before falling from the grid, $\mathrm{n}$ is the number of events in which both hind paws (i) or a fore or a hind paw (j) became detached from the grid, $\mathrm{T}_{\text {double }} \mathrm{i}$ is the number of seconds the $\mathrm{i}$-th event lasted, $\mathrm{T}_{\text {single } \mathrm{j}}$ is the number of seconds the $\mathrm{j}$-th event lasted, as previously described ${ }^{13}$. Mice were tested at the same time of the day, in the afternoon, once every 15 days, from 13 to 22 months of age.

\section{Extension reflex}

Extension reflex was quantified using the following 3-point score: 3, hindlimbs extended to an angle of 120 degrees; 2.5 , hindlimbs extended to $<90$ degrees with decreased reflex in one limb; 2.0, as 2.5 with decreased reflex in both hindlimbs; 1.5 , loss of reflex with marked flexion in one hindlimb; 1 , as 1.5 with marked flexion in both hindlimbs; 0.5 , loss of reflex with hindlimbs and paws held close to the body. Mice were tested at the same time of day, in the afternoon, once every 15 days, from 13 to 22 months of age.

\section{Isolation of PBMCs and plasma}

Blood was drawn by standard venipuncture into Vacutainer ${ }^{\circledR}$ Plus Plastic K2EDTA Tubes (Becton, Dickinson and Company) and kept at $4^{\circ} \mathrm{C}$ until shipment to the Istituto di Ricerche Farmacologiche Mario Negri IRCCS. PBMCs were isolated from ALS patients and healthy individuals and proteins were extracted as previously described ${ }^{7}$. Briefly, PBMC were isolated from EDTA-blood by FicollHypaque (Ficoll-Plaque ${ }^{\mathrm{TM}}$ Plus, GE Healthcare) density gradient centrifugation. Mononuclear cells were harvested from the interface and washed with RPMI 1640 medium (EuroClone). To extract proteins, PBMC pellets were suspended with buffer 1 (20 mM Tris- $\mathrm{HCl} \mathrm{pH} 7.5,0.1 \%$ NP40, 0.1\% SDS, cOmplete ${ }^{\mathrm{TM}}$ Protease Inhibitor Cocktail Tablets, Roche), kept at $95^{\circ} \mathrm{C}$ and shaken at $800 \mathrm{rpm}$ for $5 \mathrm{~min}$, then centrifuged at $16,000 \mathrm{xg}$ for $10 \mathrm{~min}$ at $4{ }^{\circ} \mathrm{C}$. The supernatants (Soluble) were collected and the pellet (Insoluble) was suspended with buffer $2\left(1 \% \mathrm{SDS}\right.$ at $\left.95^{\circ} \mathrm{C}\right)$, kept at $95^{\circ} \mathrm{C}$ and shaken at $800 \mathrm{rpm}$ for $5 \mathrm{~min}$ ). To isolate plasma samples, blood was centrifuged at $3000 \mathrm{xg}$ for 20 minutes and plasma was stored at $-80^{\circ} \mathrm{C}$ until use. 


\section{Mutation screening}

We examined a cohort of 959 ALS patients from Northern Italy and 677 healthy controls matched by age, sex and geographical origin. Informed written consent was obtained for all subjects and the study was approved by the ethics committees involved. Standard protocols were followed for DNA extraction from peripheral blood. Whole-genome sequencing was done at The American Genome Center (Uniformed Services University, Walter Reed National Military Medical Center campus, Bethesda, MD, USA). Libraries were prepared using TruSeq DNA PCR-Free High Throughput Library Prep Kit (Illumina Inc.). Sequencing was done on an Illumina HiSeqX10 sequencer using paired-end 150 base pair reads. Sequence reads were processed as per Genome Analysis Toolkit's (GATK) standard practices (https://software.broadinstitute.org/gatk/best-practices/). The GATK variant quality score method with default filters was used for variant quality control. Genome Reference Consortium Human Build 38 was used as the reference. Variant annotation was done using KGGseq version 1.0 (http://grass.cgs.hku.hk/limx/kggseq/). We screened for coding, nonsynonymous and loss-of-function SNPs in the PPIA gene. We retained only rare variants with minor allele frequency $(\mathrm{MAF})<1 \%$ that were absent from the internal healthy control cohort. The gnomAD ${ }^{13}$ (https://gnomad.broadinstitute.org/) database was used to determine allele frequency in Non-Finnish Europeans. The whole genome sequence data is publicly available on dbGaP at phs001963.

\section{Molecular dynamics (MD) simulations}

The structure of WT PPIA was retrieved from PDB 1CWA (ligand coordinates were removed). The mutant form was generated by swapping the lysine 76 with glutamate using UCSF Chimera ${ }^{33}$. MD simulations were carried out in Gromacs $2018^{73}$ and protein topologies were generated with Charmm36m ${ }^{74}$ (explicit solvent, TIP3P water). The following protocol was employed for both the WT and K76E PPIA. Each protein structure was positioned in a cubic box with $10 \AA$ minimum distance from the walls. The system was solvated, the protein net-charge neutralized with counterions $\left(1 \mathrm{Cl}^{-}\right.$for the $\mathrm{WT}, 1 \mathrm{Na}^{+}$for $\left.\mathrm{K} 76 \mathrm{E}\right)$ and the final $\mathrm{NaCl}$ concentration was brought to $0.15 \mathrm{M}$. Then energy minimization was carried out using the steepest descent algorithm with tolerance set at 100 $\mathrm{kJ} /(\mathrm{mol} \cdot \mathrm{nm})$. The system was then equilibrated for $1 \mathrm{~ns}$ in the NVT ensemble, followed by another 1 ns equilibration in the NPT ensemble. NVT was equilibrated using the V-rescale thermostat ${ }^{75}$ with reference temperature $310 \mathrm{~K}$; NPT equilibration was carried out using the V-rescale thermostat (310 $\mathrm{K})$ and the Parrinello-Rahman Barostat ${ }^{76}$ with reference pressure 1 bar. During both equilibrations, position restraints on heavy atoms were applied with force constant $1000 \mathrm{~kJ} /\left(\mathrm{mol} \cdot \mathrm{nm}^{2}\right)$. After 
equilibration, position restraints were removed and a production simulation of the total length of $1 \mu \mathrm{s}$ was done. This procedure, starting from NVT equilibration, was repeated three times for both WT and mutant PPIA, yielding a cumulative simulation time of $3 \mu$ s for each structure. Equilibrations and productions were carried out using the leap-frog integrator with a $2 \mathrm{fs}$ step. The cutoff for Coulomb short-range interactions was set at $12 \AA$, and particle mesh Ewald was employed to treat long-range electrostatics. The cutoff for Van der Waals interactions was set at $12 \AA$ using force-switch with radius $10 \AA$. RMSD and RMSF of MD trajectories were computed using Gromacs 2018; graphs were plotted using Matplotlib ${ }^{77}$ in Python-3, and images of protein structures were produced in UCSF Chimera.

\section{Mutant PPIA cloning}

The construct coding for mutant PPIA K76E was obtained by site-directed mutagenesis of the original plasmid encoding wild-type PPIA (Origene \#RC203307, NM_021130) using the following forward (F) and reverse (R) primers: K76E-F, 5'-GCCATAATGGCACTGGTGGCGAGTCCATCTAT-3', K76E-R, 5'- CAAATTTCTCCCCATAGATGGACTCGCCACCA-3'. The entire sequence of PPIA K76E was confirmed by sequencing using the following forward and reverse primers: F:5'TTTGCAGACAAGGTCCCAAA-3'; R:5'-GTCCACAGTCAGCAATGGTG-3'.

\section{Cell lines, transfection and treatments}

Experiments were done on HEK293 cells (ATCC CRL-1573).-HEK293 cells were cultured in Dulbecco's modified Eagle's medium (DMEM), high glucose, GlutaMAX (Thermo Fisher), containing 10\% fetal bovine serum (Thermo Fisher), 1\% non-essential amino acids (Thermo Fisher) and a 1:100 dilution of penicillin/streptomycin (Thermo Fisher), at $37^{\circ} \mathrm{C}$ in a humidified atmosphere at $95 \%$ air and $5 \% \mathrm{CO} 2$.

For transfection experiments, HEK293 cells were transfected with plasmids containing PPIA WT or PPIA K76E constructs, using Lipofectamine 2000 (Thermo Fisher). In detail, HEK293 cells were incubated with $0.016 \mu \mathrm{g} / \mu \mathrm{L}$ plasmid solution prepared with an Opti-MEM ${ }^{\circledR}$ Reduced-Serum Medium (Thermo Fisher), at $37^{\circ} \mathrm{C}$ in a $\mathrm{CO} 2$ incubator for $24-48$ hours before testing for transgene expression.

For cycloheximide (CHX) experiments, HEK293 cells transfected with PPIA constructs were treated with $100 \mu \mathrm{g} / \mathrm{mL}$ of CHX for 15, 30, 45 and 60 minutes. For protein extraction, HEK293 cells transfected with PPIA constructs and/or treated with CHX were resuspended in hot buffer $(1 \%(\mathrm{w} / \mathrm{v})$ 
SDS), and DNA was fragmented using a syringe. Lysates were centrifuged at 10,000 $\mathrm{xg}$ for $15 \mathrm{~min}$, and proteins were quantified with the BCA protein assay (Pierce).

\section{Immunoprecipitation}

Magnetic beads coupled with sheep polyclonal antibodies anti-rabbit IgG (Dynabeads, Invitrogen) were used for co-immunoprecipitation studies. Cells were lysed in $50 \mathrm{mM}$ Tris-HCl, $\mathrm{pH} 7.2,2 \%$ CHAPS, protease inhibitor cocktail (Roche) and quantified with the BCA protein assay (Pierce). Proteins $(500 \mu \mathrm{g})$ were diluted to $0.5 \mu \mathrm{g} / \mu \mathrm{L}$ with lysis buffer. Magnetic beads with coupled sheep antibodies anti-rabbit IgG (Dynabeads ${ }^{\circledR} \mathrm{M} 280$; Invitrogen) were washed with $0.5 \%$ bovine serum albumin immonuglobulin-free (BSA Ig-free) in PBS to remove preservatives. Three $\mu \mathrm{g}$ of rabbit polyclonal anti-human TDP-43 primary antibody (Proteintech; RRID: AB_2200505) or rabbit polyclonal anti-human Ran primary antibody (Abcam) was incubated with $20 \mu \mathrm{L}$ of anti-rabbit IgG-conjugated Dynabeads for $2 \mathrm{~h}$ at $4^{\circ} \mathrm{C}$ in $0.1 \% \mathrm{BSA} / \mathrm{PBS}$. Lysate was pre-cleared by incubation for $2 \mathrm{~h}$ at $4{ }^{\circ} \mathrm{C}$ with $30 \mu \mathrm{L}$ of beads and incubated overnight at $4^{\circ} \mathrm{C}$ with primary antibody linked to the beads. After two washing steps, first with $50 \mathrm{mM}$ Tris-HCl, pH 7.2, 0.3\% CHAPS, 0.1\% BSA Ig-free and protease inhibitor cocktail (Roche), and then with $50 \mathrm{mM}$ Tris-HCl, $\mathrm{pH} 7.2,0.3 \%$ CHAPS, and protease inhibitor cocktail (Roche), immunoprecipitated proteins were eluted by $30 \mu \mathrm{L}$ Laemmli sample buffer, DTT $1 \mathrm{mM}$ and analysed by Western blot. Controls for IP experiments were: lysate with magnetic beads linked to the secondary antibody (beads-IgGII); lysis buffer with beads-IgGII; lysis buffer with beads-IgGII and primary antibody. Immunoprecipitation experiments were repeated several times on independent sample sets, with consistent results. 
Supplementary Table 1 . The characteristics of the patients and controls

\begin{tabular}{|l|c|c|c|c|c|c|}
\hline \multirow{2}{*}{ Characteristics } & \multicolumn{2}{|c|}{ Cohort \#1 } & \multicolumn{2}{c|}{ Cohort \#2 } & \multicolumn{2}{c|}{ Cohort \#3 } \\
\cline { 2 - 7 } & ALS & Healthy & ALS & Healthy & ALS & Healthy \\
\hline No. & 79 & 89 & 21 & 19 & 51 & 20 \\
\hline $\begin{array}{l}\text { Age at sampling, } \\
\text { years, median } \\
\text { (range) }\end{array}$ & $65(38-87)$ & $61(37-87)$ & $69(58-72)$ & $68(60-72)$ & $67(42-89)$ & $61(53-66)$ \\
\hline Sex (male/female) & $42 / 37$ & $39 / 50$ & $10 / 11$ & $14 / 6$ & $26 / 25$ & $7 / 13$ \\
\hline $\begin{array}{l}\text { Site of disease } \\
\text { onset } \\
\text { (bulbar/spinal) }\end{array}$ & $16 / 59$ & - & $6 / 15$ & - & $14 / 36$ & - \\
\hline FTD & 5 & - & 0 & - & 1 & - \\
\hline $\begin{array}{l}\text { ALSFRS-R at } \\
\text { sampling, median } \\
\text { (range) }\end{array}$ & $27(8-46)$ & - & $25(10-38)$ & - & $33(10-46)$ & - \\
\hline $\begin{array}{l}\Delta \text { ALSFRS-R } \\
\text { median (range) }\end{array}$ & $0.9(0.2-5.0)$ & - & $0.8(0.3-1.3)$ & - & $0.7(0.2-4.7)$ & - \\
\hline $\begin{array}{l}\text { Symptom } \\
\text { duration } \\
\text { median (range) }\end{array}$ & $23(4-110)$ & - & $15(9-101)$ & - & $15(5-114)$ & - \\
\hline
\end{tabular}

Cohort \#1: PBMC samples analysed for PPIA and TDP-43 protein levels

Cohort \#2: PBMC samples analysed for PPIA and TARDBP mRNA transcript

Cohort \#3: Plasma samples analysed for MMP-9

${ }^{1}$ FTD: No. of patients with ALS co-morbid with FTD, according to Consensus Criteria ${ }^{31,32}$

${ }^{2} \triangle$ ALSFRS-R: 48 -ALSFRS-R score at sampling/time from symptom onset to sampling

${ }^{3}$ Symptom duration: Months from symptom onset to sampling 


\section{Supplementary figure legends}

\section{Supplementary Fig. 1. PPIA-/- mice show neuropathological alterations in specific brain} regions. (A-C) Up to 20 weeks of age, PPIA-/- mice display no motor phenotype, but have a tendency to kyphosis at four months. PPIA+/+ $(\mathrm{n}=10)$ and PPIA-/- $(\mathrm{n}=14)$ mice show a similar motor phenotype in Rotarod (A) and grid tests (B). Data (mean \pm SEM) are expressed as a percentage of maximum performance and were analysed by two-way ANOVA, Bonferroni's post hoc test. (C) Micro-CT analysis shows only a tendency to kyphosis in PPIA-/- mice compared to controls, at four months of age. Kyphosis was evaluated as the ratio between the distance from the last cervical vertebra to the last lumbar vertebra (segment $\mathrm{AB}$ ) and the perpendicular distance to the dorsal edge of the vertebra at the greatest curvature (segment CD), as shown in the micro-CT images. Data are mean \pm SD ( $n=6)$ and were analysed with Student's t-test. (D-E) The volume of total brain (D) and cerebellum (E) was measured using quantitative MRI in PPIA+/+ and -/- mice, at 6 and 12 months. Representative MRI images of PPIA+/+ and -/- brain regions at 12 months of age are shown. The white dotted line indicates the ROI for MRI quantification. Scale bar $1 \mathrm{~mm}$. The volume of the cerebellum was adjusted for total brain volume and data are expressed as relative volume. Mean \pm $\mathrm{SD}$ ( $\mathrm{n}=6$ or 5 in each experimental group). ${ }^{*} \mathrm{p}<0.05, P P I A-/-$ versus $P P I A+/+$ mice and ${ }^{*} \mathrm{p}<0.05,6$ months versus 12 months, one-way ANOVA, Tukey's post hoc test. (F) Iba-1 immunostaining in hippocampus was quantified in PPIA+/+ and -/- mice at 6 and 12 months of age. Representative Iba1 -stained brain sections are shown. Scale bar $50 \mu \mathrm{m}$. Data (mean $\pm \mathrm{SD} ; \mathrm{n}=5$ or 4 in each experimental group) are percentages of immunoreactivity in PPIA+/+ mice. (G) Dot blot analysis of GFAP and Iba-1 in cortex of PPIA+/+ and -/- mice at 6 and 12 months. $P P I A+/+$ and PPIA-/- mice have similar levels of GFAP (upper panel) and Iba-1 (lower panel). Immunoreactivity was normalized to protein loading. Data (mean $\pm \mathrm{SD}, \mathrm{n}=3$ or 5 in each experimental group ) are percentages of immunoreactivity in PPIA+/+ mice. There was no significant difference between groups, one-way ANOVA, Tukey's post hoc test.

\section{Supplementary Fig. 2. TDP-43 pathology and alterations in other RNA binding proteins in} PPIA-/- mice. (A) Equal amounts of nuclear and cytoplasmic fractions from cerebellum of $P P I A+/+$ and -/- mice at 6 months of age were analysed for TDP-43 or pTDP-43. Immunoreactivity was normalized to protein loading. Data (mean $\pm \mathrm{SD}, \mathrm{n}=6$ or 5 in each experimental group ) indicates the immunoreactivity normalized to total protein loading, in arbitrary units (A.U.).and were analysed with Student's t-test. (B) Analysis of the Triton-insoluble proteins (TIF) from cortex of $P P I A+/+$ and -/- mice at 6 months. TIF is normalized to soluble proteins. Data (mean $\pm \mathrm{SD}, \mathrm{n}=5$ ) are percentages of immunoreactivity in PPIA+/+ mice. *p $<0.05$ Student's t test. (C-F) The level of TDP-43 (C), 
pTDP-43 (D), hnRNP A2/B1(E), TIA1 (F) in the TIF from cortex of PPIA+/+ and -/- mice at 6 months, measured by dot blot with the specific antibodies. Immunoreactivity was normalized to protein loading. Data (mean \pm SD; TDP-43, pTDP-43 and hnRNPA2/B1: $n=7 ;$ TIA1: $n=6$ are percentages of immunoreactivity in PPIA+/+ mice. ${ }^{*} \mathrm{p}<0.05$, Student's $\mathrm{t}$ test. (G-H) pTDP-43 immunostaining was analysed in hippocampus $(\mathbf{G})$ and cortex $(\mathbf{H})$ of $P P I A+/+$ mice at 12 months of age. Scale bar $50 \mu \mathrm{m}$.

Supplementary Fig. 3. C57_PPIA-/- mice present TDP-43 pathology. Equal amounts of nuclear and cytoplasmic fractions from cortex (A) and cerebellum (B) of C57_PPIA+/+ and -/- mice at six months of age were analyzed for TDP-43 or pTDP-43 by dot blot. Immunoreactivity was normalized to protein loading. (A-B) Data (mean $\pm \mathrm{SD}, \mathrm{n}=5$ or 4 in each experimental group) indicates the immunoreactivity normalized to total protein loading, in arbitrary units (A.U.) and were analysed with Student's t-test. (C) Analysis of the total TIF from cortex of C57_PPIA+/+ and -/- mice at six months of age. Total TIF is the amount of TIF isolated from the specific tissue and is the ratio of TIF to soluble proteins. The levels of insoluble TDP-43 (D) and pTDP-43 (E) in cortex of $P P I A+/+$ and -/- mice at six months of age were measured by dot blot with the specific antibodies. Immunoreactivity was normalized to protein loading. (C-E) Data (mean $\pm \mathrm{SD}, \mathrm{n}=5$ ) are percentages of immunoreactivity in C57_PPIA+/+ mice. ${ }^{*} \mathrm{p}<0.05$, Student's t test.

Supplementary Fig. 4. PPIA-/- mice present no evident motor dysfunction. Rotarod test (A) and grid test (B) show similar motor phenotypes in PPIA+/+ $(\mathrm{n}=13)$ and PPIA-/- $(\mathrm{n}=14)$ mice up to 22 months. Data (mean $\pm \mathrm{SEM}$ ) are expressed as percentages of maximum performance and were analysed by two-way ANOVA and Bonferroni's post hoc test.

\section{Supplementary Fig. 5. Analysis of TDP-43 and PPIA in the PPIA K76E ALS patient. (A,B)}

Analysis of PPIA protein (A) and transcript (B) levels in the PPIA K76E patient. (A) Total PPIA protein was analysed in PBMCs from the PPIA K76E ALS patient in comparison with ALS patients and healthy subjects of a retrospective cohort $^{7}$ (Cohort \#1, Supplementary Table1).. Scatter dot plots (mean $\pm \mathrm{SD} ; \mathrm{n}=89$ healthy controls, $\mathrm{n}=74$ ALS patients; $\mathrm{n}=3$ technical replicates of the PPIA K76E ALS patient) are percentages of healthy controls and the dotted line indicates the mean of healthy controls. ${ }^{*} \mathrm{p}<0.05$ versus healthy controls, Student's t-test. (B) Real-time PCR for PPIA mRNA transcripts was done in PBMCs of PPIA K76E ALS patient, healthy controls and ALS patients (Cohort \#2, Supplementary Table1). Data (mean $\pm S D ; n=19$ healthy subjects; $n=21$ ALS patients; $\mathrm{n}=8$ technical replicates of the PPIA K76E ALS patient) are normalized to $\beta$-actin and expressed as 
percentages of healthy controls relative mRNA. The dotted line indicates the mean value of healthy controls. ${ }^{*} \mathrm{p}<0.05$ versus healthy controls, Student's t-test. (C,D) Analysis of TDP-43 transcript (C) and protein (D) levels in a PPIA K76E patient. (C) Real-time PCR for TARDBP mRNA transcripts was done in PBMCs of the PPIA K76E ALS patient, healthy controls and ALS patients (Cohort \#2, Supplementary Table1). Data (mean \pm SD; $n=19$ healthy subjects; $n=21$ ALS patients; $n=8$ technical replicates of the PPIA K76E ALS patient) are normalized to $\beta$-actin and expressed as percentages of healthy controls' relative mRNA. The Dotted line indicates the mean of healthy controls. ${ }^{*} p<0.05$ versus healthy controls, Student's t-test. (D) Total TDP-43 protein levels were analysed in PBMCs from the PPIA K76E ALS patient, ALS patients and healthy subjects of a retrospective cohort $^{7}$ (Cohort \#1, Supplementary Table1). Scatter dot plots (mean \pm SD; $n=69$ healthy controls, $n=65$ ALS patients; $n=3$ technical replicates of the PPIA K76E ALS patient) are percentages of healthy controls and dotted line indicates the mean of healthy controls. ${ }^{*} p<0.05$ versus healthy controls, Student's ttest.

\section{Supplementary Fig. 6. All-atom RMSD and RMSF and RMSD of protein residues computed} from the MD simulations of WT and K76E PPIA. (A) The graph presents the all-atom RMSD of WT (blue) and K76E (orange) PPIA plotted as a function of the simulation time. Lines and filled curves represent the mean and standard error of the RMSD, respectively, computed for the three replicates of the WT and K76E protein. (B,C) The RMSF $(\mathbf{B})$ and the RMSD $(\mathbf{C})$ of the protein residues are shown. RMSD is computed using the initial frame as reference state. The WT bars are depicted in blue, and the K76E bars in orange. Vertical lines indicate standard errors. 
A

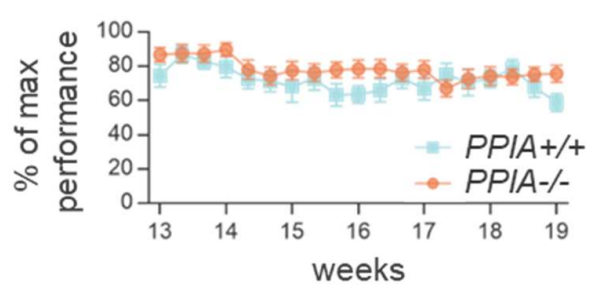

C

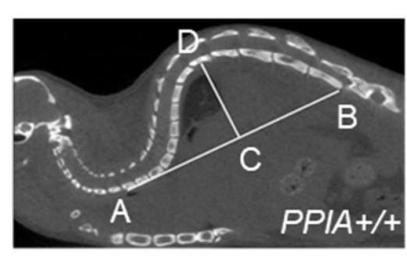

D

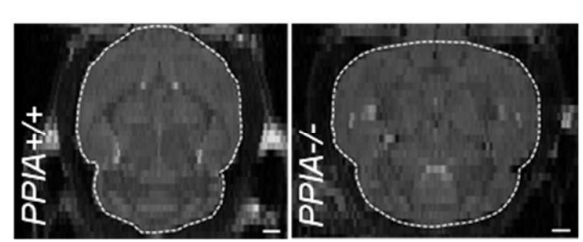

Brain

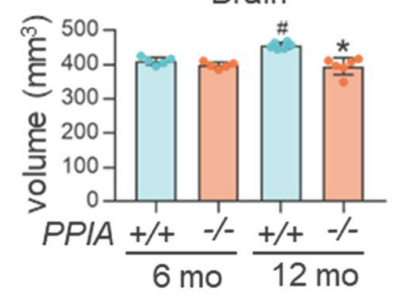

$\mathbf{F}$

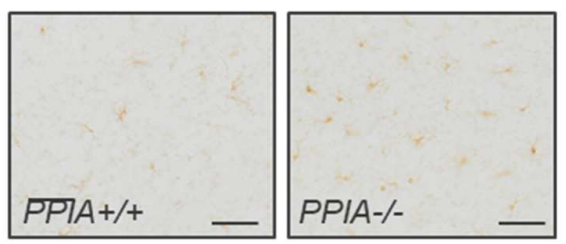

Hippocampus

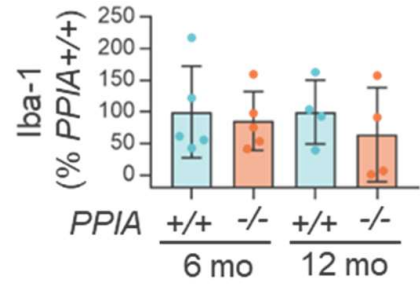

B
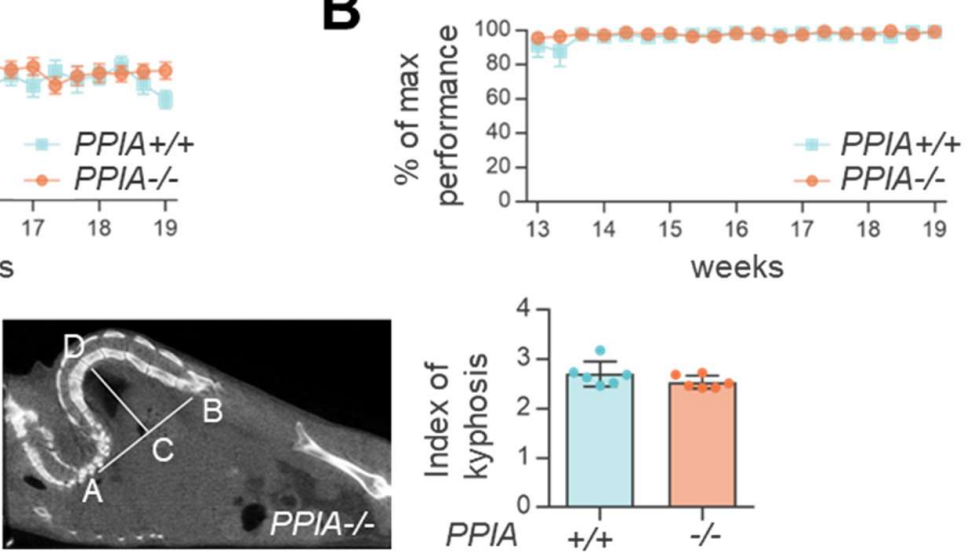

E

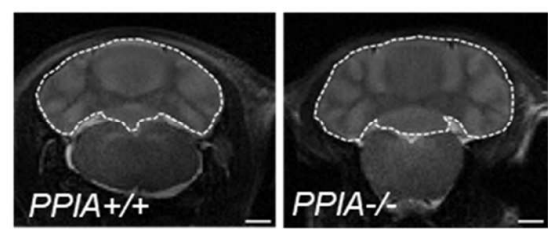

Cerebellum

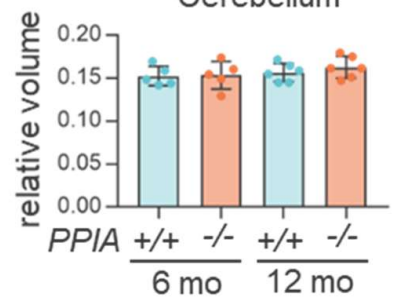

G

Cortex
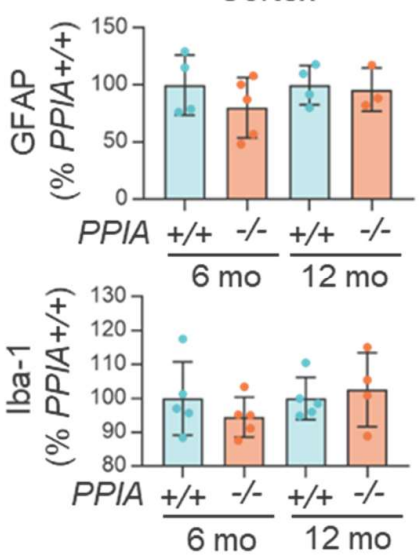

\section{Supplementary Figure 1}


A

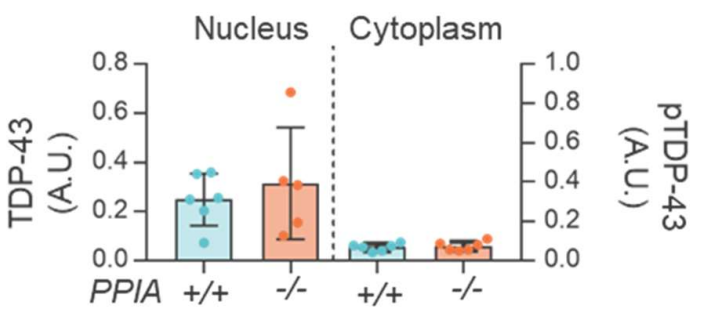

D

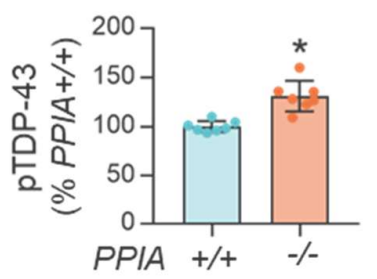

G
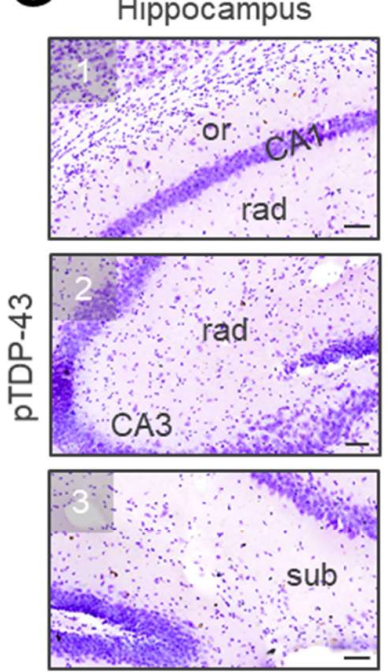

年
B

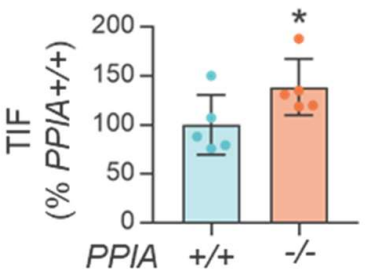

C

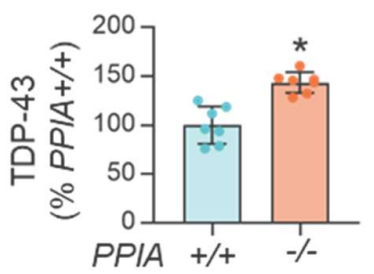

$\mathbf{F}$

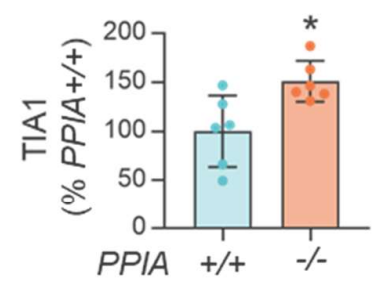

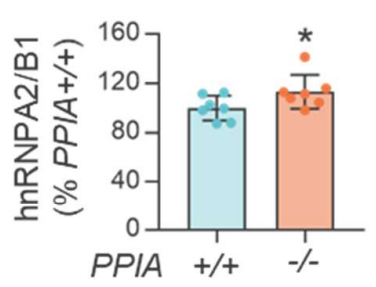

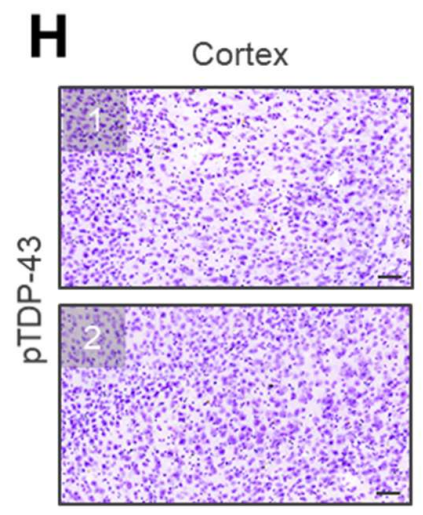


A

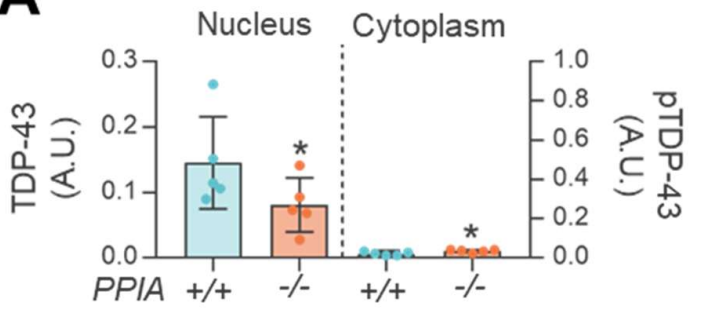

C

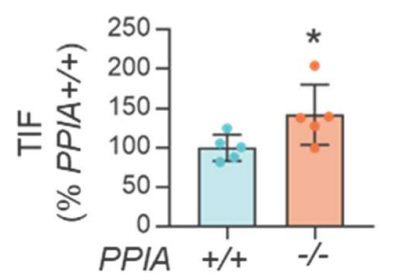

D
B
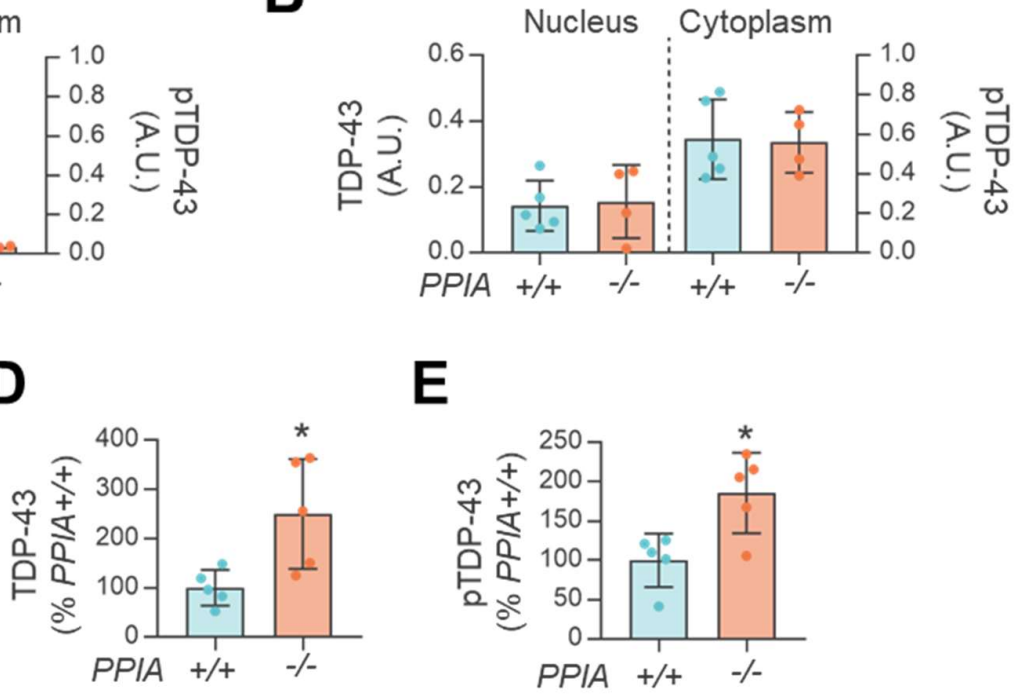

E

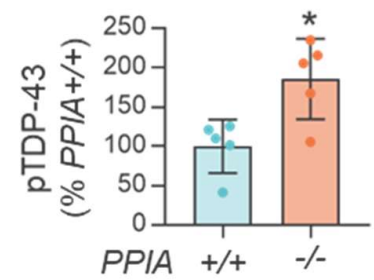


bioRxiv preprint doi: https://doi.org/10.1101/2020.06.08.129528; this version posted May 7, 2021. The copyright holder for this preprint (which was not certified by peer review) is the author/funder, who has granted bioRxiv a license to display the preprint in perpetuity. It is made available under aCC-BY-NC 4.0 International license.

A

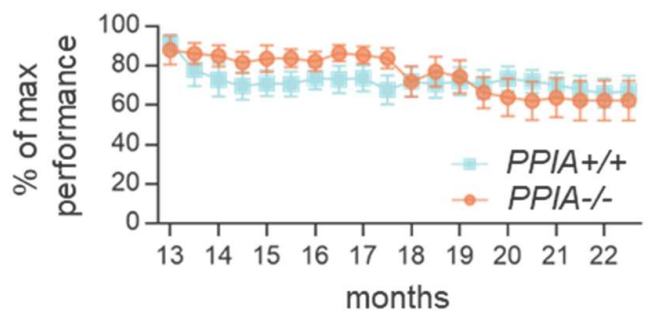

B

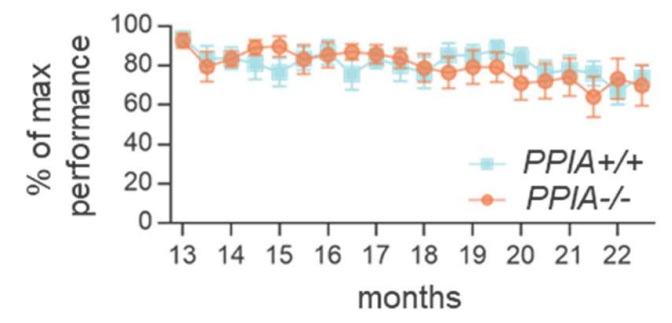

\section{Supplementary Figure 4}


A

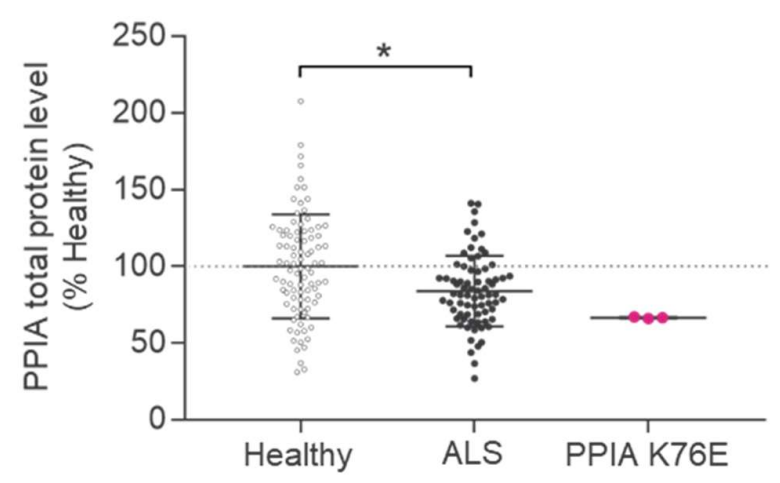

C

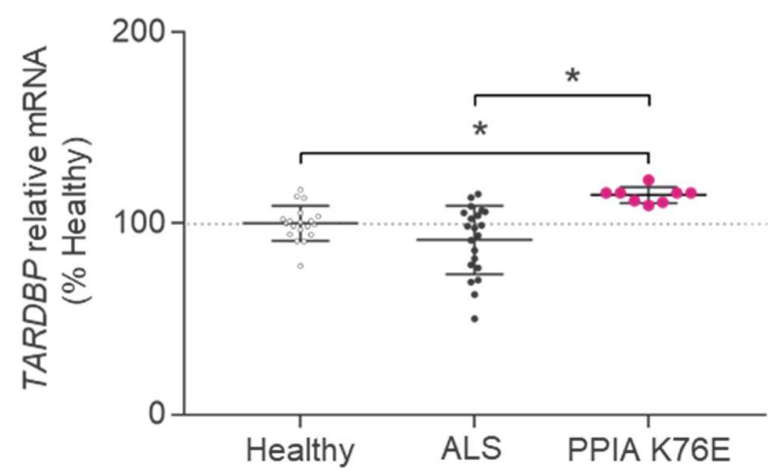

B

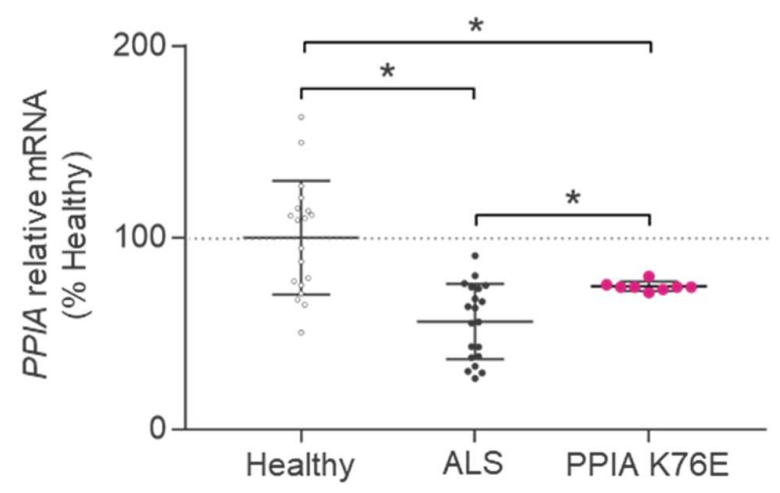

D

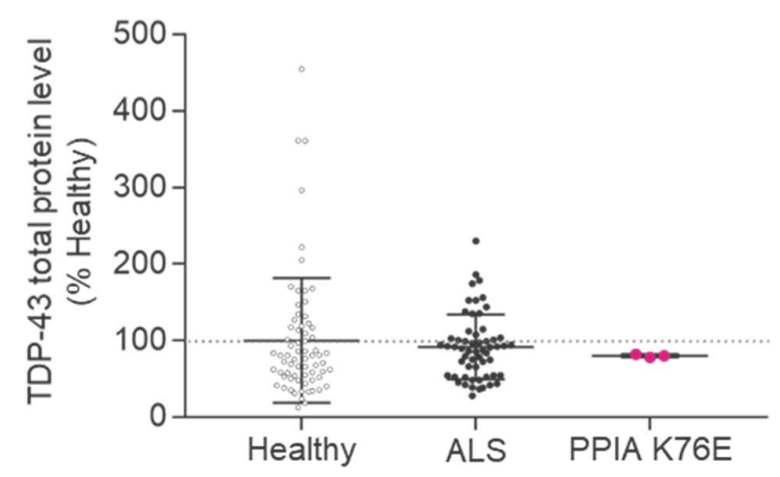


bioRxiv preprint doi: https://doi.org/10.1101/2020.06.08.129528; this version posted May 7, 2021. The copyright holder for this preprint (which was not certified by peer review) is the author/funder, who has granted bioRxiv a license to display the preprint in perpetuity. It is made available under aCC-BY-NC 4.0 International license.

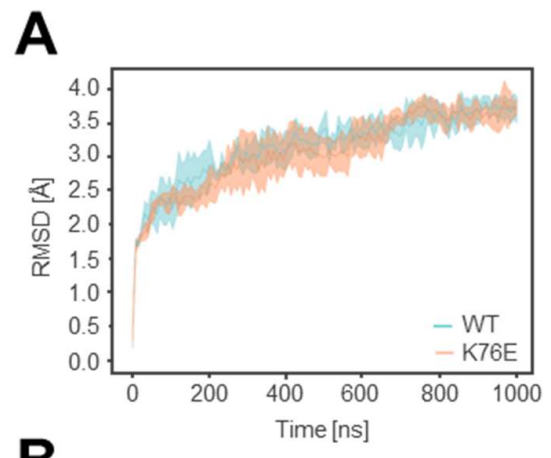

B

Root mean squared fluctuation of protein residues
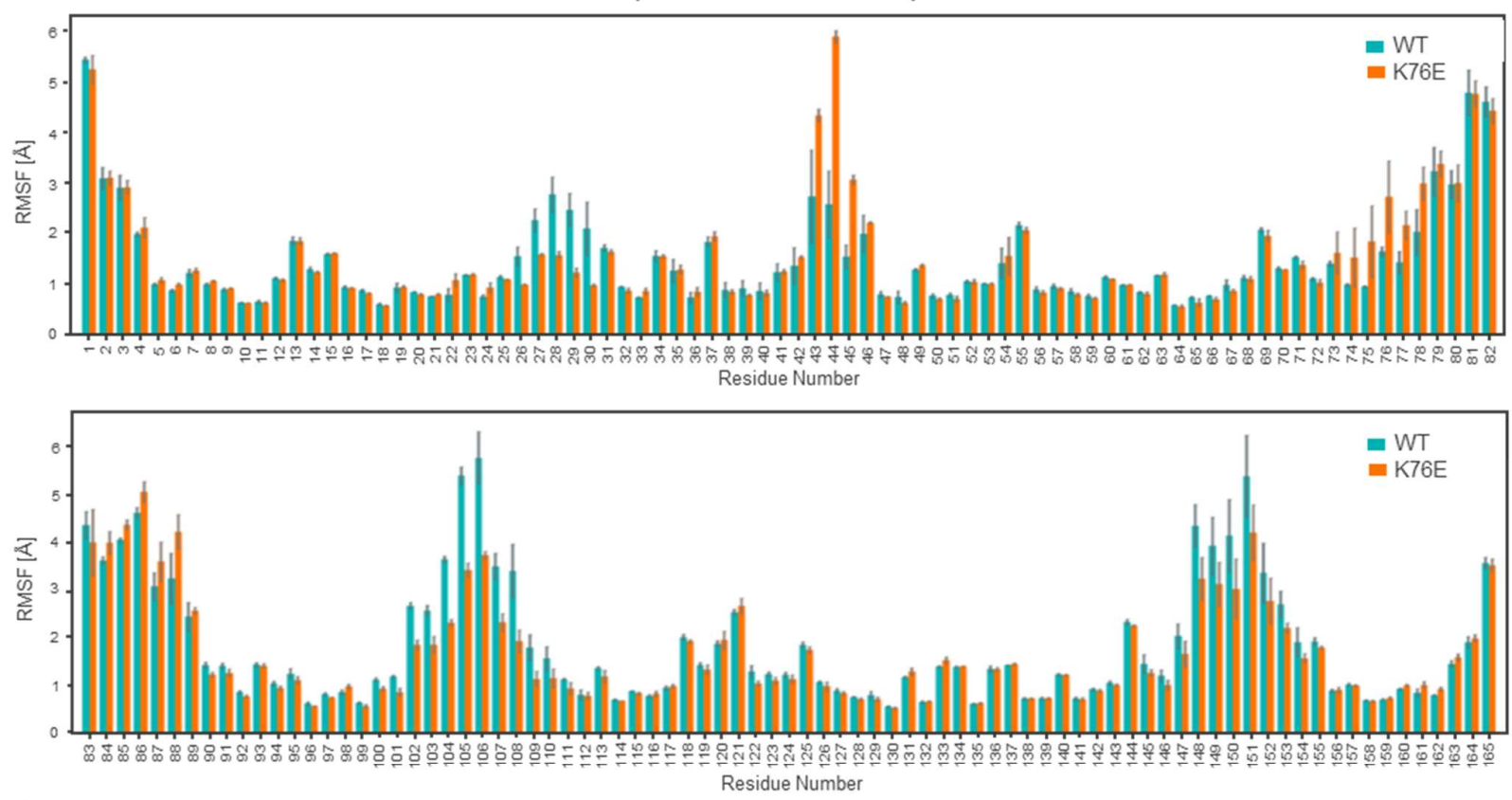

C

Root mean squared deviation of protein residues
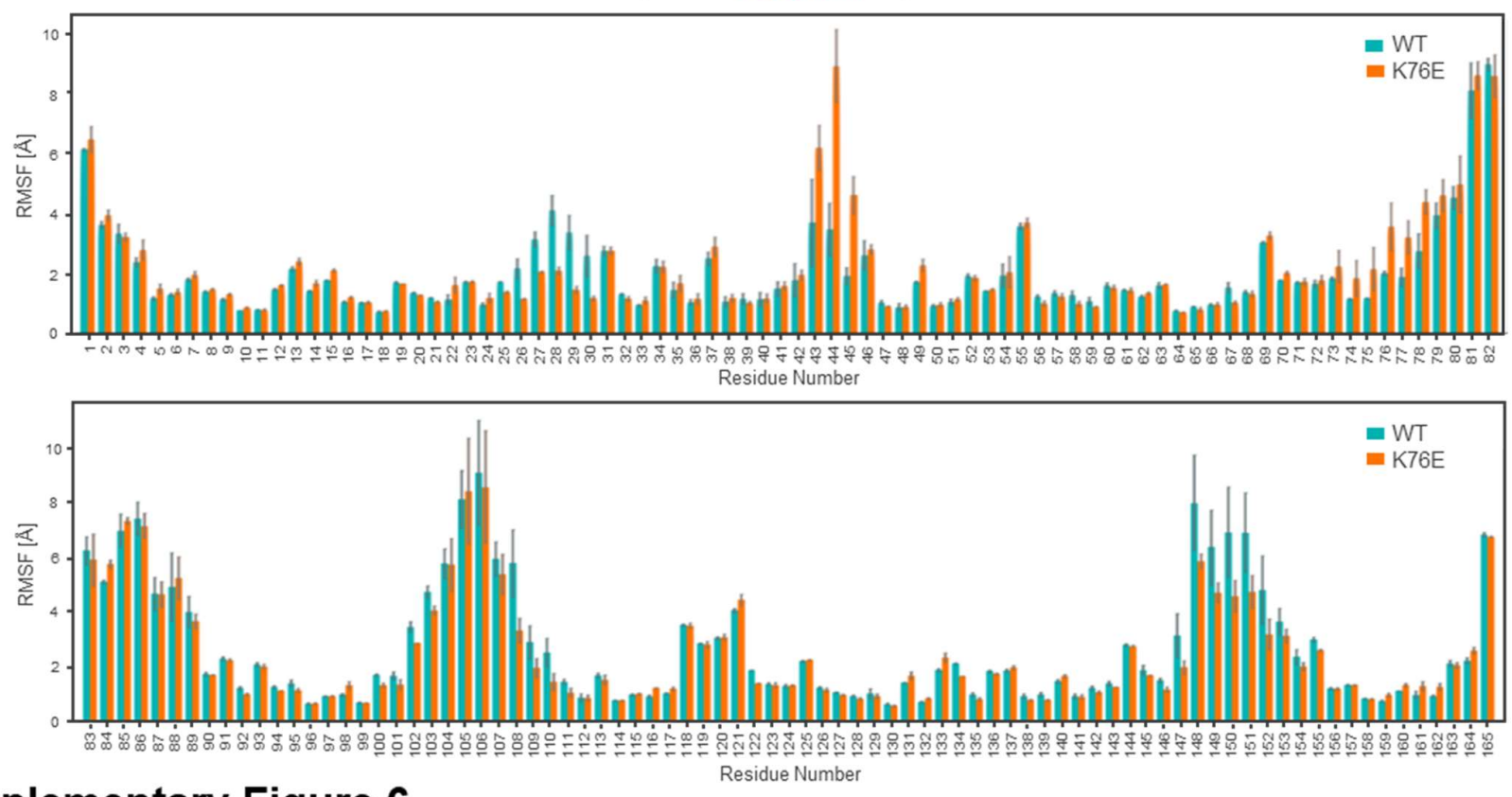

\section{Supplementary Figure 6}

